\title{
Incomplete Acquisition, Attrition and Maintenance of Heritage Speakers' Family Language: \\ Iranians in New Zealand
}

\author{
Khadijeh Gharibi
}

\author{
A thesis \\ submitted to Victoria University of Wellington \\ in fulfilment of the requirements for the degree of \\ Doctor of Philosophy
}



Khadijeh Gharibi

Incomplete Acquisition, Attrition and Maintenance of

Heritage Speakers' Family Language: Iranians in New Zealand

Supervisors:

Associate Professor Frank Boers

Dr. Corinne Seals 
Dedicated to the memory of my father (1943-2006), and my mother, My role models... 


\begin{abstract}
This dissertation is composed of a quantitative investigation of Incomplete Heritage Language Acquisition and Attrition in heritage speakers' vocabulary knowledge. This portion is followed by a qualitative investigation of Heritage Language Acquisition and Maintenance in which the immigrant parents' attitudes towards heritage language acquisition and maintenance for their children are explored.
\end{abstract}

Three groups of participants took part in this study. One group consisted of thirty 6-18 year old Persian-English simultaneous and sequential bilinguals in New Zealand. To obtain benchmark data, a control group was recruited, comprised of thirty monolingual speakers of Persian in Iran who were matched with the heritage speakers in terms of age, gender, number of siblings and their family's socio-economic status. The third group of the participants consisted of twenty-four parents of the heritage speakers. Information about the bilinguals' demographic and socio-linguistic factors was collected through semi-structured interviews with their parents.

The quantitative investigation commences with a study that examines young heritage speakers', either simultaneous or sequential bilinguals, vocabulary knowledge in their family language compared to the matched monolingual counterparts, and the factors that account for a difference, if there is any, are investigated. These factors include current age, age at emigration, length of emigration, frequency of heritage language use and parents' attitude towards heritage language acquisition and maintenance. The results of productive and receptive vocabulary knowledge tests showed that the heritage speakers were outperformed by the monolinguals, but the gap was wider in the case of the simultaneous bilinguals. Additionally, the parents' attitude was found to be a strong predictor of the simultaneous bilinguals' vocabulary knowledge, while the sequential bilinguals' vocabulary knowledge was associated mostly with age at emigration.

The second study in the quantitative investigation examines whether the simultaneous and sequential bilinguals differ from monolinguals with regard to lexical richness, according to measures of lexical diversity and lexical sophistication, in their family language. It also weighs the influence of the demographic and/or sociolinguistic factors on the difference between these subgroups, if there is any. A film-retelling task was used to collect free speech samples. As expected, the monolinguals' narratives tended to manifest greater lexical richness according to both measures, but did most markedly so according 
to the lexical sophistication measure, suggesting that the latter is a better parameter in detecting the differences between heritage speakers and monolinguals. Of the factors investigated, the simultaneous and sequential bilinguals' lexical richness was predicted by age, showing that the older the children were when they moved to the second language environment, the better their family language vocabulary tended to be.

The sociolinguistic variables (i.e. Persian use and parental attitude) were not found to play a significant role in the results of the two quantitative studies. This might have been due to the fact that the demographic variables (i.e. age and age at emigration) were so strong that they overrode the influence of the sociolinguistic variables. Alternatively, the Likert-scale items used in the questionnaire-based interview may have been too blunt an instrument to discern subtle and yet relevant sociolinguistic differences among families. This raised a need to conduct a qualitative investigation in case a more in-depth analysis of the interview data might reveal a clearer picture of their influence.

The qualitative portion of this dissertation begins with an exploration of the immigrant parents' attitudes towards their children's development and maintenance of their heritage language by utilizing Spolsky's (2004) model of language policy as a methodological framework. The data consist of the same semi-structured interviews with twenty-four parents of the heritage speakers as used in the quantitative investigation. The findings reveal that although the parents hold positive beliefs about family language acquisition and maintenance, there are discrepancies between their language ideologies and family language practices and efforts. In light of these inconsistencies, this study suggests that analyses of parental language attitudes towards heritage language maintenance should not only consider their beliefs towards minority language acquisition and maintenance, but also their language practices and management. It was also found that the majority of Iranian parents in this study were satisfied if their children had good conversational skills in Persian. This finding led me to look into the parents' attitudes towards their children's acquisition and maintenance of Persian literacy.

Following the first part of this investigation, the parents' beliefs, practices and management strategies were explored to see how they reflect their attitudes towards their children's heritage language literacy acquisition and maintenance. The findings revealed that it was very uncommon for the heritage speakers to have high literacy skills, which the parents attributed largely to the lack of community-based heritage language schools in the host country. Furthermore, parents' efforts in heritage language literacy development and 
maintenance can be explained through the concept of investment (Norton, 2000). It seems that the parents choose not to promote investment in heritage language literacy, when they do not see it as a part of their children's imagined identities. Additionally, while conversational fluency and cultural knowledge were continuously positioned as being extremely important for the heritage language speaking children by the parents, it was not seen as connected to traditional literacy.

Investigating the different aspects of heritage speakers' lexical knowledge, the quantitative portion of this dissertation furthers our understanding of incomplete acquisition and attrition of family languages in simultaneous and sequential bilinguals. Additionally, the qualitative portion illustrates that positive parental beliefs do not guarantee heritage language acquisition and maintenance. This investigation also raised immigrant parents' awareness of the role literacy can also play in heritage language maintenance. Taken together, this dissertation draws the attention of researchers, educators, immigrant parents and communities to various social and linguistic aspects of young heritage speakers' acquisition and maintenance of their family language as they grow up. 


\section{ACKNOWLEDGEMENTS}

Coming to New Zealand and doing a $\mathrm{PhD}$ was like a metamorphosis for me to which many wonderful people contributed. When I started my $\mathrm{PhD}$ with Frank, as one of the great people at the School of Linguistics and Applied Language Studies (LALS), I felt that I was so lucky to have him as my supervisor. I owe him a debt of gratitude for his ongoing support, guidance, patience and generosity with time. After one and a half years, when I finished the quantitative portion of my project, Corinne joined LALS. Having another wonderful supervisor made me feel that I am truly one of the luckiest PhD students. I am endlessly grateful to both of them.

I was very lucky to start my $\mathrm{PhD}$ journey with wonderful friends as my first officemates, Kieren, Ewa and Keely, and continue to have more as my last officemates, Evan, Ayman and Shelley. This journey has been all the more enjoyable because of having amazing friends with whom I could always share my thoughts about my PhD research and life in New Zealand, Emily, Diego, TJ, Pim, Amy, Matt and my circle of Iranian friends. I always enjoyed our conversations on Friday nights.

LALS is absolutely one of the best places to develop as a researcher. Dr. Meredith Marra and Dr. Jonathan Newton have always been there for me to answer my questions when I really needed to clear my thoughts and my supervisors were not around. I also wish to thank Dr. Averil Coxhead for supporting my Doctoral scholarship application. I was thrilled to be a student at the school where Professor Janet Holmes is based and having the privilege of receiving her feedback. I would also appreciate Dr. John Macalister's support in his role as the head of school. Janet Attrill reminded me of my first day at the school as she showed me around. These people are some of those who make LALS an incredibly pleasant environment. I would also like to thank Dr. Dalice Sim who generously helped me with the statistical analyses of my research project. Tony Quinn, an amazing librarian, has also been always helpful during these years.

The years of doing $\mathrm{PhD}$ would not have been as enjoyable without the Doctoral Scholarship offered to me by Victoria University of Wellington. The generous conference grants by the School of Linguistics and Applied Language Studies and Victoria University have also given me invaluable opportunities to share my research project with notable scholars in New Zealand and overseas. 
This research could not have been done without the friendly and welcoming Iranian families and their children who participated in this study. I have been overwhelmed by the Iranian families' generosity with their time and hospitality. They invited me to their homes and shared their experiences with me even prior to data collection. My special thanks also go to my Iranian friends who helped me in finding my participants in different cities in New Zealand and Iran as well.

Of course I have been lucky enough to have a wonderful brother, Yousef, who taught me to have big goals in my life and an amazing sister, Naji, who encouraged me to start this journey. I would also like to thank my mother, who is one of the nicest human beings ever, for letting me follow my dreams. I also dedicate this dissertation to my father, who taught us to be strong and have a strong desire for success. I am sure I could not be where I am now without their love and support. 


\section{CONTENTS}

Chapter 1: Introduction ...............................................................................3

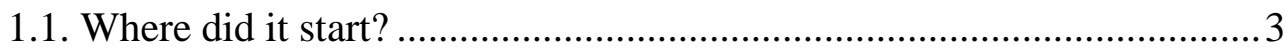

1.2. Iranian diaspora in New Zealand ..................................................... 4

1.3. Studies on Iranian heritage speakers ...................................................5

1.4. Minority language maintenance in New Zealand .................................. 7

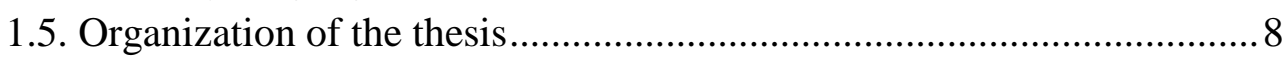

Chapter 2: Theoretical background............................................................13

2.1. Heritage speakers ................................................................. 13

2.2. Simultaneous and sequential bilinguals ............................................... 14

2.3. Vocabulary knowledge in bilingual children ...................................... 16

2.4. Incomplete acquisition and language attrition .................................... 17

2.5. Theoretical accounts of incomplete acquisition and language attrition and

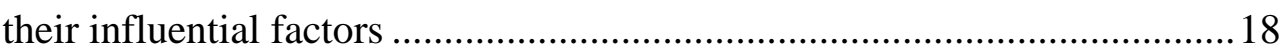

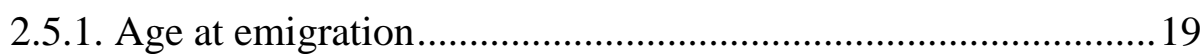

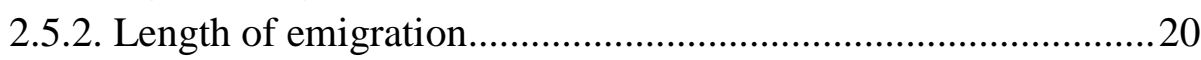

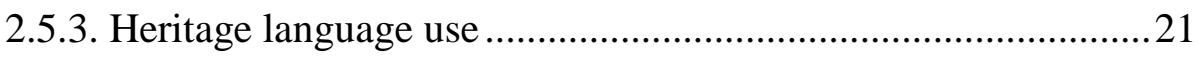

2.5.4. Parental attitudes ............................................................... 22

2.6. Heritage Language Maintenance .......................................................... 23

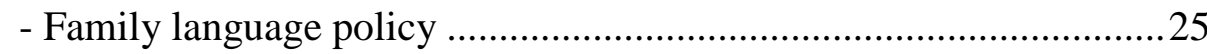

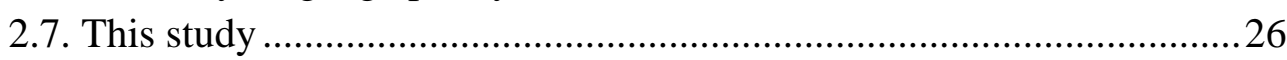

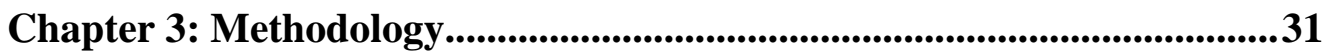

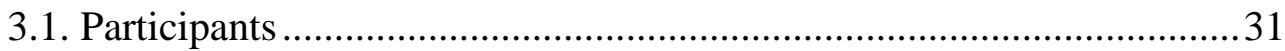

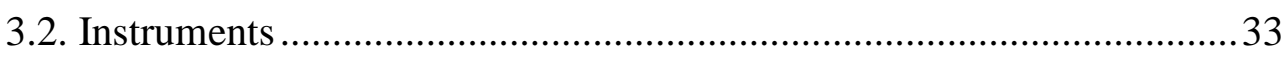

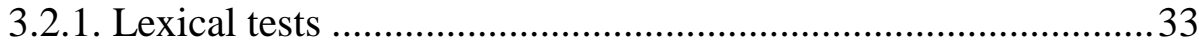

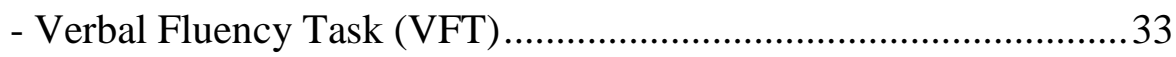

- Auditory Picture-Word Matching Task (APWMT) ...........................34

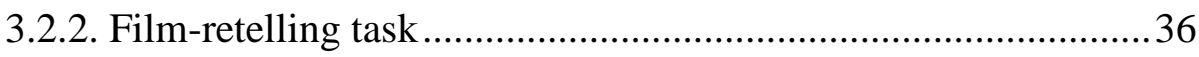

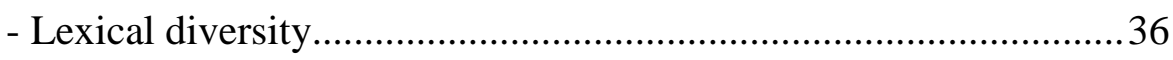

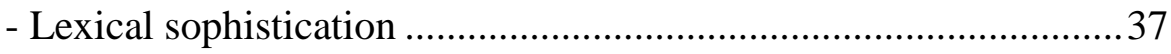

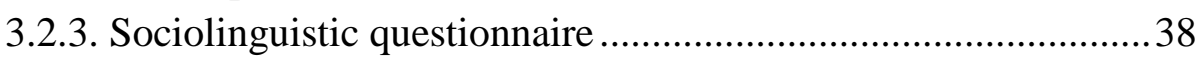

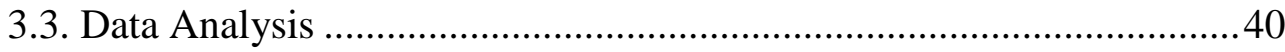

3.3.1. The quantitative studies ...................................................... 40

- Data processing of the lexical tasks .............................................40

- Data processing of the film-retelling task.......................................40

- Data processing of the sociolinguistic questionnaire ......................4 41

3.3.2. The qualitative studies ............................................................... 42 
Chapter 4: Part I: incomplete heritage language acquisition and attrition: a quantitative investigation ...................................................................47

4.1. Introduction to the quantitative investigation....................................47

4.2. The first study: Heritage speakers' productive and receptive vocabulary knowledge in their family language ........................................................4 47

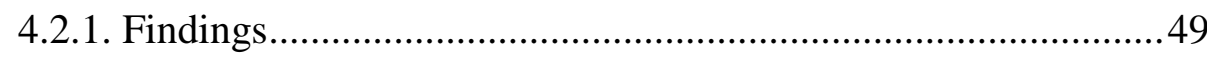

- Comparing bilinguals' and monolinguals' vocabulary test scores .49

- Comparing the simultaneous and sequential bilinguals with their matched controls ........................................................................ 51

- The effects of demographic and sociolinguistic variables on productive and receptive vocabulary knowledge .............................53

4.2.2. Conclusions, implications and limitations of the study on heritage speakers' productive and receptive vocabulary knowledge...........57

4.3. The second study: Lexical diversity and lexical sophistication in young

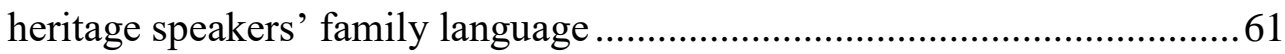

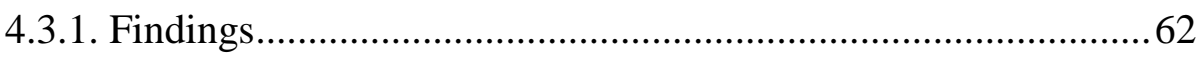

- Comparing bilinguals' and monolinguals' results of lexical richness

- Comparing the simultaneous and sequential bilinguals with their matched controls ........................................................................65

- The effect of demographic and sociolinguistic variables on lexical

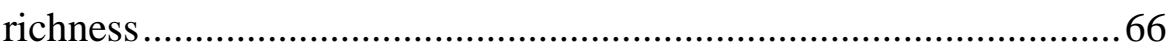

4.3.2. Conclusions, implications and limitations of the study on lexical

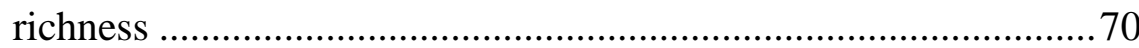

4.4. Discussion of the quantitative investigation....................................... 75

Chapter 5: Part II: heritage language acquisition and maintenance: a qualitative investigation ......................................................................83

5.1. Introduction to the qualitative investigation....................................... 83

5.2. The first qualitative study: Parental attitudes towards heritage language

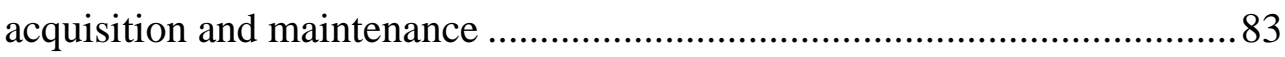

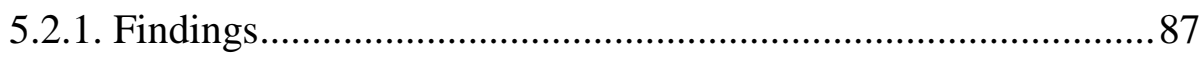

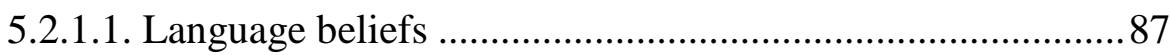

- Parents' reasons for heritage language maintenance .....................8 87

- Having regrets in the case of heritage language loss .......................90

5.2.1.2. Language practices ........................................................... 93

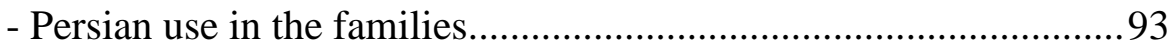

- Iranian friends and Persian use ......................................................99

- Contact with the home country ................................................... 100 
- Watching Persian movies and listening to Persian songs ............. 101

5.2.1.3. Language management................................................... 102

- Encouraging children to use the heritage language ........................102

- Correcting heritage speakers' Persian............................................ 105

- Other sources of language management ...................................... 105

5.2.2. Conclusion of the study on parental attitudes towards heritage language acquisition and maintenance....................................... 108

5.3. The second qualitative study: Parental attitudes towards heritage language literacy acquisition and maintenance ........................................ 111

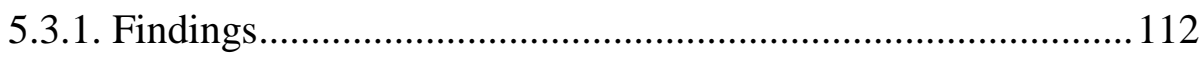

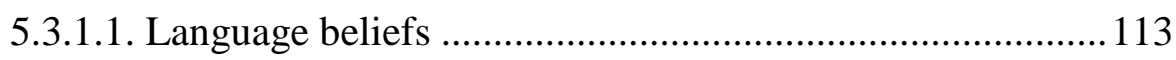

- Lack of community-based heritage language schools .................. 113

- Perceived inability in heritage language literacy teaching ............113

- Becoming home heritage language teachers ................................. 114

- The need for community-based heritage language schools .......... 115

- Heritage language literacy maintenance ....................................... 116

- The need to develop heritage language literacy............................. 117

- The perception of bilingualism and biliteracy ............................. 120

5.3.1.2. Language practices ........................................................ 121

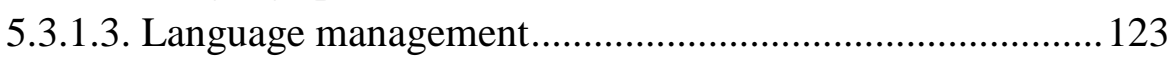

- Overcoming the challenges of heritage language literacy

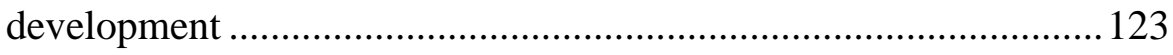

- Lack of enough resources ........................................................... 124

- Lack of incentives for heritage speakers to develop Persian literacy

5.3.2. Conclusion of the study on parental attitudes towards heritage language literacy acquisition and maintenance.......................... 126

5.4. Discussion of the qualitative investigation...................................... 128

Chapter 6: Conclusion .......................................................................137

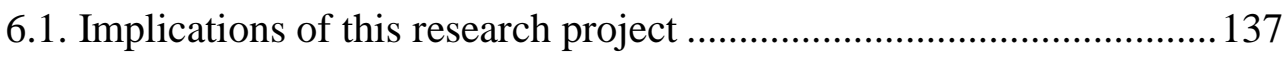

6.2. Directions for further research ....................................................... 143

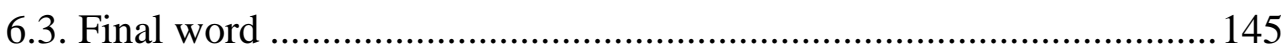

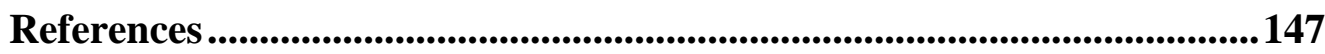

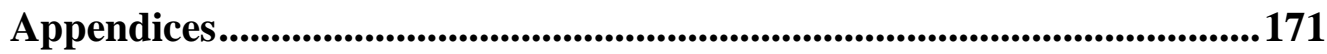

Appendix A: Information sheet for parents (English).............................. 171

Appendix B: Information sheet for parents (Persian) ............................... 173

Appendix C: Information sheet for participants over 16 (English)............ 175

Appendix D: Information sheet for participants over 16 (Persian) ............ 177 
Appendix E: Consent form for parents (English)

Appendix F: Consent form for parents (Persian)

Appendix G: Consent form for participants over 16 (English)

Appendix H: Consent form for participants over 16 (Persian) 182

Appendix I: Human Ethics Committee memorandum 183

Appendix J: Sociolinguistic Questionnaire (English) 184

Appendix K: Sociolinguistic Questionnaire (Persian) 192 


\section{LIST OF TABLES}

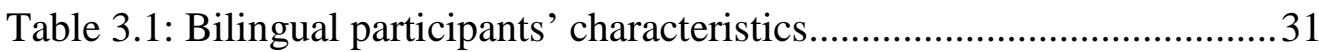

Table 3.2: Compound variables extracted from the questionnaire ..................4 42

Table 4.1: VFT results of the heritage speakers and matched monolinguals ..49

Table 4.2: APWMT results of the heritage speakers and matched monolinguals

Table 4.3: ANCOVA of VFT results of bilinguals and monolinguals ............50

Table 4.4: ANCOVA of APWMT results of bilinguals and monolinguals .....50

Table 4.5: Multivariate tests of VFT and APWMT together............................51

Table 4.6: Multivariate tests of VFT and APWMT separately ........................51

Table 4.7: Independent samples t-test in the subgroups and their controls on

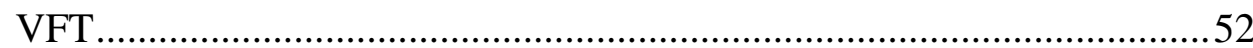

Table 4.8: Independent samples t-test in the subgroups and their controls on

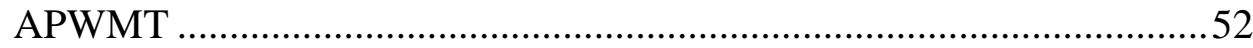

Table 4.9: Correlations and coefficients for VFT in all bilinguals .................54

Table 4.10: Correlations and coefficients for APWMT in all bilinguals.........54

Table 4.11: Correlations and coefficients for VFT in the simultaneous bilinguals .55

Table 4.12: Correlations and coefficients for VFT in the sequential bilinguals

Table 4.13: Correlations and coefficients for APWMT in the simultaneous

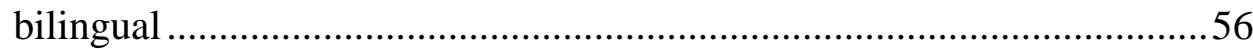

Table 4.14: Correlations and coefficients for APWMT in the sequential

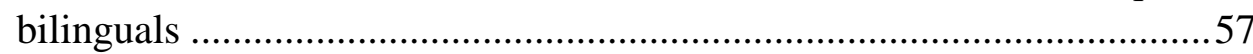

Table 4.15: Lexical diversity in bilinguals and monolinguals per 100 words 63

Table 4.16: Lexical sophistication in bilinguals and monolinguals.................63

Table 4.17: ANCOVA analysis of lexical diversity in bilinguals and

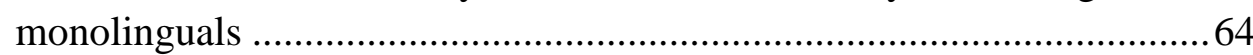

Table 4.18: ANCOVA analysis of lexical sophistication in bilinguals and

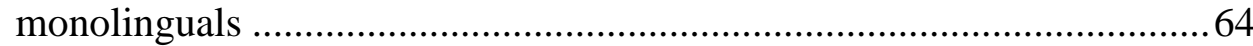

Table 4.19: Multivariate tests of lexical diversity and lexical sophistication together

Table 4.20: Multivariate tests of lexical diversity and lexical sophistication separately

Table 4.21: Independent samples t-test in the subgroups and their controls on lexical diversity.

Table 4.22: Independent samples t-test in the subgroups and their controls on lexical sophistication

Table 4.23: Correlations and coefficients for lexical diversity in the heritage speakers 
Table 4.24: Correlations and coefficients for lexical sophistication in the

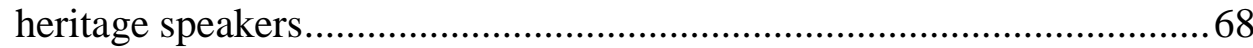

Table 4.25: Correlations and coefficients for lexical diversity in the

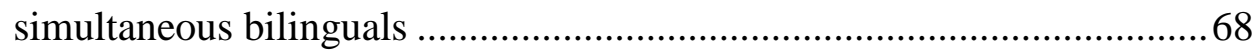

Table 4.26: Correlations and coefficients for lexical diversity in the sequential

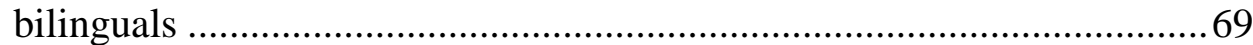

Table 4.27: Correlations and coefficients for lexical sophistication in the simultaneous bilinguals .................................................................. 70

Table 4.28: Correlations and coefficients for lexical sophistication in the

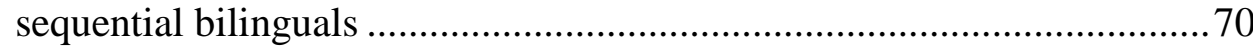

\section{LIST OF FIGURES}

Figure 2.1: The Graded Intergenerational Disruption Scale (GIDS) as pictured

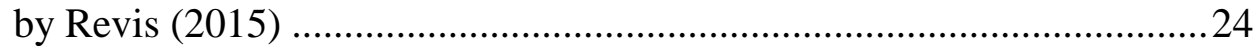

Figure 2.2: Spolsky's (2004) model of language policy as visualized in

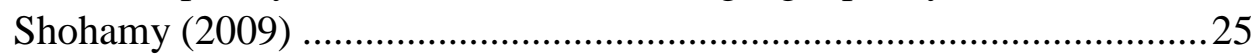

Figure 5.1: The multilayered construct of attitude in this study ......................86

Figure 5.2: Heritage language maintenance and family language use continuum .94

Figure 5.3: Visualization of Spolsky's (2004) model of language policy in this study..... 


\section{A Note to Readers}

The following articles from this project have been submitted for publication. The first two are included in the quantitative investigation of this dissertation which explores incomplete acquisition and attrition of heritage speakers' lexical knowledge in their family language. The qualitative investigation comprises the last two articles on parental attitudes towards heritage language acquisition and maintenance.

- Gharibi, K. \& Boers, F. (2016). Influential factors in incomplete acquisition and attrition of young heritage speakers' vocabulary knowledge. Language Acquisition. doi: 10.1080/10489223.2016.1187613

- Gharibi, K. \& Boers, F. (under review). Influential factors in lexical richness of young heritage speakers' family language.

- Gharibi, K. \& Seals, C. A. (under review). Bridging family language policy and parental attitudes towards heritage language acquisition and maintenance.

- Gharibi, K. \& Seals, C. A. (under review). Parental attitudes towards heritage language literacy acquisition and maintenance. 


\section{INTRODUCTION}




\section{Chapter 1 : Introduction}

\subsection{Where did it start?}

Kid: Mummy! Mummy! I want that toy.

Mother: No honey, you've got lots of toys.

Father: I will buy you that if you are nice to granny.

$$
\text { يدر: ببخشيد آقا، اين قيمتش קنده؟ }
$$

Father (in Persian): Excuse me sir, how much is this?

I was listening to this conversation between a young girl and her Iranian parents in a shopping mall in Shiraz, Iran. They had come to Iran to visit their families, and the young girl could not communicate in Persian. The parents also seemed to have no problem about speaking English to their daughter.

Before starting my PhD, I repeatedly encountered young children who could not speak Persian, coming to visit their relatives in Iran with their parents, it appears that they were missing a key language in which they would be able to converse with some relatives, particularly their grandparents. Seeing these young children, and how their parents communicated in English with them, made me wonder why these Iranian parents who appeared to have emigrated did not try to help their children acquire Persian, especially if they wanted them to be able to communicate with their grandparents and other relatives when visiting Iran. Are they aware of the fact that their children lose the opportunity to learn their heritage language as they grow up? Are they aware of the role they can play in raising their children bilingually? Do they consider it a sign of higher social status if their children cannot speak Persian? What are important factors in their children's proficiency development in their heritage language? Does parents' Persian use at home or their attitudes towards their children's heritage language acquisition and maintenance make a difference? How about the age of the children when they left Iran? Do they lose their Persian proficiency more the longer they live in the host country?

All these questions pushed me to start reading about bilingual children in immigrant families- those who use a language at home that is different from the societally dominant language. Through that, I came across the notion of "first language attrition" in Schmid (2011) as the loss of a first language as a result of decreasing use by speakers who have changed their linguistic environment. Then in reading Montrul (2008), I realized that language attrition 
in children is referred to as "incomplete acquisition", when they do not have the chance to reach age-appropriate levels of proficiency in their first language. Knowing about these two areas of research, I began a quantitative investigation to compare the differences between heritage speakers and their matched monolinguals. I was particularly interested to know the impact of parental attitudes on Persian acquisition, maintenance, and use in New Zealand for Iranian children. This is how I started my PhD.

\subsection{Iranian diaspora in New Zealand}

Iranians initially started leaving their home country en masse as a result of the Islamic Revolution of 1979. It was the major cause for "the growth of Iranian diaspora population worldwide" (Bozorgmehr, 1998, p. 5). The postrevolution wave of immigrants included political refugees or exiles, Iranians who left the homeland because of religious or cultural reasons (such as Baha'is, Jews, Christians, Armenians and Assyrians) and educated Iranians, who settled mainly in Europe and the United States (Bozorgmehr, 1995; Hakimzadeh, 2006; Chaichian, 2012).

The second wave of immigration was caused primarily by the Iran-Iraq war which lasted for eight years. During this period (1980-1988), many professionals, academics, left-wing party members, women escaping religious restrictions and gender-based discrimination, and men trying to escape the military service left the country (Chaichian 2012, p. 23). Finally, the most recent wave of emigration from Iran occurred in the aftermath of the presidential election in 2009. There was an increase in the number of skilled and educated Iranian immigrants as well as refugees and asylum seekers after this election (Chaichian, 2012).

New Zealand has been one of the destinations for Iranian immigrants and refugees. In 2013, one-fourth of New Zealanders were overseas-born (Statistics New Zealand, 2013 Census). Iranian-New Zealanders (informally known as Persian-Kiwis) include New Zealanders who were born in Iran and their children who were born in the host country. The New Zealand 2013 census estimated the number of Iranians in the country to be at 3,195, which is less than one percent of the population of New Zealand. However, it is believed that the actual number of Iranian immigrants with permanent or temporary visas exceeds that number. It is estimated that around 8,000 Iranian immigrants live in some capacity in New Zealand (Etemaddar, Tucker \& Duncan, 2015). 
According to the census in 2013, 19\% of the Iranian immigrants ( $n=600$ people) were born in New Zealand and less than $10 \%$ of them were younger than 15 years old that is, over $90 \%$ are over 15 years old. In addition, more than $75 \%$ of the Iranian immigrants reside in Auckland, the biggest city in New Zealand.

Although Iranians who originally moved to New Zealand (after the 1979 revolution) left the country mainly because of political or religious reasons (such as Baha' is and Christians), the recent Iranian immigrants to New Zealand are primarily skilled migrants under New Zealand's skilled migrant scheme or those who moved to New Zealand for educational purposes and decided to stay in the country after graduation (see also Chaichian, 2012). The skilled migrants are voluntary immigrants who moved to New Zealand as a result of a change in its immigration policy. In 1991, a points-based selection system was introduced in New Zealand to attract qualified people to contribute to "skilled human capital" (e.g., Bedford, Bedford, Ho \& Lidgard, 2002, p. 72). This policy led to the highest annual net migration gains since 1870s with considerable numbers of immigrants from East Asian countries (Bedford, Bedford, Ho \& Lidgard, 2002, p. 75).

Little research has investigated Iranians in New Zealand, though more has been done in other countries. However, there is no doubt that the community of Iranians is smaller than many other immigrant communities in New Zealand (Statistics New Zealand, 2013 Census ethnic group profiles: Iranian/ Persian). The families recruited in the present study immigrated to New Zealand during the second and new waves of Iran's emigration. The majority of them are skilled workers and professionals who immigrated to New Zealand after the change in the immigration policy, as well as those who moved to undertake tertiary education. Of the latter, some already have New Zealand residency, and some have not decided yet if they will stay in New Zealand or go back to Iran after graduation.

\subsection{Studies on Iranian heritage speakers}

Iranian heritage speakers have been rarely studied. Most of the existing research on Iranian heritage speakers has been conducted on Persian-Iranian bilinguals in the USA, which hosts the highest number of Iranian immigrants compared to the other countries in the world (Bozorgmehr, 1998). One of the

first studies on heritage language maintenance and loss in Iranian immigrants 
was carried out by Modarresi (2001). As he indicates, the first-generation Iranian immigrants in the United States would like their children to maintain Persian and they try to pass it on to their children through different means such as national Iranian ceremonies, radio and TV programs, newspapers, magazines, books, etc. (p. 93). Yet, the language shift happens in second generation Iranian immigrants mainly because of pressure to assimilate into the host society (Modarresi, 2001; p. 93). In another study on Iranian immigrants in the United States, Felling (2006) found that the Iranian parents in her study would like their children to have some proficiency in Persian and they enforce heritage language-only policy at home. The main motivation they reported for their children's heritage language acquisition was connections to their ethnic culture and families back in the home country. The first-generation Iranian immigrants in the US started to organize some heritage language classes in order to connect their children to Persian and Iranian culture (Atoofi, 2012). Thus, thanks to the existence of community-based heritage language weekend schools and classes, it seems that in areas with a large population of Iranian immigrants in the United States, heritage language loss has not been a major concern (Sedighi, 2010). However, Iranian-Americans' efforts to maintain their heritage language are nonetheless affected by a complex interplay of linguistic ideologies and perceived language status (Ramezanzadeh, 2010).

Regarding their heritage language vocabulary knowledge, Megerdomian (2009) found that Persian heritage speakers, like other heritage speakers (see also Polinsky, 1997), have difficulties in accessing lexical items and idiomatic phrases. Moreover, she found that while Persian heritage speakers generally have good knowledge of the spoken forms of words, they need training in reading and writing and also in mapping between written and conversational forms. A recent study by Payesteh (2015), which compared Persian-English preschoolers in the United States to a control group of English monolingual preschoolers, highlighted the correlation between parental input and children's productive skills in Persian.

In addition to the United States, some studies on Persian language maintenance and loss have been conducted in Sweden with more than 100,000 Iranian immigrants (Naghdi, 2010). These studies (Sohrabi, 1992, 1997; Jahani, 2004; Namei, 2008) indicated that the Iranian immigrants in Sweden do not use Persian exclusively as the language of the family domain. They found that both Swedish and Persian are used at home between parents and their children.

This brief sketch of Iranian immigrants' heritage language use and efforts to pass on the language to their children provides a general overview. It 
shows that Iranian immigrants appear to be using their ethnic language at their homes, which leads to their children's development of Persian. This dissertation aims to grasp an understanding of the community of Iranian immigrants in New Zealand. I try to illustrate what Persian acquisition and maintenance is like in heritage speakers from Iranian community in New Zealand, which is a comparatively small community - much smaller than counterparts in the host countries investigated in the aforementioned studies. In addition, there is little educational support and few community language schools for their ethnic language development and maintenance available in New Zealand, unlike in contexts where the ethnic community is larger. The results of this research can thus also serve a comparative analysis of heritage language acquisition and maintenance by communities of immigrants in different contexts.

\subsection{Minority language maintenance in New Zealand}

New Zealand has changed from an assimilationist to a multicultural society (e.g., Irwine, 1989; Peters \& Marshall, 1989). During the 1970s, immigrants as well as the Māori population were encouraged to give up their ethnic language and learn English to fully acculturate into the dominant society (e.g., Walker, 1989: Benton, 2001; Crezee, 2008). Currently, New Zealand, with "more ethnicities than the world has countries", is home to 160 languages (Statistics New Zealand, 2013 Census). New Zealand is known as "a de facto multicultural nation" with a positive attitude towards immigrants and multiculturalism (Ward \& Masgoret, 2008, p. 228), encouraging immigrants to use their own ethnic languages (Walker, 2011; Ward \& Liu, 2012). Consequently, the number of multilingual speakers in New Zealand has continued to rise, from $15.5 \%$ in 2001 to $18.6 \%$ in 2013 (Statistics New Zealand, 2013 Census).

New Zealand has a rich research literature on ethnic language maintenance and language shift. Studies have been conducted on ethnic language maintenance and shift in Dutch communities (Hulsen, 2000; Johri, 1998; Roberts, 1999, 2010; Crezee, 2008, 2012), Korean communities (Johri, 1998; Stark \& Youn, 1998; S. H. Park, 2000; Kim, 2001; Kim \& Stark, 2005; Kim, 2007), Pasifika languages (Taumoefolau, Starks, Davis \& Bell, 2002; Seals, forthcoming), Samoan immigrants (Pilkington, 1990; Johri, 1998; Roberts, 1999; MacCaffery \& Tuafuti; 2003), Afrikaans-speaking immigrants (Barkhuizen \& Knoch, 2005; Barkhuizen, 2006), Arabic-speaking communities (Al-Sahafi \& Barkhuizen, 2006; Al-Sahafi, 2010; Tawalbeh, forthcoming), 
Cantonese speaking immigrants (Sun, 1999; Cui, 2012), Italian immigrants (Berardi-Wiltshire, 2009), and Japanese immigrants (Nakanishi, 2000) in New Zealand. Additionally, a recent study by Revis (2015) has investigated heritage language maintenance and shift in Colombian and Ethiopian refugee communities in New Zealand.

The studies above illustrate that language maintenance and shift has been a frequent topic of research in New Zealand. Investigating Persian acquisition and maintenance in Iranian heritage speakers in New Zealand as well as their parents' attitude towards heritage language acquisition and maintenance, the current research aims to contribute to this rich literature on ethnic language maintenance and loss in New Zealand.

\subsection{Organization of the thesis}

This introductory chapter is followed by theoretical background for this research. The factors found in the literature to be influential in heritage language acquisition, maintenance and loss are outlined in Chapter 2.

Chapter 3 describes the participants of the study and how data was collected in this research project. As detailed in this chapter, the participants were young heritage speakers in New Zealand and their parents, and a group of matched monolingual speakers of Persian in Iran. To collect information about family language use and parental attitude, the young heritage speakers' parents were interviewed about their language practices and views about heritage language maintenance. The measures of Persian vocabulary knowledge of the heritage speakers were two controlled tests, one intended to measure productive knowledge and the other to assess receptive knowledge. A film-retelling task was also applied to collect free speech samples from the same young participants and their matched benchmarks.

This dissertation is composed of two main investigations on language loss and language maintenance. Part I, as discussed in Chapter 4, is a quantitative investigation of incomplete heritage language acquisition and attrition in young bilinguals' lexical knowledge which includes two studies. The first study compares the heritage speakers' vocabulary knowledge in their heritage language with that of the matched monolinguals. It also identifies influential variables in heritage speakers' proficiency in their family language. As the group of young heritage speakers included both simultaneous and sequential bilinguals, the difference between these two subgroups in 
comparison with their matched controls is also explored. The second study in this investigation examines the young heritage speakers' lexical knowledge through comparing lexical richness of their oral narratives to their matched controls'. Unlike the first study, the data were free speech samples to judge how heritage speakers use their family language 'naturally' (Schmid, 2011). It also like the first study in this investigation, compares the heritage speakers', either simultaneous or sequential bilinguals, lexical richness in Persian with that of the benchmarks. In addition, it tries to identify factors impacting the heritage speakers' lexical richness. The difference between the two subgroups of heritage speakers in comparison with their matched controls is also examined in this study.

From the two quantitative studies, a need for a qualitative investigation emerged in order to obtain a richer picture of the impact of sociolinguistic variables such as heritage language use and parental attitudes towards heritage language acquisition and maintenance for their children.

Part II, as outlined in Chapter 5, is a qualitative investigation on heritage language acquisition and maintenance, which presents two qualitative studies. These studies both are further explorations of the aforementioned interview data initially collected for the purpose of identifying sociolinguistic factors that help explain the variance in young heritage speakers' vocabulary knowledge. This qualitative investigation of the dissertation thus shifts the focus of the research project from the young heritage speakers to their parents. The first study investigates attitudes of the heritage speakers' parents towards Persian acquisition and maintenance. This study, furthermore, presents a methodological framework in examining parental attitude in the family context by utilizing the model of language policy by Spolsky (2004). This study shows that the parents want their children first and foremost to develop oral communicative competence in their heritage language. This outcome led me to conduct the second study in this qualitative investigation, which is an exploration of parental attitudes towards heritage language literacy acquisition and maintenance for their children.

This dissertation ends with a discussion of the implications and contributions of the quantitative and qualitative investigations as well as the limitations of the research project. Finally, suggestions are presented for future research on incomplete acquisition and language attrition. Potential areas of research on parental attitude towards heritage language acquisition and maintenance are discussed. 
THEORETICAL BACKGROUND 


\section{Chapter 2 : Theoretical background}

This chapter presents an overview of the theoretical background and frameworks that have been applied in this research project. I started this research aiming to show the role of input in the form of parental attitude in bilingual children in immigrant families. However, unexpected findings led me to conduct a qualitative investigation on the data to answer the primary question. This overview gives the reader an understanding of the theories and studies that form the basis for my doctoral research and situates this research in the literature. The research questions I aimed to find answers to in each study in the quantitative and qualitative investigations are outlined at the beginning of the results section of each study. The rationale for this is to help readers better understand the aims of each study before the presentation of their results. Therefore, this dissertation is structured differently from conventional theses.

\subsection{Heritage speakers}

Currently, children are more likely to grow up with more than one language due to increasing mobility around the world (Tucker, 1998). Among bilinguals, heritage speakers are those who were born in or emigrated to the host country during their childhood (Montrul, 2012) and grew up hearing and possibly speaking a minority language in the family (Polinsky, 2011, p. 306). As Valdés (2000, p. 1) describes, a heritage speaker (in the United States) is "a bilingual raised in a home where non-English language is spoken, who speaks or merely understands the heritage language, and who is to some degree bilingual in English and the heritage language." This definition shows that heritage speakers can have various linguistic abilities in their family language. While some may have native-like proficiency in the heritage language, some heritage speakers may only understand the language (Montrul, 2013). Heritage speakers are often weaker in their family language than in the majority language (Montrul \& Polinsky, 2011) and they may even become monolingual speakers of the majority language (Fillmore, 1991). A heritage language can be completely lost in the course of three generations (Fishman, 1991) as a result of attrition and incomplete acquisition (Montrul, 2002; Polinsky, 2007). While heritage speakers' knowledge of grammar has often been the focus of research in this area (e.g., Montrul, 2008; Polinsky, 2006), comparatively little attention has been paid to their vocabulary knowledge (Montrul, 2009, 2016). And yet, the lexicon has been found to be affected by language attrition earlier and more 
dramatically than morphology and syntax (e.g., Köpke \& Schmid, 2009). It has also been found that the lexicon is more susceptible to bilingual-monolingual differences (Unsworth, 2013). Besides, degrees of grammar knowledge and vocabulary knowledge are strongly correlated (Polinsky, 1997, 2007), and vocabulary test scores can serve as fairly reliable indicators of language proficiency more generally (Montrul, 2009). In the field of second language acquisition, for example, vocabulary test scores have been shown to correlate very strongly with learners' performance in speaking tasks (Iwashita, Brown, McNamara, \& O’Hagan, 2008; Koizumi \& In'nami, 2013) and listening comprehension tests (Staehr, 2009).

\subsection{Simultaneous and sequential bilinguals}

Bilinguals differ with regard to the sequence and the timing of two languages they acquire. Early bilinguals are those whose onset of bilingualism is before puberty while in late bilinguals, this process starts after puberty. This distinction in bilinguals is based on the age of acquisition of the second language. Another parameter to distinguish bilinguals is the order of acquisition of languages. According to this criterion, simultaneous bilinguals are those who acquire two languages concurrently while sequential bilinguals acquire languages successively. Simultaneous bilingualism takes place for those who acquire two languages (two L1s) at the same time since birth when they do not yet have any linguistic foundation, whereas sequential bilinguals acquire the second language when the basic knowledge of the first language has already been established, which is roughly around the age of three (McLaughlin, 1978; De Houwer, 1995; Genesee, Paradis \& Cargo, 2004). If sequential bilingualism occurs before puberty, it can be distinguished as early sequential bilingualism. On the other hand, late sequential bilinguals are those whose second language acquisition takes place after puberty (Montrul, 2008). Simultaneous bilingual acquisition has been referred to as "bilingual first language acquisition" (De Houwer, 1990). Simultaneous and sequential bilinguals have been found to differ in their lexical development in their two languages (J. Paradis, 2007, p. 18-20 and 25-27, for a review). The acquisition of two languages in simultaneous bilinguals is "simultaneous and independent but parallel" (Montrul, 2016, p. 36). Simultaneous bilinguals are believed to use the same cognitive mechanisms to learn words in their two languages, although the vocabulary growth may initially be slower than monolinguals'. When sequential bilinguals acquire vocabulary in their second language, however, this is likely 
to be influenced by their earlier L1 vocabulary learning experience, and so their lexical development in the two languages is likely to be qualitatively different. That line of research has implications mostly for L2 vocabulary development, though.

Research on bilingual acquisition commonly adopts a comparative approach to determine how similar the language development in bilingual settings is to the acquisition of a first language in monolinguals. Researchers try to determine if the acquisition of two first languages in simultaneous bilinguals follows the same path as the acquisition of those languages in monolinguals (Unsworth, 2013). Unsworth (2013) draws attention to the fact that compared to monolingual acquisition, development of multiple languages occurs in different circumstances. She also highlights that comparing these two processes may answer some theoretical questions about language acquisition. These questions address the role of input and its interaction with the process of language acquisition. It has been shown that the quality of quantity of input influences bilingual and monolingual language acquisition (e.g., Unsworth, forthcoming). Although some studies (e.g., Meisel, 1989; De Houwer, 1990) tried to determine if bilingual children develop their languages as one or two systems, it is generally presumed that children separate their languages early on in their bilingual acquisition, although some levels of interaction (i.e. crosslinguistic influence) between the two languages remain (Paradis \& Genesee, 1996).

One of the central debates in linguistics is how languages are acquired. As Unsworth and Blom (2010) describe, according to a generative approach to language acquisition, the input children are provided with in their native language is not adequate to acquire many properties of the language. Accordingly, they are credited with innate linguistic knowledge (or a specialpurpose, innate language acquisition device). On the other hand, according to the usage-based approach, children are believed to induce properties of their native language from the input through general cognitive processes and abilities which operate also outside the realm of language. Montrul (2008) argues that according to the usage-based hypothesis, language is a part of general cognition which enables people to learn mainly through interaction with the environment (Tomasello \& Bates, 2001). Although cognitive predispositions for learning are innate in this approach, they are not assumed to be specific to language learning alone (Montrul, 2008, p. 9).

Studies on heritage speakers as "an important largely untapped source of linguistic enquiry' (Rothman, 2007, p. 386), can shed light on the debates on 
language acquisition. In addition, studies on simultaneous and sequential bilinguals provide insights into understanding if there are benefits in receiving early and sustained input during language development (Montrul, 2013). They also provide us with opportunities to explore the influence of input in relation to age. Unsworth and Blom (2010) also assert that the comparison of different language acquirers (e.g., monolingual first language speakers vs. simultaneous and sequential bilinguals) enhances our understanding of some of the core questions in language acquisition research. Additionally, Rothman (2009, p. 159) emphasizes that studying heritage speakers helps us answer larger questions related to "the very nature of mental constitution of language and cognition" and "determining how and why languages change through space and time and the role 'nurture' has beyond 'nature' in the process of language acquisition and maintenance".

\subsection{Vocabulary knowledge in bilingual children}

Vocabulary knowledge in bilingual children has been a frequent topic of research (Serratrice, 2013). Size of the lexicon in bilinguals' languages has commonly been investigated. Young bilinguals have usually been found to score lower than age-matched monolinguals on productive (e.g. Junker \& Stockman, 2002; Yan \& Nicoladis, 2009) and receptive (e.g. Nicoladis, 2003; 2006; Yan \& Nicoladis, 2009) vocabulary knowledge tests. Since bilinguals are exposed to two languages, they often have less exposure to each language compared to monolinguals (Pearson, Férnandez, Lewedeg \& Oller, 1997), resulting in the distribution of lexical items between their languages (Pearson, 1998). This finding has been attributed to the fact that bilingual children typically acquire their languages in different contexts. The context-specific nature of vocabulary development in bilingual children was confirmed by Bialystok et al. (2010), where they found bilingual-monolingual differences in home-related vocabulary items but not in words relevant to a school context, where bilingual children seem to receive the same quantity and quality of input.

Language learners have commonly been presumed to understand lexical items before learning to produce them (see Harris, Yeeles, Chasin \& Oakley, 1995). Additionally, it has been assumed that "producing words is harder (i.e. requires more practice) than understanding them" (Yan \& Nicholadis, 2009, p. 324), because it necessitates motoric representations of lexical items (e.g. Fromkin, 1987). Less frequent exposure/practice might affect production more than comprehension in bilingual children, resulting in lower scores in 
production compared to comprehension tasks due to their difficulties in lexical access (Yan \& Nicholadis, 2009, p. 324).

\subsection{Incomplete acquisition and language attrition}

Incomplete L1 acquisition and L1 attrition both account for "language loss across generations" (Montrul, 2008, p. 21). Incomplete L1 acquisition occurs when properties of the first language remain absent from the heritage speakers' resources due to a lack of opportunities (or motivation) for picking them up, whereas L1 attrition occurs when a property of the first language was acquired by heritage speakers, but they can no longer produce or understand it or do so with high error rates. As language development is an incremental process where newly acquired knowledge can (temporarily) be forgotten, it is hard to attribute a young heritage speaker's degree of proficiency to either incomplete acquisition or to attrition, whether they be simultaneous or sequential bilinguals. Strictly speaking, a particular lacuna in a heritage speaker's vocabulary knowledge can only be said to be the result of attrition if there is evidence that this speaker did have this knowledge at an earlier point in time. As Montrul (2008) argues, the best way to tease apart incomplete acquisition and attrition is by carrying out longitudinal case studies. It seems reasonable to expect more evidence of attrition in sequential than in simultaneous bilinguals, because in the former a certain amount of L1 knowledge was acquired prior to arrival in the L2 environment - and so it is easier to show evidence of loss when it happens. However, L1 vocabulary acquired while the family is living within the L2 environment can be lost if it is not activated for a long period of time. Young heritage speakers' L1 knowledge is therefore likely to reflect incomplete acquisition and language attrition "simultaneously or sequentially" (Montrul 2008, p. 21).

Describing heritage speakers' knowledge of their family language as "incomplete", Montrul (2008) clarifies that she does not support a deficit model of bilingualism. She asserts that this term should be understood as a descriptive term, not a value judgment (p. 7) which refers mainly to non-mastery of language acquisition, when individuals do not reach native-like competence. Cabo and Rothman (2012) challenged the use of this term, arguing that heritage speakers' state of competence should not be described as "incomplete", since it ignores the role of input as a central component of language acquisition. They argued that heritage speakers' competence is not incomplete but different from monolinguals' due to environmental reasons, emphasizing that the input 
heritage speakers are provided with is different from monolinguals'. Heritage speakers are exposed to input, mainly from their parents, whose language has already undergone cross-generational attrition. Therefore, Cabo and Rothman (2012) highlighted the fact that heritage speakers may have completed the mastery of the attrited input that they are exposed to. In addition to qualitatively different input, they discussed another reason to problematize the use of this term. Montrul (2008) used "incomplete acquisition" as a cover term to attribute the differences between heritage speakers' competence to benchmark monolinguals, regardless of whether these are due to incomplete acquisition or language attrition. As Cabo and Rothman (2012) assert, using 'incomplete acquisition' as a cover term as in Montrul (2008) is misleading, since it is impossible to distinguish incomplete acquisition and attrition in heritage speakers' state of competence in the absence of longitudinal data (however Montrul acknowledged this point). They argue that the differences between heritage speakers' and monolingual benchmarks' competence should not be regarded as deficits, since they are an opportunity to deepen "our understanding of linguistic representation, the architecture of the human mind and the language faculty" (p. 454). As Cabo and Rothman (2012) argue, heritage speakers show a greater role for cognition in the process of language acquisition, since they are dealing with "competing inputs" (p. 454) from their family language and majority language at the same time.

Recently, Montrul (2016) clarified that referring to heritage speakers' knowledge of their ethnic language as incomplete is "theoretically problematic" (p. 125), since it cannot be claimed that languages can be acquired completely. In this research project, for simplicity's sake, I use "incomplete acquisition" to refer to the knowledge heritage speakers have not acquired regardless of whether this is due to insufficient input or a lack of opportunities for its acquisition at the time of changing their language environment. On the other hand, "heritage language attrition" in this dissertation refers to properties of the home language that were acquired before heritage speakers' age at emigration, but which they can no longer produce or understand.

\subsection{Theoretical accounts of incomplete acquisition and language attrition and their influential factors}

This section describes the theoretical background of this investigation. Due to the complex and multifaceted nature of heritage languages, more than a single theory is required to explain their nature (Montrul, 2016). It also 
discusses some of the factors that are likely to impact incomplete heritage language acquisition and attrition in young bilinguals.

\subsubsection{Age at emigration}

In exploring the effect of age on heritage language competence, two age factors should be distinguished: (a) biological age at the time when the study is conducted, and (b) age at emigration. The age at which heritage speakers emigrate to the second language environment has been found to be a very strong predictor of various facets of heritage language proficiency, including pronunciation, morpho-syntax, and lexis (see e.g., Bylund, 2009a, for a review). Heritage language competence can dramatically be eroded if attrition starts well before puberty, while those whose attrition sets in after puberty, tend to experience only limited language loss in their heritage language competence (see Köpke \& Schmid, 2004 for a review). The earlier the extensive exposure to the majority language starts, the more severe the family language loss is likely to be (Montrul, 2008, p. 161), because children will then have had much less L1 input by the time they embark on their bilingual journey (Montrul, 2008, p. 249). To explain the effect of age on the process of language loss in children, the Critical Period Hypothesis (Lenneberg, 1967) has often been referred to (e.g., Bylund, 2009b; Polinsky, 2011). This hypothesis has primarily been applied to account for differences between children's and adults' success in first language acquisition - although typically with a focus on phonology and morpho-syntax rather than lexis. Montrul (2008) argues that if the Critical Period Hypothesis helps to explain successful language acquisition by children, it may also shed light on the fast and drastic language loss in children as compared to adults when they change their language environment. If it is true that children enjoy a window of opportunity where their developing linguistic competence is still quite malleable and particularly susceptible to cues in their linguistic environment, then a change in the linguistic environment during that same window of sensitivity will also have a greater impact than if the changes were to occur later on in life. It follows, then, that age at emigration is a likely predictor of the proficiency of heritage speakers in their family language. However, as already mentioned, the Critical Period Hypothesis has been used to speculate why post-puberty learners of a language are unlikely to reach ultimate attainment in their mastery of phonology (including accent and prosody) and morpho-syntax, but it seems a less adequate explanation when it comes to vocabulary. After all, new words can be picked up throughout one's lifetime. Even though the ability for incidental vocabulary acquisition does 
seem to decline gradually with age (Hoyer \& Lincourt, 1998), this is evidently a gradual change, unlike the more drastic closing of a window after puberty, as suggested by the Critical Period Hypothesis (e.g., Bahrick, Hall, Goggin, Bahrick \& Berger, 1994; Davis \& Kelly, 1997). That having been said, it is well established that age of acquisition does matter also for vocabulary, but in the sense that words which were acquired at an early age tend to be retrieved faster and more accurately than words which were acquired later in life (e.g., Bonin, Fayol \& Chalard, 2001; Izura \& Ellis, 2002, 2004; Bonin, Barry, Méot \& Chalard, 2004). Given this age-of-acquisition effect, it is not surprising that heritage speakers tend to experience less difficulty retrieving L1 words acquired prior to emigration than words acquired later (Ammerlaan, 1996; Hulsen, 2000; Montrul, 2009; Montrul \& Foote, 2014). Consequently, age at emigration is likely to be associated with heritage speakers' command of lexis in their family language. Rothman (2009, p. 159) asserts that "Given the fact that heritage language competence is in many ways more comparable to adult L2 than to L1 monolingual outcomes tells us that age-at-acquisition alone is not the only variable that contributes to comparative incompleteness."

\subsubsection{Length of emigration}

The length of residence in the L2 environment may seem an obvious factor in heritage language loss, but studies with adult heritage speakers have found rather mixed results regarding the effect of length of emigration on attrition, which shows that time per se may not be a crucial factor. Some investigations on adult bilinguals (e.g., Soesman, 1997) have shown that the longer one lives in an L2 environment, the more one's knowledge of the mother tongue is affected, whereas other studies (e.g., Schmid, 2002; Hutz, 2004) have revealed only a weak effect. Additionally, some studies (e.g., de Bot \& Clyne, 1994) have found that the rate of L1 attrition is relatively high in the first years of residence in the $\mathrm{L} 2$ environment, but declines over time, with at least some bilinguals not manifesting any additional L1 attrition after ten years of residence in that environment. Consequently, the role this factor can play in first language attrition is not settled yet (Köpke \& Schmid, 2004). Since first language attrition, in particular lexical attrition, in young heritage speakers is an underresearched area, it is difficult to make predictions about the effect of length of emigration on heritage language vocabulary knowledge in the population I focus on in the present investigation (i.e. young heritage speakers). The main reason is that, as they grow older in the host country, these young language users 
may continue to develop their heritage language lexicon while at the same time losing certain lexical items they acquired when younger.

\subsubsection{Heritage language use}

Another factor likely to influence the rate of language maintenance and loss in children is amount of input and use (e.g., De Houwer, 2007; Montrul, 2008). In addition to the internal variables such as age and age at emigration in heritage speakers, it can be claimed that "the only external variable necessary to guarantee linguistic acquisition is sufficient exposure to input" (Rothman, 2007, p. 361). Numerous studies have shown the impact of home language use on children's development of language skills (Paradis, Nicoladis, Cargo \& Genesee, 2011; Unsworth, forthcoming). While more input promotes more language use (Pearson, 2007), the absence of input is both a hindrance for acquisition and a cause of attrition (e.g., Köpke, 2007; M. Paradis, 2007). Accessibility of language items based on their frequency of use refers to the Activation Threshold Hypothesis, a theoretical framework suggested by M. Paradis (2004). This framework explains the relation between activation and frequency of use, assuming that the more frequently activated (i.e., used or encountered) language items are readily accessible or retrievable from memory. Conversely, knowledge that is not activated for a long time may be forgotten. Language disuse may thus lead to language attrition, with low frequency items or features being lost before high frequency ones. Some studies (e.g., de Bot, Gommans \& Rossing, 1991; Köpke, 1999 as cited in Schmid, 2007) have indeed shown a correlation between frequency of use and bilinguals' L1 attrition. Other studies, however, did not find compelling evidence of this correlation (Jaspert \& Kroon, 1989, as cited in Schmid, 2007). These different results led Schmid (2007) to conceive of the impact of language use on first langage attrition by applying Grosjean's (2001) notion of language modes. She proposed three language modes: the bilingual mode setting (with family and friends), the intermediate-mode setting (social contexts such as churches, clubs and the workplace) and the monolingual mode setting (with native L1 speakers). While her study with adult bilinguals did not show the impact of L1 use with family and friends on L1 attrition, it found that the only language environment that played a significant role was the intermediate-mode setting. In another study with adult bilinguals, Schmid and Dusseldrop (2010) used a factor analysis to quantify the amount of L1 use and examine its impact on language attrition along with other factors. Language use with family and friends was not found 
to be a strong predictor of L1 attrition in that study either (since a similar methodology is used in quantifying heritage language input in the present study, it will be further discussed in section 2.3.1.2.3). Although the aforementioned studies did not demonstrate the effect of language use with family and friends on first language attrition in adult bilinguals, it is conceivable that it exerts a greater influence on incomplete first language acquisition in young heritage speakers, since heritage speakers' L1 acquisition relies heavily on heritage language use in the nuclear family and exposure to L1 in a second language environment is likely to be more infrequent outside that setting.

According to the Activation Threshold model, receptive knowledge tends to be retained longer than productive knowledge, because production requires a higher level of activation (Hulsen, 2000; M. Paradis, 2007, p. 125; Montrul 2008, p. 81) and so language users will fail more often to retrieve a word for productive purposes (rather than recognize the meaning of a word as one encounters it). O'Grady, Schafer, Perla, Lee and Wieting (2009) also proposed that frequency of language use aids language maintenance because speakers may feel reluctant to use the less accessible lexical items or grammar patterns and this then leads to further erosion of their memory traces. This is similar to the input-proficiency-use cycle suggested by Pearson (2007, p. 401), proposing that increased input leads to more proficiency, which in turn promotes more use of the language.

Input and output are usually combined into one language score (e.g., Bedore, Pena, Summers, Boerger, Resendiz, Greene \& Gillman, 2012). However, Unsworth (forthcoming) indicates that output may be a better predictor of children's proficiency in their minority language, since "using a language (i.e. output) forces the learner to process the language in a way that only hearing it (i.e. input) does not" (Bohman, Bedore, Pena, Mendez-Perez, \& Gilan, 2010, p. 339). By investigating simultaneous and sequential bilinguals, I aim to examine both the role of input and age at emigration (age at onset), which were addressed by a handful of studies as Unsworth (2016) pointed out.

\subsubsection{Parental attitudes}

Attitudes towards a minority language have been considered one of the most influential factors in language maintenance (Fishman, 1991; Schmid, 2002; Ben-Rafael \& Schmid, 2007). However, not all studies have found a significant impact of attitude on L1 attrition (e.g., Hulsen, 2000; Schmid \& 
Dusseldorp, 2010). In a recent study, Cherciov (2012) argues that positive attitudes towards a minority language by themselves do not guarantee its maintenance, if, as Bennett (1997) argues, these feelings do not lead to more frequent use of the language. In the case of child heritage speakers, it has been shown that parents' attitudes towards the heritage language can affect its maintenance (e.g., Park \& Sarkar, 2007). Pearson (2007) also argues that parents' attitude, if it promotes family language use, can play a crucial role in heritage language maintenance. Parents with a positive attitude towards the heritage language are likely to make an effort at passing on this language to their children and will be more likely to use it in the family setting. If sustained language input is vital for acquisition and for keeping attrition at bay, then a positive attitude on the part of the parents can be expected to at least indirectly exert a positive influence on their children's lexical competence in the heritage language. The impact of parental attitude in heritage language acquisition and maintenance is discussed more in the following sections.

\subsection{Heritage Language Maintenance}

Raising a bilingual child is a big challenge for immigrant parents. Previous studies have disproven early assumptions that immigrant children become bilingual by simply acquiring the language of the host country (e.g., Fillmore, 1991; Hinton, 1999; Kouritzin, 1999). In fact, young heritage language speakers tend to replace their heritage language with the societally dominant one if deliberate efforts are not made to develop and preserve the family language (Fillmore, 1991, 2000). Furthermore, minority languages are regularly lost within three generations in immigrant populations (Fishman, 1991).

Fishman (1991) introduced the Graded Intergenerational Disruption Scale (GIDS) which depicts eight sociolinguistic situations in favor of intergenerational transmission of ethnic languages. The higher stage on the GIDS refers to the higher degree of ethnic language attrition in a community. Stage 8 on this scale refers to contexts where a minority language is used by isolated older individuals with high levels of attrition. Conversely, in stage 1, which is the most advantageous to language maintenance, a minority language is used in higher education, government and media. Figure 2.1 shows different stages of the Graded Intergenerational Disruption Scale (GIDS) as adopted by Revis (2015) for minority languages of New Zealand. 


\begin{tabular}{|l|l|}
\hline $\begin{array}{l}\text { Stage } \\
8\end{array}$ & minority language is used by isolated older speakers \\
\hline $\begin{array}{l}\text { Stage } \\
7\end{array}$ & minority language is used by socially integrated speakers beyond child-bearing age \\
\hline $\begin{array}{l}\text { Stage } \\
6\end{array}$ & $\begin{array}{l}\text { Intergenerational language transmission of the minority language assisted by } \\
\text { institutional support }\end{array}$ \\
\hline $\begin{array}{l}\text { Stage } \\
5\end{array}$ & minority language literacy efforts in the community \\
\hline $\begin{array}{l}\text { Stage } \\
4\end{array}$ & minority language is used in lower education \\
\hline $\begin{array}{l}\text { Stage } \\
3\end{array}$ & minority language is used in lower work sphere \\
\hline $\begin{array}{l}\text { Stage } \\
2\end{array}$ & minority language is used in lower government services and mass media \\
\hline $\begin{array}{l}\text { Stage } \\
1\end{array}$ & minority language is used on higher levels of government and media \\
\hline
\end{tabular}

Figure 2.1: The Graded Intergenerational Disruption Scale (GIDS) as adopted by Revis (2015)

Fishman (1991) draws a link between language maintenance and minority language use in the home context in Stage 6, asserting that using the minority language by the family is extremely crucial for its maintenance. Research has shown that the (nuclear) family plays a crucial role in children's minority language maintenance and loss (e.g., King, Fogle \& Logan-Terry, 2008; Schwartz, 2010 to name a few). If not hindered, natural intergenerational transmission of minority languages occurs within the family (Spolsky, 2012, p. 4). Although immigrant parents want their children to develop high levels of proficiency in the societally dominant language as "the primary means for social integration" (Guardado, 2002, p. 343), they often simultaneously desire for their children to acquire and maintain their heritage language (e.g., Lee, 2002). At the individual level, some influential factors in heritage language maintenance are speakers' current ages, ages at emigration and length of residence in the second language environment (Kipp, Clyne \& Pauwel, 1995). Language practices at home between children and their parents, as well as positive positioning by their parents, have been identified as two of the strongest predictors of heritage language development and maintenance (Fishman, 1991; Seals, 2013, forthcoming). Additionally, parents' attitudes towards the heritage language significantly influence their children's proficiency (e.g., Kouritzin, 1999; Li, 2006; Park \& Sarkar, 2007). The more parents value and use the heritage language, the more their children tend to acquire and maintain it (e.g., De Houwer, 1999; Zhang \& Slaughter-Dafoe, 2009). 


\section{Family language policy}

Family has been regarded as "the central driving force" in heritage language maintenance and loss in children (Schwartz, 2010, p. 171). Family language policy (King et al., 2008, p. 907) in particular discusses how languages are managed, learned and negotiated within families. Family language policy argues that these negotiations have an important role in children's language development in immigrant families (Schwartz, 2010). Defined as "explicit and overt planning in relation to language use within the home among the family members" (King et al., 2008, p. 907), family language policy emerged through the application of the language policy model to child language acquisition (King et al., 2008, p. 907). Like other language policies, family language policy integrates the analyses of language ideology, practices and management, which were categorized by Spolsky (2004).

Spolsky's model (2004) of language policy is classified into three components: language beliefs (ideologies), which refers to "the beliefs about language and language use"; language practices, which are "the habitual pattern of selecting among the varieties that make up its linguistic repertoire"; and language management, which includes "any specific efforts to modify or influence that practice by any kind of language intervention, planning or management" (p. 5) (see Figure 2.2).

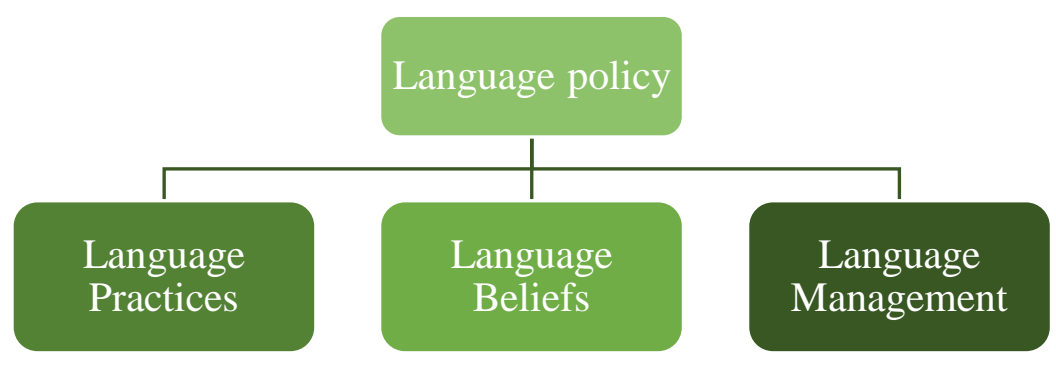

Figure 2.2: Spolsky's (2004) model of language policy as visualized in Shohamy (2009)

Research on family language policy to date has mainly focused on bilingual or multilingual families to understand how to better promote heritage language maintenance in the family context (Fogle \& King, 2013). Researchers on family language policy seek to answer questions such as: why and how do some children in immigrant families become monolinguals while some maintain their heritage language(s)? What policies are applied by immigrant 
parents to encourage or discourage the use of their ethnic language(s) in the home (Curdt-Christiansen, 2013, p. 1)?

Family language policy has increasingly been researched over the last decade (Curdt-Christiansen, 2013) in different populations and from different sociolinguistic angles (see Schwartz, 2010; King \& Fogle, 2013; Schwartz \& Verschik, 2013, for reviews). These studies have highlighted the impact of some factors such as family structure (e.g., Fillmore, 1991, 2000; Fishman, 1991), parental education (e.g., King \& Fogle, 2006), family cohesiveness (e.g., Fillmore, 2000; Okita, 2002; Tannenbaum \& Howie, 2002), parental heritage language input (e.g., De Houwer, 1999, 2007; Lanza, 2004, 2007), parental immigration experiences (e.g., Curdt-Christiansen, 2009), and children's agency (e.g., Fogle, 2009; Fogle \& King, 2013) on family language policy, as well as heritage language maintenance or loss in immigrant families. Some of these studies are focused on different immigrant populations such as Russianspeaking families in Israel (e.g., Spolsky \& Shohamy, 1999; Schwartz, 2008; Kopeliovich, 2013), Chinese families (e.g., Chao, 1996; Li, 2006) and Korean immigrant families in the United States (e.g., Lee, 2002; Park, 2007), Japanese families in Canada (e.g., Kondo, 1997; Sakamoto, 2006; Hashimio \& Lee, 2011) and Chinese families in Singapore (e.g., Curdt-Christensen, 2012, 2014, 2016).

\subsection{This study}

As previously mentioned, the primary aim of this research project was to show the role of input in heritage language acquisition and maintenance in young bilinguals where the language used in their home context is different from the language of the host society. To do this, I started a quantitative investigation which looks at young bilinguals' vocabulary knowledge in their heritage language, i.e., Persian. Some of the participants are simultaneous bilinguals while others are sequential bilinguals. In accordance with the aforementioned distinctions (section 2.2), children who were born in or emigrated to a second language environment before the age of three were classified as simultaneous bilinguals in the present study, while I consider sequential bilinguals as those heritage speakers who were born in the home country or emigrated to the second language environment after the age of three. This investigation was launched to elaborate the interplay of demographic variables (i.e. age, age at emigration and length of emigration) and sociolinguistics variables such as heritage language use and parental attitude on heritage language proficiency in the simultaneous and sequential bilinguals. The 
quantitative investigation failed to furnish compelling evidence of the role of input in heritage language proficiency. This finding raised a need for a qualitative analysis on the data to find out if an in-depth investigation portrays a better picture of the role of parental input on heritage language acquisition and maintenance. This is the overarching aim for conducting the quantitative and qualitative investigations. To help readers grasp a better understanding of the aims of the four studies in this research, the sub-questions of each study are outlined before the presentation of their findings in Chapters 4 and 5 . 
METHODOLOGY 


\section{Chapter 3 : Methodology}

In this chapter, I discuss the demographics of the participants as well as the process of data collection for the quantitative and the qualitative portions of this dissertation. As mentioned, the quantitative investigation focuses mainly on the heritage speakers, while the main emphasis in the qualitative investigation is on their parents. In other words, these two investigations explore the same data from the same participants from different angles.

\subsection{Participants}

Three groups of participants took part in this study. The main participants of the quantitative investigation were a group of 6-18 year-old children/teenagers. This group of heritage speakers (see Table 3.1) consisted of 30 Persian-English bilinguals (14 boys and 16 girls; mean age: 10.3) who have been living in New Zealand for different lengths of time (mean: 6.9 years). This made it possible to evaluate the effect of length of stay in the second language environment on vocabulary knowledge in the minority language, in interaction with other factors, such as the participants' age when they arrived in the second language environment, their age at the time of data collection, and sociolinguistic variables. In addition, the reason for choosing heritage speakers from this age range was that children at this age connect with peers and adults, and they go through "tough assimilative pressure" (Hinton, 1999, p. 5) mainly from their peers at schools (see also Harris, 1995).

Table 3.1: Bilingual participants' characteristics

\begin{tabular}{lllll} 
& Mean & SD. & Min. & Max. \\
\hline Age & 10.3 & 3.5 & 6 & 18 \\
Age at emigration & 3.8 & 4.2 & 0 & 14 \\
Length of residence & 6.9 & 3.8 & 1 & 17 \\
\hline
\end{tabular}

Eleven of the heritage speakers were born in New Zealand or other countries where English is the dominant language, while the others moved there at different ages. Among the heritage speakers, four emigrated to the second language environment before the age of three. Heritage speakers are considered to be sequential bilinguals only if their exposure to the second language started 
after the age of three (McLaughlin, 1978; De Houwer, 1995; Genesee, Paradis \& Cargo, 2004; Montrul, 2008). Accordingly, I consider as 'simultaneous' bilinguals all the participants who were born in the host country or emigrated to the second language environment before the age of three. This means that the sample includes the same number of simultaneous $(n=15)$ as sequential bilinguals $(n=15)$.

To investigate the development of vocabulary knowledge of bilinguals in the heritage language, one would in principle need two measures: the current knowledge of the bilingual participants and their knowledge at an earlier stage, for example before emigration. While the current measure is obtainable, finding pre-emigration data is problematic. However, Ronowicz (1999) argues that L1 proficiency before the onset of attrition can be estimated by referring to the proficiency data of monolingual first language speakers of the same age, education and social status. Although establishing a baseline for heritage speakers has been a matter of debate (Benmamnoun, Montrul \& Polinsky, 2010), heritage speakers are usually compared to native-speakers of their home language of similar age and socioeconomic status in the home country. Following this line of reasoning, I used a control group to obtain 'benchmark' data of non-migrants' vocabulary knowledge. This control group consisted of 30 young monolingual Persian speakers in Iran, matched in terms of age, gender, number of siblings and their family's socio-economic status to each of the 30 heritage speakers in New Zealand. In short, for each of the Iranian young immigrants, I obtained a measure of what their vocabulary knowledge might have been like if they had grown up in Iran. The thirty monolingual participants in Iran were recruited through networking. The test instruments and test procedures were identical to those used to collect data from the bilingual participants in New Zealand.

The third group of participants, who were the main focus of the qualitative studies in this dissertation, were parents of the heritage speakers in New Zealand. These participants were twenty-four Iranian parents who were born in Iran and immigrated to New Zealand at different ages. Their ages at the time of the data collection ranged from 31-61 years old, and they had been living in New Zealand between 1-30 years. The parents who participated directly in the interviews were mostly mothers (fourteen mothers and four fathers) and in an additional three families, both parents took part in the interviews. Seven of the immigrant families that took part in the study moved to New Zealand for the purpose of higher education and they did not know whether they would return to Iran after graduation, while the others have New Zealand permanent 
residency. Ten families had one child, while the others had two or more children (some of whom also participated in the study). Standard Persian was the first language of all families except for one where both Turkish and Persian were used at home (Turks are one of the ethnic groups in Iran). This family had a son and a daughter who could speak and understand some Turkish as well as Persian.

Since I took part in the Iranian community events prior to recruiting the participants, gaining access to this community was facilitated. The families were initially contacted through some heads of Iranian communities in three main cities in New Zealand: Wellington, Christchurch and Auckland, and information sheets about the study were distributed among potential participants. I also recruited some participants through snowball sampling (i.e., using participants' social networks to recruit more). Almost all families I had initially contacted participated in the study. Each informant received a gift as a token of appreciation for their participation.

\subsection{Instruments}

To compare the simultaneous and sequential bilinguals' Persian proficiency with that of their matched monolinguals, various measures were used in this project. These measures included some controlled tests to assess the young participants' productive and receptive knowledge in their home language. To collect free speech samples from these participants, a filmretelling task was applied in the quantitative investigation. In addition, background information about the bilingual participants' Persian use and parental attitudes towards heritage language use and maintenance for their children was obtained through semi-structured interviews with their parents based on a sociolinguistic questionnaire. These instruments are described in this section.

\subsubsection{Lexical tests}

\section{Verbal Fluency Task (VFT)}

One of two vocabulary tests I used was the so-called Verbal Fluency Test (VFT). There are two types of VFT. In the semantic VFT, participants are asked to list as many semantically related words as they can in a certain period 
of time, usually 60 or 90 seconds. In the formal VFT, participants are asked to produce words which start with a certain letter. Both of these tasks are commonly used to examine lexical retrieval difficulties as early signs of attrition (Schmid, 2011). It is assumed that the number of items produced by participants reflects their ease or difficulty accessing items in the mental lexicon (Schmid, 2007). The semantic VFT has been the preferred type in language attrition studies (e.g., Schmid, 2007; Schmid \& Keijzer, 2009; Schmid \& Jarvis, 2014). One of the reasons is that a word onset letter can be confusing as a prompt, for instance due to inconsistencies in grapheme-phoneme correspondences (e.g., t

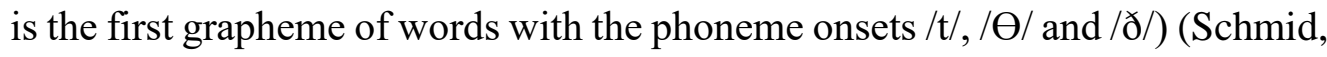
2011, p. 148). Given the young age of some of the participants, I also deemed the semantic version of the VFT more suitable. The participants were asked to orally produce as many Persian words as they could be belonging to two semantic fields, "fruit and vegetables" and "animals", in 60 seconds for each of the prompts. A stopwatch was used to time them and their performance was recorded. The young age of some of the participants motivated my choice to elicit words belonging to concrete semantic fields. It is worth mentioning that the label used for this test, i.e. Verbal Fluency, can be slightly misleading, because it is not the kind of test that is commonly used in psycholinguistic measurements of speech fluency (such as speech rate, length of run, and phonation-time ratio; see e.g., Segalowitz, 2010, for a review). The VFT was originally used in research on lexical access difficulties in participants with brain damage, aphasia, dementia etc. (e.g., Fallgatter, Roesler, Sitzmann, Heidrich, Mueller \& Strik, 1997). It was subsequently also adopted by researchers to investigate lexical access in the domain of first language attrition (Schmid, 2011).

\section{Auditory Picture-Word Matching Task (APWMT)}

In the area of language acquisition, the Peabody picture-word matching task (PPVT) has frequently been used to measure the receptive vocabulary knowledge in children and adult bilinguals (e.g., Bialystok, Luk, Peets \& Yang, 2009). It has also been used in some studies on second language attrition (e.g., Tomiyama, 1999, 2000). Different revisions of this test have been developed from the original one which was devised in 1959 by Dunn and Dunn (see Hoffman, Templin \& Rice, 2012). In this test, four pictures are presented to respondents and they are asked to choose the picture for a word spoken by an examiner. In this research project, however, the vocabulary test used to measure 
the heritage speakers' and their matched monolinguals' receptive knowledge in their family language was an auditory picture-word matching test (APWMT). Picture-word matching tests (PWMT) have often been used to test participants' recognition of word meaning (Schmid, 2011). Since most of the participants in this study were Persian illiterate, however, I could not use a format with orthographic representations of words. Instead, a multiple-choice auditory picture-word matching task was developed. In this test, a picture is presented on a computer screen and the participant is asked to listen to four recorded L1 words and to decide which one corresponds to the picture. To my knowledge, auditory tests have not been used in any attrition studies yet, while they are a necessary alternative for written mode tests when participants are illiterate in their minority language.

The pictures were selected from the standardized set of 260 pictures developed by Snodgrass and Vanderwart (1980) by using a number of selection criteria. Considering the young age of some of the participants in my study, I felt it appropriate to make a selection so as to reduce the length of the test. First, pictures for which no Persian word was available and/or which represented things that are relatively alien to Persian culture (e.g., asparagus) were excluded. Some other pictures were removed because they looked ambiguous. Pictures eliciting strong cognates and loan words across English and Persian (e.g., guitar) were also excluded (see Dijkstra, Miwa, Brummelhuis, Sappelli \& Baayen, 2010). A final criterion was to ensure that the test would assess knowledge of words at varying frequency levels. Because there is as yet no general corpus of Persian, nor a validated word frequency list for Persian, I asked ten native Persian speakers who were postgraduate students in New Zealand to group the remaining words (198 out of 260 in Snodgrass \& Vanderwart, 1980) into three bands based on the frequency (high, medium, or low) with which they thought they were used by young Persian speakers in the home country. Sixteen target words (and their corresponding pictures) of each frequency band were then chosen to be included in the auditory word-picture matching test. These 48 stimuli were chosen because of the high agreement among the Persian native speakers in assigning these particular words to their frequency bands. Following Schmid (2011), I developed multiple-choice items where each correct choice was accompanied by a semantically related, a phonologically related and an unrelated distractor. The order of the test items was randomized. 


\subsubsection{Film-retelling task}

As noted, controlled tests were used to measure the heritage speakers' and their monolingual controls' productive and receptive vocabulary knowledge in Persian. However, a different method was applied to probe the participants' lexical competence during content-focused oral communication, and for this, measures of lexical richness were used. In order to elicit free speech data, some researchers have used autobiographical interviews with participants (e.g., Yilmaz \& Schmid, 2012; Schmid \& Jarvis, 2014) or film and story retelling tasks (e.g., Schmid, 2007; Schmid \& Fägersten, 2010; Schmid \& Jarvis, 2014). I used a film-retelling task to collect free speech samples. This task allows extracting data with a controlled content with fairly homogenous choice of vocabulary, style and so forth across the samples (Schmid \& Fägersten, 2010). A considerable number of studies have used a Charlie Chaplin silent movie in the film-retelling task that was first used by Perdue (1993; as cited in Schmid, 2011). Considering the age range of the participants, it was believed that the Charlie Chaplin movie risked being too distant from the lives of some of the children. Instead, an episode of "Tom and Jerry" was chosen which lasted about six minutes. Unlike the other stories of this series, the episode was a friendly story about a puppy that was found by Jerry. Jerry tries to take it into the house which Tom lives in but Tom keeps throwing them out. He feels bad about what he has done and goes out to find them, but he falls into the river. Jerry and the puppy save him and Tom lets the puppy stay and live with them.

The participants were asked to watch the episode of "Tom and Jerry" and retell the story. Since this task was not timed, the participants were free to retell the story as detailed as they wanted. The same film-retelling task was used to collect benchmark data from the monolinguals in Iran who were matched in terms of age, gender, number of siblings and family socioeconomic status. All film-retellings were recorded and transcribed according to CHAT conventions (http://childes.psy.cmu.edu/manuals/CHAT.pdf). Subsequently, I checked the transcriptions of the narratives again. The speech samples were analyzed in terms of lexical richness, which is used as an umbrella term in the current study to refer to the measures of lexical diversity and sophistication.

\section{Lexical diversity}

MTLD (measure of textual lexical diversity) has been found to be the measure of lexical diversity least influenced by the text length (Koizumi, 2012). 
Considering this, MTLD seemed the best measure of lexical diversity to be used in the present study, because the length of the participants' narratives differed considerably.

In order to measure lexical diversity, the transcripts of "raw speech" by all participants were checked for any inconsistency in typing the same words throughout the texts. Base forms and their inflected forms should be considered as different types in the analysis of MTLD (see Koizumi, 2012). Following this, the words sag 'a dog' and sagha 'dogs' or khordam 'I ate', mikhorand 'they eat' and bokhor 'eat, second person singular imperative' were counted as different types (although they were considered as the same lemma in the lexical sophistication analysis - see below). After checking the transcripts, MTLD was calculated using Gramulator. (https://umdrive.memphis.edu/pmmccrth/public/software/software_index.htm)

\section{Lexical sophistication}

In order to measure lexical sophistication, researchers tend to use representative corpora (e.g., British National Corpus and the Corpus of Contemporary American English) and corpus-based frequency lists (e.g., Laufer \& Nation, 1995), and these have informed tests of second language vocabulary knowledge (e.g., Nation \& Beglar, 2007). However, for languages for which no such corpora or frequency lists are available, a different procedure is necessary. There are some corpora available for Persian; however they are mostly compiled from newspapers (e.g., Bijankhan Corpus, Bijankhan, 2004). Considering the fact that many of the participants in the present study are children, whose familiarity with much of the lexis used in newspapers must be limited, it was found that those corpora are not appropriate for measuring lexical sophistication of these participants' discourse. Besides, newspaper discourse is unlikely to bear much resemblance to the language needed to narrate a Tom and Jerry cartoon.

In order to tackle this issue for Turkish, for which no reliable spoken or written corpus-based frequency lists are available yet either, Yilmaz and Schmid (2012) measured the lexical sophistication by using the output by all nativespeaker participants of Turkish in their study (bilinguals and monolinguals) as a small corpus. After lemmatizing the speech samples, the average frequency of all lemmas used by the participants was calculated. 
Lemmatization involves excluding function words and stripping content words of their inflectional morphemes (i.e., tense, number, person, case, etc.). Items which share the same root are counted as one lemma. To illustrate, the words go, are going, went, has gone and had gone are all coded as the lemma "go". Accordingly, I manually excluded proper nouns (e.g., Tom \& Jerry), function words (e.g., $M a$ 'we'), and inflectional morphemes (e.g., -am 'first person singular verbal suffix') to arrive at lists of lemmas used in the transcripts. To exemplify, the word raft 's/he went', raftim 'we went', miravam 'I go', dashtand miraftand 'they were going' and boro 'go, second person singular imperative' were all coded under the lemma raft 'go'. To illustrate more, the words miandazand 'they throw', andaakht 's/he threw' and andaakht-e-shun 's/he threw them' were categorized as one lemma.

\subsubsection{Sociolinguistic questionnaire}

The semi-structured interviews with the parents of the participants were based on a sociolinguistic questionnaire which comprised 68 items (mainly 5point Likert scale items). This was based on a questionnaire retrieved from the language attrition website of the University of Groningen (www.let.rug.nl/languageattrition/SQ). Since the original questionnaire was designed for adult migrants, changes in wording were made to make it appropriate for parents talking about their children. The questionnaire consisted of five sections. The first elicited demographic information such as age, length of residence in New Zealand, the children's age at the time of emigration, and whether the family had spent time in another English-speaking country before moving to New Zealand. There were also questions on the frequency of return visits to Iran and visits by Iranian friends and relatives.

In the next section the parents were asked if they and their children had received any education in English before coming to New Zealand. They were also asked to self-evaluate their proficiency in English and their children's proficiency in Persian over the years they have been living in New Zealand. Family language use was explored in the third section of the questionnaire. Parents were asked to indicate in which language they spoke to their spouse, children and friends. They were also asked how often they were in touch with relatives in Iran. This section was followed by some questions on the children's language use in different situations in which they had the opportunity to develop or maintain their productive and receptive abilities in Persian. There were also some questions about participants' literacy and the time they spent reading and 
writing in Persian if they were Persian literate. In the last part, other factors previously identified in the literature as reflecting attitudes towards the heritage language were explored. For example, parents were asked if they correct their children when they make mistakes in Persian. They were also asked about how they value heritage language maintenance in their children (see Appendix J).

All participants were tested in their own homes or a place of their own choice. The APWMT, for which I used a laptop computer, was conducted after the VFT task since participants might hear some words in the matching task that they might subsequently use in the production task. Subsequently, they were asked to do the film-retelling task. All test responses were recorded. After the three tests (i.e. VFT, APWMT, and FRT) were completed, the parents (and some of the older participants) were interviewed with the aid of the sociolinguistic questionnaire. Semi-structured interviews were also conducted in the families' homes or places of their choosing. I went over the questionnaire items with the respondents, clarified questions or statements where necessary and completed the questionnaire, including the Likert-scale items, in consultation with the interviewees. All interviews were carried out in Persian, with participants able to code-switch between languages as they chose. All parents reported feeling more comfortable speaking in Persian than in English, except for two fathers who reported having no preference. The participating parents were also given the opportunity to freely expand upon any experiences regarding Persian use and maintenance with their children. The interviews, which took for less than one hour, were recorded so noted responses could be verified during data processing. In some cases, the children were present during the interview and occasionally contributed comments in addition to their parents' answers to the questions.

Additionally, I have been involved in the Iranian community since prior to data collection, therein giving me access to "an insider perspective" (Guardado, 2002, p. 351). I got invited to the families' homes and have observed language use amongst spouses, children and siblings. I have also maintained contact with the families after data collection finished, as I am a member of their community. This allows me to contribute a more holistic understanding of parents' attitudes towards heritage language acquisition and maintenance for their children. 


\subsection{Data Analysis}

\subsubsection{The quantitative studies}

\section{Data processing of the lexical tasks}

After transcribing the recordings of the participants' test performance, their scores on the two Verbal Fluency Tasks (fruit/vegetables and animals) were calculated by counting the number of correctly generated Persian words. Repeated words and English words were deleted from the overall count. Words unrelated to the specified semantic fields were not counted either.

Each participant had two VFT scores. The correlation between the two VFTs $\left(r^{2} .87, p<.0001\right)$ justified collapsing the two scores for each individual, and so the means of the two scores were entered into statistical analyses. The number of correct answers in the APWMT was counted for each participant. Although reaction times were not measured, it was evident that the participants tended to respond faster when matching pictures with high frequency nouns compared to low frequency ones. Application of the Chi-Square test shows that failure in identifying the correct words was more common in the case of low frequency words. The difference was significant between all three frequency bands, but frequency band 3 (the least frequent words) showed the greatest jump in proportion of wrong responses $\left(\chi^{2}(2)=1.00 ; p<.0001\right)$.

The scores on the VFT and the APWMT were significantly correlated $\left(r^{2} .66 ; p<.0001\right)$, but I deemed the correlation not strong enough to justify collapsing the two scores. Besides, I had purposefully opted for two different tests in order to measure productive and receptive knowledge separately, as it may be hypothesized that word retrieval is compromised earlier than word recognition as a result of infrequent language use $(C f$. the Activation Threshold Hypothesis).

\section{Data processing of the film-retelling task}

In collecting data for the analyses of lexical richness, one of the participants refused to retell the story in Persian. In addition to this, four of the bilinguals were removed from the analyses due to not having enough tokens in their speech samples, since there should be at least 100 tokens in the samples for the MTLD measure to be valid (Koizumi, 2012). It should be noted that all these participants were simultaneous bilinguals with lower Persian proficiency 
compared to other heritage speakers as found in the results of the lexical tests. To preserve the balance between the two samples, I excluded their matched monolingual controls from the analyses too. So the actual number of heritage speakers and the monolinguals for the analyses of lexical richness was 50, although 60 participants were recruited initially (i.e. 10 simultaneous bilinguals and their matched controls, as well as 15 sequential bilinguals and their matched controls).

Turning to lexical sophistication, the corpus of 50 film-retellings in this study consisted of 9,791 tokens, comprising 509 different lemmas. For each participant, the frequency of every lemma in the film-retelling was calculated in the corpus by using R, a programming language for statistics (https://www.rproject.org/) (also see Field, Miles \& Field, 2012). Following this, the average frequency of all lemmas used by each participant in the corpus was assessed to show the level of their lexical sophistication compared to all other participants in the study. Consequently, the higher figures for lexical sophistication demonstrate higher average word frequencies, whereas the lower figures indicate the use of less frequent words. For example, the lower-frequency word refigh 'friend' was used alongside the higher-frequency synonym $d u s t$ 'friend' by some of the monolinguals while the bilinguals only used the latter.

\section{Data processing of the sociolinguistic questionnaire}

In order to analyze the data elicited through the semi-structured interviews, the recorded interviews were transcribed and the questionnaire responses were codified according to guidelines retrieved from the language attrition website (http://www.let.rug.nl/languageattrition/tools). Following this, two composite variables were created by using the IBM SPSS 20 function "Compute variable" (also see Schmid \& Dusseldorp 2010, on a similar procedure for creating composite variables from their attrition questionnaire). The first composite variable, the use of Persian (with a Cronbach's alpha of .71), included responses concerning (a) the parents' use of Persian with their children and with their spouse, (b) the participants' use of Persian at home to communicate with their father and with their mother (c) the participants' use of Persian to communicate with Iranian friends and acquaintances, and (d) the participants' listening to Persian songs and watching movies in Persian. It may be worth mentioning that data concerning participants' frequency of Persian use to siblings was excluded from this composite variable since not all participants 
had siblings, while having or not having siblings was kept as a separate variable in the bilingual vs. monolingual analyses.

The other composite variable (with Cronbach's alpha .63) was the parents' attitude towards Persian and towards the desirability of language maintenance. Following other studies on the role of attitude (e.g., Cherciov, 2012), items included here were visits to Iran, the fostering of friendships with other Persian-speaking immigrants, maintenance of contacts with relatives in Iran, the parents' evaluation of the need for their children to master Persian, the amount of encouragement they give to their children to speak Persian, the inclination to correct their children's mistakes when they speak Persian, and regrets about their children's loss of Persian. In the interview, parents were also asked whether they encouraged their children to read and write in Persian, but this item was excluded from the composite variable because very few of the youngsters were literate in Persian.

Table 3.2: Compound variables extracted from the questionnaire

\begin{tabular}{lllll} 
& Mean & SD. & Min. & Max. \\
\hline $\begin{array}{l}\text { Participants' } \\
\begin{array}{l}\text { Persian Use } \\
\text { Parents' attitude }\end{array}\end{array}$ & 8.01 & 1.54 & 4.25 & 10.25 \\
\hline
\end{tabular}

Descriptive and inferential statistics were applied in the quantitative analysis of the results of controlled tests and free speech samples (see Chapter 4).

\subsubsection{The qualitative studies}

To analyze the data qualitatively, the Grounded Theory approach was used (Strauss and Corbin 1998). This constructivist approach "begins with inductive data, invokes iterative strategies of going back and forth between data and analysis, uses comparative methods, and keeps you interacting and involved with your data and emerging analysis" (Charmaz, 2014, p. 2). The data was coded and analyzed using the software program NVivo 10, which operates from the Grounded Theory approach. All interviews were imported into this program, and nodes (coding labels) were created. These nodes were composed of theoretically informed concepts that emerged from participants' responses to 
questions in the sociolinguistic questionnaire, including "feeling regretful in the case of Persian loss" and "language use with Iranian peers", as well as applied linguistics categories such as "parents' low English proficiency and Persian use" and "teachers' advice for Persian use". Nodes were checked in full again at the end to ensure accuracy and comprehensibility. 


\section{PART I \\ Incomplete Heritage Language Acquisition \\ and Attrition: \\ A Quantitative Investigation}




\section{Chapter 4 : Part I}

\subsection{Introduction to the quantitative investigation}

This chapter includes the findings of two quantitative studies on incomplete acquisition and attrition in heritage speakers' vocabulary knowledge in their family language. The first study examines young heritage speakers', either simultaneous or sequential bilinguals, productive and receptive lexical knowledge in their family language compared to matched monolingual counterparts. The second quantitative study explores the lexical richness of the same heritage speakers' oral narratives in their family language. Both of these studies explore the factors that account for the difference between heritage speakers and their monolingual controls, if there is any. These factors include current age, age at emigration, frequency of heritage language use and parents' attitude towards heritage language acquisition and maintenance.

This chapter starts with the results of the first study, in which two controlled tasks were used to measure the heritage speakers' productive and receptive knowledge. Following the discussion of the findings of this study and its limitations, the rationale for conducting the second quantitative study is explained. The second study examines simultaneous and sequential bilinguals' lexical richness in their family language. Elicited oral narratives were analyzed in order to judge heritage speakers' real-time language use (Schmid, 2011, p. 194). It should be noted that both studies in this investigation were conducted on the same participants and they share some parts of the methodology (i.e., semi-structured interviews based on a sociolinguistic questionnaire). This chapter ends with a discussion of the results of both quantitative studies on incomplete acquisition and attrition of heritage speakers' vocabulary knowledge in their family language.

\subsection{The first study: Heritage speakers' productive and receptive vocabulary knowledge in their family language ${ }^{1}$}

\footnotetext{
${ }^{1}$ This study has been published as the following article: Gharibi, K. \& Boers, F. (2016). Influential factors in incomplete acquisition and attrition of young heritage speakers' vocabulary knowledge. Language Acquisition. doi: 10.1080/10489223.2016.1187613
} 
The first quantitative study looks into simultaneous and sequential bilinguals' vocabulary knowledge in their heritage language. It examines their productive and receptive vocabulary knowledge in comparison with that of matched monolingual controls as far as age, gender, number of siblings, and the families' socioeconomic status are concerned. Additionally, it explores the factors (touched upon in the Theoretical Background) that may account for the (expected) constrained knowledge in the heritage speakers. These factors (or predictors) include demographical variables, such as age, age at emigration and length of emigration, as well as sociolinguistic and attitudinal variables, particularly the amount and frequency of heritage language use and parents' attitudes towards the heritage language.

Since my participants consists of simultaneous as well as sequential bilinguals, I examine more specifically whether the vocabulary knowledge of these two subgroups differs from that of the monolingual controls to the same extent and whether the factors that help to account for the difference between the bilinguals' and the monolinguals' vocabulary knowledge are the same for both subgroups. Marked differences between the simultaneous and the sequential bilinguals in these respects would furnish support for Montrul's (2008, p. 98) assertion that "The distinction between simultaneous and sequential bilingualism in childhood [...] is significant for incomplete acquisition and language attrition in childhood."

The questions this study seeks answers to are therefore:

1. Do young heritage speakers have limited knowledge of L1 vocabulary in comparison to matched monolinguals?

2. Do simultaneous and sequential bilingual heritage speakers differ from each other in relation to their matched monolinguals as regards heritage language vocabulary knowledge?

3. Which demographic (age, age at emigration and length of emigration) and/or sociolinguistic factors (heritage language use and parental attitudes towards heritage language acquisition and maintenance) help to account for the young heritage speakers' level of L1 vocabulary knowledge?

4. Can the level of heritage language vocabulary knowledge of simultaneous and sequential bilingual heritage speakers be accounted for by the same demographic and/or sociolinguistic factors? 


\subsubsection{Findings}

\section{Comparing bilinguals' and monolinguals' vocabulary test scores}

As expected, the descriptive statistics indicate that the monolinguals outperformed the bilinguals in both tests (see Tables $4.1 \& 4.2$ ), and T-tests for independent samples confirm that the difference is statistically significant: $\mathrm{t}(58)$ $=3.45, p=.001$, and $\mathrm{t}(58)=5.34, p<.0001$, for the VFT scores and the APWMT, respectively.

Table 4.1: VFT results of the heritage speakers and matched monolinguals

\begin{tabular}{lllll} 
& Mean & SD. & Min. & Max. \\
\hline Bilinguals & 8.2 & 5.9 & .5 & 27.5 \\
Monolinguals & 13.4 & 5.8 & 4.5 & 24 \\
\hline
\end{tabular}

Table 4.2: APWMT results of the heritage speakers and matched monolinguals

\begin{tabular}{lllll} 
& Mean & SD. & Min. & Max. \\
\hline Bilinguals & 36.6 & 8.9 & 12 & 48 \\
Monolinguals & 45.7 & 2.4 & 40 & 48 \\
\hline
\end{tabular}

In case other variables apart from participant group (i.e., bilingual versus monolingual) influence test performance, I also conducted analyses of covariance (ANCOVA). In the analyses, "BiMo" stands for whether participants belonged to the group of heritage speakers (bilinguals) or the group of monolingual counterparts. After initially running a full model, nonsignificant interaction effects were removed. The final model is reported for each measure together with its interpretation. All main effects (age, gender, BiMo, having siblings) were included in all the models. Recall that the heritage speakers and their monolingual counterparts were matched for age, gender, number of siblings and family socioeconomic status. Thus, when the effect of BiMo was tested in each model, I was controlling for age, gender and number of siblings. Tables 4.3 and 4.4 sum up the results for the VFT and the APWMT, respectively. 
Table 4.3: ANCOVA of VFT results of bilinguals and monolinguals

\begin{tabular}{lllll} 
& & Mean \pm SD & F & P \\
\hline Gender & Male & $10.23 \pm .93$ & 1.32 & .25 \\
& Female & $11.66 \pm .9$ & & \\
BiMo & Bilingual & $8.31 \pm .9$ & 18.47 & .000 \\
& Monolingual & $13.5 \pm .92$ & & \\
Sibling & Sibling & $10.6 \pm .72$ & .68 & .41 \\
& No Sibling & $11.2 \pm 1.1$ & & \\
Age & Coefficient & $1 \pm .18$ & 31.03 & .000 \\
\hline
\end{tabular}

Table 4.4: ANCOVA of APWMT results of bilinguals and monolinguals

\begin{tabular}{lllll} 
& & Mean \pm SD & F & P \\
\hline Gender & Male & $41.24 \pm 1.01$ & 1.4 & .23 \\
& Female & $42.83 \pm .97$ & & \\
BiMo & Bilingual & $38.16 \pm 1.02$ & 24.44 & .000 \\
& Monolingual & $45.9 \pm 1.05$ & & \\
Sibling & No sibling & $44.3 \pm 1.26$ & 9.1 & .004 \\
& Sibling & $39.77 \pm .78$ & & \\
BiMo*Age & & & 10.4 & .002 \\
BiMo*Sibling & & & 5.1 & .027 \\
Age & Coefficient & $.37 \pm .27$ & 26.4 & .000 \\
\hline
\end{tabular}

As shown in Tables 4.3 and 4.4, apart from the bilingual vs. monolingual distinction (or BiMo), the covariate age was also significantly related to both the VFT results $(\mathrm{F}(1,55)=31.03, p=.000)$ and the APWMT scores $(\mathrm{F}(1,53)$ $=26.4, p=.000)$. No significant effect of gender emerged from the analysis, but having siblings appears to negatively affect APWMT scores.

In order to examine the differences between the bilinguals and the monolinguals in the test results of VFT and APWMT together, a multivariate analysis of variance (MANOVA) was conducted. The outcome is presented in Tables 4.5 and 4.6 . 
Table 4.5: Multivariate tests of VFT and APWMT together

\begin{tabular}{lllll} 
& Wilks' Lambda & F & P & Partial eta squared \\
\hline Age & .6 & 17.9 & .000 & .39 \\
BiMo & .59 & 19.7 & .000 & .41 \\
\hline
\end{tabular}

Table 4.6: Multivariate tests of VFT and APWMT separately

\begin{tabular}{lllll} 
& Tests & F & P & Partial eta squared \\
\hline Age & VFT & 33.19 & .000 & .36 \\
& APWMT & 16.48 & .000 & .22 \\
BiMo & VFT & 18.52 & .000 & .24 \\
& APWMT & 36.11 & .000 & .38 \\
\hline
\end{tabular}

The significant difference between the two groups is confirmed also in this analysis: $\mathrm{F}(2,56)=19.7, p=.000$; Wilks' Lambda $=.59$; partial eta squared $=.41$. Although the mean scores of bilinguals and monolinguals were significantly different in both tasks, the between-group difference in the APWMT (partial eta squared $=.38$ ) was greater than in the VFT (partial eta squared $=.24)$. Again, age was also a significant factor $(p=.000)$.

I turn next to the question of whether the gap between the heritage speakers' and their monolingual counterparts' test scores is equally wide for sequential bilinguals as for simultaneous bilinguals.

\section{Comparing the simultaneous and sequential bilinguals with their matched controls}

In order to know if simultaneous and sequential bilinguals are significantly different from their matched monolingual counterparts, I first conducted independent-samples t-tests for each subgroup. The results for the VFT and the APWMT are summed up in Tables 4.7 and 4.8 respectively. 
Table 4.7: Independent samples t-test in the subgroups and their controls on VFT

\begin{tabular}{llllll} 
Groups & Mean & SD. & t & df & P \\
\hline $\begin{array}{l}\text { Simultaneous } \\
\text { Bilinguals }\end{array}$ & 5.6 & 3.3 & -4.4 & 28 & .000 \\
Controls & 11.9 & 4.3 & & & \\
\hline $\begin{array}{l}\text { Sequential } \\
\text { Bilinguals }\end{array}$ & 10.8 & 6.9 & -1.6 & 28 & .1 \\
Controls & 15.03 & 6.7 & & & \\
\hline
\end{tabular}

Table 4.8: Independent samples t-test in the subgroups and their controls on APWMT

\begin{tabular}{llllll} 
Groups & Mean & SD. & $\mathrm{t}$ & $\mathrm{df}$ & $\mathrm{P}$ \\
\hline $\begin{array}{l}\text { Simultaneous } \\
\text { Bilinguals }\end{array}$ & 32.1 & 9.5 & -5.4 & 15.4 & .000 \\
Controls & 45.8 & 2.1 & & & \\
\hline $\begin{array}{l}\text { Sequential } \\
\text { Bilinguals }\end{array}$ & 41.1 & 5.7 & -2.7 & 20.08 & .013 \\
Controls & 45.6 & 2.7 & & & \\
\hline
\end{tabular}

While the simultaneous bilinguals' mean VFT and APWMT scores were statistically different from their matched monolingual controls', the sequential bilinguals' VFT results were not. A comparison of the t-values also shows that the gap between the bilinguals' and the monolinguals' test performance on both tests is much wider in the case of the simultaneous bilingual subgroup (Tables 4.7 and 4.8). This is consistent with previous findings (e.g., Montrul, 2008) that the $\mathrm{L} 1$ competence of heritage speakers who have had the opportunity to acquire their L1 to a certain degree before emigration bears a closer resemblance to monolinguals' in comparison with the heritage language competence of those who were born in the L2 environment (or arrived there at an early age). At first glance, a comparison of Tables 4.7 and 4.8 suggests that it is receptive knowledge (APWMT) rather than productive knowledge (VFT) that distinguishes sequential bilinguals from monolinguals. This seems to run counter to the expectation - underpinned by the Activation Threshold Hypothesis (see Chapter 2) - that productive knowledge of vocabulary is most prone to attrition. However, it is likely that the VFT (as applied in this study - 
using just two prompts) was simply not as sensitive a measure as the APWMT to distinguish between the sequential bilinguals and their monolingual controls.

\section{The effects of demographic and sociolinguistic variables on productive and receptive vocabulary knowledge}

In order to evaluate to what extent variables such as age, age at emigration and length of emigration as well as the two composite variables, i.e., frequency of use of Persian and parents' attitude towards Persian and language maintenance, help to account for the variance in the heritage speakers' test performance, hierarchical regression analyses were conducted. Length of emigration was removed from the analyses, since it was highly correlated with age and age at emigration (see Schmid, 2011), resulting in problems with estimation due to multicollinearity. Therefore, the variables that were entered in the analyses were age, age at emigration and the two compound variables extracted from the interview data.

First, hierarchical regression analyses were carried out on all 30 bilinguals' test results to identify the demographic and/or socio-linguistic factors (if any) which account for the young heritage speakers' level of L1 vocabulary knowledge. Because of the wide age range of the participants (6-18 years old), age was entered as the first block into the hierarchical regression model to show how much it can predict the variance in the results by itself. The analysis revealed that all the variables correlated significantly with the VFT results. In the regression model for the VFT results of all bilinguals, age explained $22 \%$ of the variance in the test scores. After entering age at emigration, the model significantly, $\mathrm{F}(2,27)=13.3, p=.000$, explains $46 \%$ (Adjusted $\mathrm{R}^{2}=.46$ ) of the variance in the test results, while the sociolinguistic variables did not add much explanatory power to the model. In the final model, age at emigration was the only variable which was statistically significant, as displayed in Table 4.9. 
Table 4.9: Correlations and coefficients for VFT in all bilinguals

\begin{tabular}{lllll} 
Variables & $\mathrm{r}$ & $P$ & Beta & $P$ \\
\hline Age & .49 & .00 & .21 & .15 \\
Age at emigration & .67 & .00 & .57 & .00 \\
Persian use & .45 & .00 & -.03 & .85 \\
Parents' attitude & .31 & .04 & .27 & .06 \\
\hline
\end{tabular}

Regarding the results of the matching task, all variables were significantly correlated with the results with participants' Persian use having the highest correlation $(r=.65)$. In the regression model, age, which was entered as the first step, predicted $26 \%$ of the result (Adjusted $\mathrm{R}^{2}=.26$ ). Age at emigration increased the explanatory power of the model. The final model which reached statistical significance, $\mathrm{F}(4,25)=8.8, p=.000$, predicted $52 \%$ (Adjusted $\mathrm{R}^{2}=$ $.52)$ of the variance in the test results with children's Persian use as the only significant variable $($ Beta $=.36, p=.03)$ as displayed in Table 4.10.

Table 4.10: Correlations and coefficients for APWMT in all bilinguals

\begin{tabular}{lllll} 
Variables & $\mathrm{r}$ & $P$ & Beta & $P$ \\
\hline Age & .53 & .00 & .27 & .07 \\
Age at emigration & .6 & .00 & .25 & .15 \\
Persian use & .65 & .00 & .36 & .03 \\
Parents' attitude & .30 & .05 & .15 & .25 \\
\hline
\end{tabular}

To answer RQ 4, i.e., whether the same factors predict vocabulary knowledge equally well in simultaneous and sequential bilinguals, separate hierarchical regression analyses were conducted per subgroup. In the subgroup of 15 simultaneous bilinguals, age at emigration and length of emigration were not entered in the analyses, since age at emigration was 0 for eleven participants and 2 for four of them in this subgroup and their length of stay in New Zealand equaled their age at the time of testing or 2 years less than their age. Therefore, the only variables that were entered into the analyses for this subgroup were age and two compound variables extracted from the interview data. As noted, because of the wide age range of the participants (6-18 years old), age was entered as the first block into the hierarchical regression. Age and the two compound variables were found to correlate significantly with test performance and, interestingly, the parents' attitude towards Persian acquisition and 
maintenance showed the strongest correlation $(r=.70)$. Parents' attitude and participants' Persian use were highly correlated with each other $(r=.85)$, preventing entering them into the hierarchical regression model together. Therefore, two separate regression analyses were conducted to find out which variable can predict the VFT results of the simultaneous bilinguals better. Age by itself predicted $29 \%$ of the variance in the results (Adjusted $R^{2}=.29$ ). The model with age and parental attitude, $\mathrm{F}(2,12)=6.7, p=.01$, explained the variance of the results better (Adjusted $R^{2}=.44$ ). Table 4.11 displays the outcome of the regression analysis for the VFT scores of simultaneous bilinguals.

Table 4.11: Correlations and coefficients for VFT in the simultaneous bilinguals

\begin{tabular}{lllll} 
Variables & $\mathrm{r}$ & $P$ & Beta & $P$ \\
\hline Age & .54 & .01 & .22 & .39 \\
Persian use & .67 & .00 & .54 & .05 \\
\hline Age & .54 & .01 & .23 & .35 \\
Parents' attitude & .7 & .00 & .57 & .03 \\
\hline
\end{tabular}

In the regression analysis conducted on the VFT results of the 15 sequential bilinguals (see Table 4.12), length of emigration was removed again because of multicollinearity. Therefore, the variables that were entered in the analyses were age as the first block, age at emigration, and the two compound variables extracted from the interview data. As shown in Table 4.12, the only variable which was significantly correlated with the results of the VFT in this subgroup was age at emigration $(r=.68, p=.003)$. Age, which was entered into the regression model as the first block, predicted $7 \%$ of the VFT results of the sequential bilinguals (Adjusted $\mathrm{R}^{2}=.07$ ). Having entered age at emigration, the regression model reached significance, $\mathrm{F}(2,12)=5.3, p=.02$, and accounted for $38 \%$ of the variance in the VFT scores (Adjusted $\mathrm{R}^{2}=.38$ ) in this subgroup. The other variables in this analysis did not make a significant contribution to the prediction of the results. Therefore, age at emigration was the only variable that contributed significantly to the prediction of the results of VFT in the sequential bilinguals. 
Table 4.12: Correlations and coefficients for VFT in the sequential bilinguals

\begin{tabular}{lllll} 
Variables & $\mathrm{r}$ & $P$ & Beta & $P$ \\
\hline Age & .36 & .08 & -.1 & .74 \\
Age at emigration & .68 & .00 & .95 & .05 \\
Persian use & .13 & .31 & -.4 & .32 \\
Parents' attitude & .23 & .19 & .00 & .99 \\
\hline
\end{tabular}

In the analysis of the APWMT scores of the simultaneous bilinguals (see Table 4.13), like the results of VFT, parents' attitude and participants' Persian use were highly correlated with each other $(r=.85)$, resulting in not entering both in the hierarchical regression model at the same time. So, two separate regression analyses were conducted. As in the VFT results of this subgroup, parents' attitude was found to be most strongly associated with the test performance $(r=.7, p=002)$. In the hierarchical regression model, age predicted $34 \%$ of the results (Adjusted $\mathrm{R}^{2}=.34$ ). The model with age and parents' attitude, which significantly predicted the variance $(\mathrm{F}(2,12)=8.1, p$ $=.006$ ) explained about $50 \%$ of the variance (Adjusted $\mathrm{R}^{2}=.50$ ).

Table 4.13: Correlations and coefficients for APWMT in the simultaneous bilingual

\begin{tabular}{lllll} 
Variables & $\mathrm{r}$ & $P$ & Beta & $P$ \\
\hline Age & .62 & .00 & .43 & .12 \\
Persian use & .58 & .01 & .32 & .23 \\
\hline Age & .62 & .00 & .34 & .14 \\
Parents' attitude & .7 & .00 & .51 & .04 \\
\hline
\end{tabular}

As regards the sequential bilinguals (see Table 4.14), significant correlations were obtained between the APWMT scores and age at emigration ( $r=.68, p=.002)$ and participants' use of Persian $(r=.45, p=.04)$, while age and parents' attitude failed to reach significance. Age, which was entered into the hierarchical regression model first, could not predict the result (Adjusted $\mathrm{R}^{2}=-.014$ ), however with age at emigration, the regression model explained $39 \%$ of the variance (Adjusted $\mathrm{R}^{2}=.39$ ). The other variables did not add any weigh to the final model, $(\mathrm{F}(4,10)=2.7, p=.08)$, which did not reach significance. 
Table 4.14: Correlations and coefficients for APWMT in the sequential bilinguals

\begin{tabular}{lllll} 
Variables & $\mathrm{r}$ & $P$ & Beta & $P$ \\
\hline Age & .24 & .19 & -.2 & .51 \\
Age at emigration & .68 & .00 & .91 & .06 \\
Persian use & .45 & .04 & -.1 & .73 \\
Parents' attitude & -.07 & .39 & -.2 & .36 \\
\hline
\end{tabular}

\subsubsection{Conclusions, implications and limitations of the study on heritage speakers' productive and receptive vocabulary knowledge}

Two controlled tasks were used in the first quantitative study to measure the productive and receptive knowledge of the heritage speakers and compare them with their monolingual counterparts. I was particularly interested in knowing whether the predictive variables in the heritage speakers' vocabulary knowledge are the same in simultaneous and sequential bilinguals.

As expected, the results of the two vocabulary tests show that, overall, the young heritage speakers who participated in this study have more limited L1 vocabulary knowledge than their monolingual counterparts, and this seems to hold true for receptive as well as productive knowledge. Age was also shown to be a significant variable in both tests. In the receptive knowledge test (i.e., the word-picture matching task), having siblings was found to exert a negative influence. This is compatible with other studies (e.g., Fillmore, 1991; Kouritzin, 1999; Guardado, 2002; Spolsky, 2007) that found that siblings in immigrant families tend to communicate in the dominant language even though they may have some level of proficiency in the heritage language. This reduces the exposure to the family language and thus the opportunities for the heritage speakers (especially the younger siblings) to further develop their heritage language.

Consistent with Montrul (2008), the test scores of the sequential bilinguals were more similar to their monolingual counterparts' scores than was the case for the simultaneous bilinguals: while the mean test scores of both simultaneous and sequential bilinguals were significantly different from their monolingual counterparts', this difference was more pronounced in the case of the simultaneous bilinguals, especially on the receptive, matching test (APWMT). That the evidence for the bilingual - monolingual difference in test performance was less compelling in the VFT data may be somewhat surprising, 
since the ability to retrieve words for productive purposes is expected to be affected first by attrition, while receptive recognition of word meaning is expected to be less susceptive to it. However, it is possible that the validity of the VFT as a test of productive vocabulary knowledge needs to be reassessed (Schmid \& Jarvis, 2014, p. 16). This observation is supported by the fact that some monolingual participants in this study had very low scores on the VFT task, although they were obviously competent native speakers.

The findings of this study lend support to Montrul's (2008, p. 98) argument that it is important to distinguish between simultaneous and sequential bilingualism when investigating processes of incomplete acquisition and attrition in childhood: The regression analyses conducted to estimate the influence of demographic and sociolinguistic factors on test performance indeed yielded different pictures for the simultaneous and the sequential bilinguals. In the latter, age at emigration was found to play a crucial role in the vocabulary knowledge of heritage speakers. The older the participants were when they moved to the second language environment, the better their L1 vocabulary tended to be. The older the participants were when they moved to the second language environment, the more opportunity they had to acquire L1 words during childhood prior to emigration, and hence the better their L1 vocabulary tended to be. This result is thus also consistent with the age-of-acquisition effect (see Bonin, Fayol \& Chalard, 2001; Izura \& Ellis, 2002, 2004; Bonin, Barry, Méot \& Chalard, 2004; see also Montrul, 2009; Montrul \& Foote, 2014). In the absence of longitudinal data, it is not possible to accurately distinguish incomplete acquisition and first language attrition in the participants (see Montrul, 2008). Nevertheless, in the case of some of the participants, who arrived in New Zealand in their early teens, it seems safe to say that their lower vocabulary test scores are mostly due to attrition rather than incomplete acquisition. In the case of the simultaneous bilinguals, who were already exposed to English at an earlier age, the lower test scores are more likely to reflect incomplete acquisition - although, as discussed in Chapter 2, heritage language words that are acquired at some point by a simultaneous bilingual can also be forgotten if they are not activated for a long time. The differing roles played by attrition and incomplete acquisition in sequential and simultaneous bilinguals' vocabulary development are therefore better viewed as matters of degree, with attrition playing the greater part in late sequential bilinguals and incomplete acquisition playing the greater role in simultaneous bilinguals.

As to the simultaneous bilinguals among the participants, the regression analyses revealed that their parents' attitude towards the heritage language and 
the desirability to pass it on to their children was particularly strongly correlated with the vocabulary test scores. This suggests that parents can play a crucial role in the heritage language development of their children, even when the children are exposed to a majority language early on in life, since the parents of young heritage speakers are their main and maybe only source of family language input, and so their preference for using the heritage language in the family and thus for providing their children with opportunities to acquire this language can be expected to make a difference. The results of the current study thus support the findings of many studies that demonstrated that immigrant parents' attitude towards the family language and their language practices play a crucial role in the heritage language proficiency of their children (e.g., Fishman, 1991; Pearson, 2007; Park \& Sarkar, 2007; Schwartz, 2008). The present finding particularly underscores the role parents can play if their children were born in or migrated to the host country at a very young age. This is a finding that emerged from the data only when I looked at the two subgroups of heritage speakers in my sample separately, and it suggests that it is worth distinguishing between different profiles of bilinguals in a study, such as the one reported here, which intends to weigh the roles of particular demographic and socio-cultural factors for language development.

It is somewhat intriguing that parents' attitude turned out not to be an influential factor in the data of the sequential bilinguals. In that group, the effect of age at emigration is so strong that it overrides the effects of the other variables. Also, it is possible that parents whose children had a solid command of the heritage language (e.g., those sequential bilinguals who arrived in the host country when they were already in their teens) saw no grounds for expressing concern in the interview about the risk of their children losing their mother tongue.

While not the strongest predictor of vocabulary knowledge in either the simultaneous or sequential bilingual subgroups, frequency of use of the heritage language nonetheless appeared as the second most important predictor, and so my findings are compatible with other studies which showed that family language use is one of the key factors in whether a heritage language will be learned by children (e.g., Fishman, 2000; Pearson, 2007). Besides, parents' attitudes to heritage language maintenance and their efforts at exposing their children to the heritage language are likely to be interrelated. In the case of late sequential bilinguals, it can be argued that it is amount of L1 use prior to emigration that matters. In other words, the importance of amount of heritage 
language use for its acquisition and preservation is probably masked in the data by other, causally related, variables (attitude and age at emigration).

Several limitations to this study need to be acknowledged. One obvious limitation is the relatively small number of participants, which makes it difficult to generalize the findings. Due to the small community of Iranian immigrants in New Zealand, I could recruit just thirty young Persian-English bilingual participants, of whom only 15 were considered simultaneous bilinguals. Despite the small sample, the findings of this study seem meaningful, however, because they do point to the different levels of vocabulary knowledge of simultaneous and sequential heritage speakers and the different influential factors in their lexical development. Still, it is clear that studies with greater numbers of participants and concerning different minority and majority languages would be very welcome.

The second limitation lies with the instruments I used to test the participants' vocabulary knowledge. Not only might it be argued that the VFT is not an entirely valid procedure for measuring productive vocabulary knowledge (see above), using just two prompts (i.e., eliciting words from only two lexical fields) inevitably raises concerns about the generalizability of the test results. With its 48 test items and its auditory format to accommodate targetlanguage-illiterate test takers, the APWMT looks more valid, but the truth remains that this is a 'controlled' test, which measures receptive knowledge of decontextualized words rather than language users' ability to use these words in real-time, authentic communication. The APWMT was administered as an untimed test. Measuring reaction times could have helped evaluate the speed of recognition of the lexical items, which might have enabled a more refined between-group comparison of vocabulary knowledge, more in keeping with activation models (e.g., Hulsen, 2000; Yilmaz \& Schmid, 2012; Schmid \& Jarvis, 2014). While it may be impossible to address all of the issues related to vocabulary knowledge of young heritage speakers in one study (Schwartz, Kozminsky \& Leikin, 2009), studies which use 'free' production tasks to estimate heritage speakers' lexical diversity and sophistication, such as storytelling, would be useful complements to the kind of study reported here (e.g., Schmid, 2011). This would also generate data to help evaluate participants' mastery of the grammatical and collocational properties (and usage patterns more generally) of the words they employ.

The third limitation is the use of self-reported data elicited from the participants' parents in the semi-structured interviews. It cannot be taken for granted that what they reported their language habits and views on language 
maintenance fully reflected reality. Triangulations with observational data would have been useful to verify and possibly adjust the codification of the parents' responses to the Likert-scale based questions concerning these issues.

Despite these limitations, the study reported here may further understanding of incomplete acquisition and attrition of the family language in young heritage speakers who were born in the host country or who migrated to the host country. The study used a methodological framework which is commonly applied in language attrition research focusing on adult bilinguals who arrived in the host country after puberty. It seems this approach can be useful also in research on factors that influence incomplete acquisition and language attrition in younger bilinguals. It is clear, however, that this primarily quantitative approach would benefit from qualitative research (see Cherciov, 2012), including longitudinal case studies, to shed more light on (a) the effects of heritage language use and parents' attitudes on child heritage speakers' lexical development and (b) the precise causes (i.e., incomplete acquisition or attrition) of particular lacunae in young heritage speakers' vocabulary knowledge.

\subsection{The second study: Lexical diversity and lexical sophistication in young heritage speakers' family language ${ }^{2}$}

In the first quantitative study, heritage speakers' vocabulary knowledge was explored. The data were collected through controlled tasks which are commonly applied in studies of language attrition in adult bilinguals. However, some researchers have argued that to judge how speakers use language naturally, free speech data should be collected, where the speaker integrates all areas of linguistic knowledge in real time (Schmid, 2011, p. 194). Accordingly, I conducted the second quantitative study to explore incomplete acquisition and attrition of heritage speakers' family language by using free speech samples. This study aims to measure lexical richness (lexical diversity and lexical sophistication) of the heritage speakers' oral narratives. It also attempts to assess the degree to which young heritage speakers', either simultaneous or sequential bilinguals, lexical richness is restricted as compared to monolingual controls

\footnotetext{
${ }^{2}$ This study has been submitted as the following article: Gharibi, K. \& Boers, F. (under review). Influential factors in lexical richness of young heritage speakers' family language.
} 
matched for age, gender, number of siblings, and the families' socioeconomic status. Additionally, as in the first quantitative study, it tries to weigh the influence on young heritage speakers' lexical richness of the factors discussed in Chapter 2, that is, age, age at emigration, heritage language use and the parents' attitude towards family language acquisition and maintenance for their children.

To explore first language attrition in adult bilinguals, studies (e.g., Schmid, 2007, Schmid \& Keijzer, 2009; Schmid \& Dusseldrop, 2010) have compared the results of their lexical diversity with those of monolinguals in addition to the results of some controlled tests (such as verbal fluency tasks, picture-word matching tasks and grammaticality judgment tasks). One of the aims of the present study is to re-examine the ability of the lexical diversity and sophistication measures to detect differences between young heritage speakers and their matched controls.

The following questions are addressed in the present study:

1. Are young heritage speakers outperformed by monolingual counterparts in their lexical richness as assessed by means of (a) a lexical diversity measure and (b) a lexical sophistication measure?

2. Do simultaneous and sequential bilingual heritage speakers differ from each other in relation to their matched monolinguals in terms of heritage language lexical richness?

3. Which demographic (age, age at emigration and length of emigration) and/or sociolinguistic factors (heritage language use and parental attitudes towards heritage language acquisition and maintenance) help to account for the variance in the degree of lexical richness in the heritage speakers?

4. Can the level of heritage language lexical richness of simultaneous and sequential bilingual heritage speakers be accounted for by the same demographic and/or sociolinguistic factors?

\subsubsection{Findings}

\section{Comparing bilinguals' and monolinguals' results of lexical richness}

As can be seen in Table 4.15 and 4.16, the descriptive statistics indicate that the heritage speakers were outperformed by the monolinguals in the results

of lexical diversity and lexical sophistication. It may be worth mentioning that 
the results of lexical diversity and lexical sophistication were highly correlated in both groups ( $r=-.62$ in bilinguals and $r=-.7$ in monolinguals). At the same time, these coefficients demonstrate that the two measures are far from identical, which supports the need to examine both.

Table 4.15: Lexical diversity in bilinguals and monolinguals per 100 words

\begin{tabular}{lllll} 
& Mean & SD. & Min. & Max. \\
\hline Bilinguals & 51.2 & 25.1 & 17.1 & 110.0 \\
Monolinguals & 58.9 & 22.5 & 24.4 & 118.2 \\
\hline
\end{tabular}

Table 4.16: Lexical sophistication in bilinguals and monolinguals

\begin{tabular}{lllll} 
& Mean & SD. & Min. & Max. \\
\hline Bilinguals & 305.5 & 46.1 & 228.4 & 420.9 \\
Monolinguals & 253.3 & 59.1 & 139.7 & 377.9 \\
\hline
\end{tabular}

I subjected the two groups' lexical diversity and lexical sophistication scores to analyses of covariance (ANCOVA). The data satisfactorily met the criterion for normality. In the analyses, "BiMo" stands for whether participants belonged to the group of heritage speakers (bilinguals) or the group of monolingual counterparts. After initially running a full model, non-significant interaction effects were removed. The final model is reported for each measure together with its interpretation. All main effects (age, gender, BiMo, having siblings) were included in all the models. Recall that the heritage speakers and their monolingual counterparts were matched for age, gender, number of siblings and family socioeconomic status. Thus, when the effect of BiMo was tested in each model, I was controlling for age, gender and number of siblings.

Regarding the Lexical Diversity data, the final model revealed significant differences in bilinguals and monolinguals $(F(1,50)=3.98, p=$ $.051)$. Additionally, age $(F(1,50)=34.57, p=.000)$ turned out as a significant predictor in the results of lexical diversity. 
Table 4.17: ANCOVA analysis of lexical diversity in bilinguals and monolinguals

\begin{tabular}{lllll} 
& & Mean \pm SD & F & P \\
\hline Gender & Male & $53.12 \pm 3.6$ & 1 & .32 \\
& Female & $58.05 \pm 3.5$ & & \\
BiMo & Bilingual & $50.6 \pm 3.6$ & 3.9 & .05 \\
& Monolingual & $60.51 \pm 3.5$ & & \\
Sibling & Sibling & $52.5 \pm 2.9$ & 1.2 & .27 \\
& No Sibling & $58.5 \pm 4.4$ & & \\
Age & Coefficient & $4.2 \pm .72$ & 34.5 & .000 \\
\hline
\end{tabular}

As to Lexical Sophistication, the analysis showed significant differences between bilingual and monolingual participants $(F(1,49)=21.41, p=.000)$. The effect of the covariate age was also significant $(F(1,49)=33.88, p=.000)$. Gender and number of siblings did not turn out to play a significant role.

Table 4.18: ANCOVA analysis of lexical sophistication in bilinguals and monolinguals

\begin{tabular}{lllll} 
& & Mean \pm SD & F & P \\
\hline Gender & Male & $285.4 \pm 8$ & .07 & .78 \\
& Female & $282.4 \pm 7.8$ & & \\
BiMo & Bilingual & $309.1 \pm 8.1$ & 21.4 & .000 \\
& Monolingual & $258.7 \pm 7.8$ & & \\
Sibling & Sibling & $279 \pm 6.5$ & .52 & .47 \\
& No Sibling & $288.2 \pm 9.7$ & & \\
Age & Coefficient & $-9.2 \pm 1.5$ & 33.8 & .000 \\
\hline
\end{tabular}

Multivariate general linear model (MANOVA) was conducted to explore the differences of the results of lexical diversity and lexical sophistication between two groups of participants. Age, which was entered as a covariate, was significantly related to the outcome $(p=.000)$. The only independent variable in the model was BiMo, which was significantly related to the results, $F(3,50)=18.6, p=.000$; Wilks' Lambda $=.54$; partial eta squared $=.45$. Gender and having siblings were also entered in the model, but they were not significantly related to the results. 
The results of lexical diversity $(p=.02$, partial eta squared $=.1)$ as well as lexical sophistication ( $p=.000$, partial eta squared $=.29$ ) were significantly different between heritage speakers and matched monolinguals. From the partial eta squared effect sizes, it can be seen that the measure of lexical sophistication had greater distinguishing power than the measure of lexical diversity.

Table 4.19: Multivariate tests of lexical diversity and lexical sophistication together

\begin{tabular}{lllll} 
& Wilks' Lambda & F & P & Partial eta squared \\
\hline Age & .54 & 18.6 & .000 & .45 \\
BiMo & .7 & 9.3 & .000 & .29 \\
\hline
\end{tabular}

Table 4.20: Multivariate tests of lexical diversity and lexical sophistication separately

\begin{tabular}{lllll} 
& Tests & F & P & Partial eta squared \\
\hline Age & LD & 26.6 & .000 & .36 \\
& LS & 27.9 & .000 & .37 \\
BiMo & LD & 5.6 & .02 & .1 \\
& LS & 18.8 & .000 & .29 \\
\hline
\end{tabular}

\section{Comparing the simultaneous and sequential bilinguals with their matched controls}

In order to know if the simultaneous and sequential bilinguals are significantly different from their matched monolingual counterparts, independent-samples t-tests were conducted for each subgroup. The results for lexical diversity and lexical sophistication are summed up in Tables 4.21 and 4.22 , respectively. 
Table 4.21: Independent samples t-test in the subgroups and their controls on lexical diversity

\begin{tabular}{llllll} 
Groups & Mean & SD. & t & df & P \\
\hline $\begin{array}{l}\text { Simultaneous } \\
\text { Bilinguals }\end{array}$ & 43.7 & 18.6 & -1.7 & 18 & .09 \\
Controls & 58.7 & 18.7 & & & \\
\hline $\begin{array}{l}\text { Sequential } \\
\text { Bilinguals }\end{array}$ & 56.2 & 28.1 & -.29 & 28 & .7 \\
Controls & 59.1 & 25.4 & & & \\
\hline
\end{tabular}

Table 4.22: Independent samples t-test in the subgroups and their controls on lexical sophistication

\begin{tabular}{llllll} 
Groups & Mean & SD. & $\mathrm{t}$ & $\mathrm{df}$ & $\mathrm{P}$ \\
\hline $\begin{array}{l}\text { Simultaneous } \\
\text { Bilinguals }\end{array}$ & 312.6 & 48.1 & 2.1 & 18 & .04 \\
$\begin{array}{l}\text { Controls } \\
\text { Sequential }\end{array}$ & 264.09 & 52.1 & & & \\
$\begin{array}{l}\text { Bilinguals } \\
\text { Controls }\end{array}$ & 2460.8 & 43.8 & 2.6 & 28 & .01 \\
\hline
\end{tabular}

While the simultaneous and sequential bilinguals' lexical diversity scores were not statistically different from their matched monolingual controls', the gap between the bilinguals' and the monolinguals' lexical diversity results was wider in the case of the simultaneous bilingual subgroup (Table 4.21). The independent samples t-tests which were conducted on the results of lexical sophistication showed that both of the heritage speaker sub-groups were significantly different from their monolingual counterparts. However, as indicated in Table 4.22, the gap between the bilinguals' and the monolinguals' lexical sophistication results was similar in both subgroups.

\section{The effect of demographic and sociolinguistic variables on lexical richness}

This part of the analyses presents the effects of demographic (age, age at emigration and length of emigration) and sociolinguistic variables (frequency of Persian use and parents' attitude towards heritage language) on the lexical profiles of the heritage speakers' oral narratives. 
Length of emigration was not entered into the analyses because of its collinearity with age and age at emigration. As in the first study, because of the wide age range of the participants, age was entered in the first step into the hierarchical regression model to see how it predicts the results by itself. Age ( $r$ $=.74, p=.000)$, age at emigration $(r=.62, p=.000)$ and heritage speakers' Persian use $(r=.34, p=.04)$ were found to be significantly correlated to the results of lexical diversity in all bilinguals. In the regression model, age predicted $53 \%$ of the results by itself (Adjusted $\mathrm{R}^{2}=.53$ ). While age at emigration contributed to the model, the compound variables of heritage language use and attitude did not add to the explanatory power of the model concerning results of lexical diversity, as shown in Table 4.23. According to the final regression model, $F(4,20)=11.3, p=.000)$, age and age at emigration were the variables that significantly predicted the variance in lexical diversity scores in the bilinguals.

Table 4.23: Correlations and coefficients for lexical diversity in the heritage speakers

\begin{tabular}{lllll} 
Variables & $\mathrm{r}$ & $P$ & Beta & $P$ \\
\hline Age & .74 & .00 & .59 & .00 \\
Age at emigration & .62 & .00 & .41 & .01 \\
Persian use & .34 & .04 & -.1 & .89 \\
Parents' attitude & .03 & .43 & .1 & .42 \\
\hline
\end{tabular}

In the regression model conducted on the lexical sophistication results for the heritage speakers, it was found that age $(r=-.65, p=.00)$ and age at emigration ( $r=-.34, p=.04$ ) were again significantly correlated to the results. Age by itself predicted $40 \%$ of the result of lexical sophistication (Adjusted $\mathrm{R}^{2}=$ .4). The final hierarchical regression model, reached statistical significance, $(F$ $(4,20)=4.3, p=.01)$, and explained $36 \%$ of the variance (Adjusted $\mathrm{R}^{2}=.36$ ). The results of lexical sophistication were mainly predicted by age (standardized coefficient Beta $=-.62, p=.002$ ). None of the compound variables from the semi-structured interviews or age at emigration reached significance in predicting the results, as shown in Table 4.24. 
Table 4.24: Correlations and coefficients for lexical sophistication in the heritage speakers

\begin{tabular}{lllll} 
Variables & $\mathrm{r}$ & $P$ & Beta & $P$ \\
\hline Age & -.65 & .00 & -.6 & .00 \\
Age at emigration & -.34 & .04 & -.1 & .41 \\
Persian use & -.09 & .33 & .15 & .41 \\
Parents' attitude & .13 & .25 & .1 & .54 \\
\hline
\end{tabular}

In order to find out which factors predict the results of lexical richness in the simultaneous and sequential bilinguals, separate hierarchical regression analyses were conducted per subgroups. In the subgroup of 10 simultaneous bilinguals (see data processing of the film-retelling task), length of emigration and age at emigration were not entered into the analyses, since age at emigration for most of them who were born in the host country was 0 and their length of emigration equaled their age. Therefore, the only variables that could be entered into the analyses for this subgroup were age and two compound variables extracted from the interview data. Age and the two compound variables were found to correlate significantly with lexical diversity results, with age showing the strongest correlation $(r=.61)$. Since participants' Persian use was strongly correlated with age $(r=.92)$, it could not be entered into the regression model. Thus, a hierarchical regression analysis was performed to find out the predictive power of the model by parents' attitude with age. In this regression model, age was entered in the first step, predicting $38 \%$ (Adjusted $\mathrm{R}^{2}=.38, p=.05$ ) of the variance in the lexical diversity results. The final model $(F(2,7)=2.8, p=.1)$ showed that none of the variables significantly contributed to the model. Table 4.25 displays correlations and the outcome of the hierarchical regression analysis for the lexical diversity scores.

Table 4.25: Correlations and coefficients for lexical diversity in the simultaneous bilinguals

\begin{tabular}{lllll} 
Variables & $\mathrm{r}$ & $P$ & Beta & $P$ \\
\hline Age & .61 & .02 & .41 & .28 \\
Persian use & .54 & .05 & - & - \\
Parents' attitude & .58 & .03 & .32 & .39 \\
\hline
\end{tabular}


Regarding the sequential bilinguals, since length of emigration in the host country is confounded with age at the time of the study, it was not entered into the analyses. Age and age at emigration were significantly correlated with the results of lexical diversity in this subgroup. In the regression model, age was entered as the first block, and it predicted $61 \%$ of the variance in the lexical diversity scores in the sequential bilinguals (Adjusted $\mathrm{R}^{2}=.61, p=.001$ ). Age at emigration was entered next. This model $(F(2,12)=36.4, p=.00)$ significantly predicted $85 \%$ of the results with both age and age at emigration as significant predictors. The compound variables (heritage speakers' Persian use and parents' attitude) did not add any weight to the model, as is shown in Table 4.26.

Table 4.26: Correlations and coefficients for lexical diversity in the sequential bilinguals

\begin{tabular}{lllll} 
Variables & $\mathrm{r}$ & $P$ & Beta & $P$ \\
\hline Age & .78 & .00 & .52 & .02 \\
Age at emigration & .79 & .00 & .57 & .04 \\
Persian use & .1 & .24 & -.34 & .88 \\
Parents' attitude & -.03 & .44 & .004 & .98 \\
\hline
\end{tabular}

To assess the influence of different variables on the results of lexical sophistication in the simultaneous bilinguals, a preliminary analysis was conducted to check multicollinearity. Age and the two compound variables were found to correlate significantly with the results of lexical sophistication, with age having the strongest correlation $(r=-.34)$. The results also illustrated that participants' Persian use was strongly correlated with age $(r=.92)$, as it was found in the results of lexical diversity, preventing its entry into the model with age. Consequently, age was entered into the hierarchical regression analysis first, and it was found to explain $11 \%$ of the variance in the results. The final model $(\mathrm{F}(2,7)=.52, p=.6)$ showed that parents' attitude did not add much explanatory power $\left(r^{2}=.13, p=.7\right)$. 
Table 4.27: Correlations and coefficients for lexical sophistication in the simultaneous bilinguals

\begin{tabular}{lllll} 
Variables & $\mathrm{r}$ & $P$ & Beta & $P$ \\
\hline Age & -.34 & .16 & -.43 & .3 \\
Persian use & -.19 & .29 & - & - \\
Parents' attitude & -.12 & .36 & .14 & .7 \\
\hline
\end{tabular}

As regards the sequential bilinguals, significant correlations were obtained between the results of lexical sophistication and age $(r=-.84, p=.000)$ and age at emigration $(r=-.49, p=.03)$, while the compound variables (frequency of heritage language use and attitude) failed to reach significance. Age, which was entered first into the hierarchical regression model, explained $71 \%$ of the variance. Age at emigration did not add much to the strength of the model. After entry of the sociolinguistic variables, the final model $(F(4,10)=$ $6.8, p=.006)$ explained $73 \%$ of the variance, with age as the significant predictor, as shown in Table 2.28 .

Table 4.28: Correlations and coefficients for lexical sophistication in the sequential bilinguals

\begin{tabular}{lllll} 
Variables & $\mathrm{r}$ & $P$ & Beta & $P$ \\
\hline Age & -.84 & .00 & -.74 & .02 \\
Age at emigration & -.49 & .03 & -.18 & .59 \\
Persian use & .02 & .4 & .01 & .96 \\
Parents' attitude & .21 & .2 & .07 & .76 \\
\hline
\end{tabular}

\subsubsection{Conclusions, implications and limitations of the study on lexical richness}

In this study, I have examined the lexical richness (lexical diversity and lexical sophistication) of young heritage speakers' oral narratives in comparison with narratives produced by monolingual counterparts. Additionally, I was interested in exploring which of the two measures of lexical richness applied in the present study lent itself best to discovering the differences between heritage speakers' and matched monolinguals' use of L1 vocabulary. I have also tried to identify the demographic and sociolinguistic factors that help predict young 
heritage speakers', either simultaneous or sequential bilinguals, level of lexical richness.

The analysis of lexical richness in this study revealed that the heritage speakers were significantly outperformed by the monolinguals on both measures - diversity (a type-token ratio measure) and sophistication (a corpusfrequency-based measure). This finding suggests that the heritage speakers use less diverse vocabulary and more high-frequency words than monolinguals do, which is likely due to a combination of incomplete acquisition and attrition in the young heritage speakers. Biological age (at the time of testing) also turned out to play a significant role in the results. Accordingly, the older heritage speakers in my sample generally displayed more diverse and sophisticated use of lexis than the younger ones. The finding that biological age at the time of the study was found to be so strongly correlated with lexical richness in the heritage speakers suggests that these heritage speakers have continued to develop (or at least maintained) knowledge of the family language as they grew up, presumably thanks mostly to the input they receive from their parents. However, to support this argument, I shall also investigate the effect of age and age at emigration in both simultaneous and sequential bilinguals (see below).

While both the lexical diversity and the lexical sophistication measure revealed significant differences between the heritage speakers and the monolingual benchmark control, the gap was wider in the results of lexical sophistication, suggesting that the latter measure may be more sensitive in detecting differences between heritage speakers and matched monolinguals. This finding has important implications for studies attempting to trace incomplete acquisition and attrition of family languages in young heritage speakers by investigating their vocabulary knowledge. This finding implies that studies of incomplete acquisition and attrition in young heritage speakers' family language should consider the frequency (lexical sophistication) in addition to the variety (lexical diversity) of the lexical items they use. In addition, the studies on language attrition in adult migrants can benefit from this finding and accordingly include lexical sophistication measure in their methodology.

The comparison of the subgroups of participants' difference in the lexical diversity relative to their monolingual benchmarks illustrated that, while the simultaneous bilinguals were significantly different from matched monolinguals, the difference in the sequential bilinguals and their matched controls did not reach significance, showing that the participants in this subgroup are closer to the benchmark. This finding, as in the first study in this 
investigation, is consistent with Montrul (2008). However, regarding the results of lexical sophistication, both subgroups were significantly different from their matched benchmarks. This finding may support the argument that the lexical sophistication measure is a better parameter for detecting the differences between bilinguals and monolinguals.

Having compared all simultaneous and sequential bilinguals, and their monolingual counterparts, I proceeded with the analyses to determine which demographic or sociolinguistic factors account for the variance in the heritage speakers' results. The hierarchical regression analyses conducted for the lexical diversity and sophistication measures yielded different pictures in all bilinguals: while age and age at emigration were found to be the most influential factors in the lexical diversity of the heritage speakers, the lexical sophistication was mainly associated with age in all bilinguals. The impact of age at emigration confirms that the earlier the heritage speakers move to a second language environment, the lower their proficiency in their family language is likely to become in terms of lexical diversity. The effect of age at emigration is in line with some studies (e.g., Ammerlan, 1996; Pelc, 2001, Bylund, 2008, 2009) that showed its strong impact on incomplete acquisition and language attrition. However, this variable has received much less attention in studies of language attrition compared to its effect on second language learning (Bylund, 2009; Schmid, 2011). The effect of age (at the time of the study) confirms the argument that lexical richness in most heritage speakers increases as they grow up in the second language environment. This finding indicates that these heritage speakers are developing their Persian proficiency in the host country despite the more limited L1 input and more limited opportunities/incentives for output. Moreover, the sociolinguistic variables (frequency of heritage language use and parents' attitudes towards heritage language maintenance) did not emerge as strongly influential variables.

The regression analyses on the results of the subgroups of the heritage speakers yielded similar pictures in the simultaneous bilinguals' lexical diversity and sophistication data. Their lexical diversity and lexical sophistication results were both predicted mainly by age, although this variable did not significantly contribute to the regression model. In the hierarchical regression analyses on the results of the sequential bilinguals, age was the only variable that was associated with the results of their lexical richness. The sociolinguistic variables did not predict the results of lexical diversity and sophistication in both subgroups significantly. The fact that the results of lexical richness in both subgroups were generally associated with the demographic 
variables (mainly age) may be because of the fact that these variables, are so strong that they overshadow the effect of the sociolinguistic variables.

Furthermore, it was found that the heritage speakers' age correlates positively to their results of language diversity and sophistication in both simultaneous and sequential bilingual subgroups. This result indicates that the heritage speakers, even those who were born in or emigrated to the host country at a young age, seem to have continued to develop their vocabulary knowledge in Persian, i.e. their weaker L1 as referred to by Montrul (2008). It should be noted that this might be the case for my participants who continue to develop their proficiency in Persian with limited input in the host country. It can be concluded that although the sociolinguistic variables did not turn out as influential factors in the results of heritage speakers' lexical richness, they do seem to play a role, since, as discussed, the participants appear to have continued to acquire and/or maintain their heritage language in the host country. It is possible that the questions used in the sociolinguistic questionnaire were too blunt an instrument to reveal variation in Persian use and parental attitude in the participating families at a more subtle or finer-grained level. There may therefore be a need to revise the sociolinguistic questionnaire so that it can detect such finer-grained differences in heritage language use and parental attitude.

As noted, while age was significantly associated with the variance in heritage speakers' lexical richness data, neither the frequency of heritage language use nor the parents' attitude towards heritage language maintenance appear to play a significant role. This, however, needs to be interpreted with caution, for at least two reasons. The first reason is that their influence may in the statistical computation simply be overridden by the stronger effect of the demographic variables. A larger sample might reveal a different picture, where factors such as frequency of heritage language use and parental attitudes towards language maintenance do reach the significance threshold. The second reason is that I based the statistics on the parents' self-reported data, and these may need to be interpreted cautiously, since the parents may have reported their desired beliefs rather than their actual daily practices and efforts in helping their children develop and maintain their heritage language. Besides, the fact that many reported high degrees of family language use and highly positive attitudes regarding language maintenance led to relatively limited variance in these socio-linguistic data, which, in turn, may have compromised the robustness of the inferential statistics. In any case, the use of self-reported data elicited from the participants' parents in the semi-structured interviews is definitely a 
limitation in this study that I need to acknowledge. It would be useful if the parents' responses to the Likert-scale based questions were verified after triangulation of self-report data with observational data. However, it should be noted that the result regarding the impact of age on lexical richness in the heritage speakers lends support to the effect of parental input in heritage language maintenance which has widely been recognized (see Fishman, 1991; De Houwer, 2007; King, Fogle \& Logan-Terry, 2008; Schwartz, 2010).

I do, of course, need to acknowledge the sample in this study was even smaller than the first study in this quantitative investigation which makes it difficult to generalize the findings to other populations of young heritage speakers. As previously mentioned, due to the small community of Iranian immigrants in New Zealand, I could recruit just thirty young Persian-English bilingual participants, of whom one, who was born in New Zealand, refused to take part in the film retelling task because she felt her proficiency in Persian was too poor. In addition, I had to exclude the results of four other simultaneous bilinguals ( 6 and 7 years old), whose narratives were too short to be subjected to proper lexical analysis. However, despite the small sample, the findings of this study are meaningful in showing the strong role the demographic factors play in young heritage speakers' lexical competence. But, as said, further research with larger number of participants would yield a clearer and more definitive picture of heritage speakers' lexical richness in their family language. Another limitation of the current study is the measures of lexical richness I used. In addition to lexical diversity and lexical sophistication, the study of lexical density and the frequency of lexical errors (Read 2000) of the participants' speech samples might provide a more comprehensive overview of the heritage speakers' lexical richness and accuracy in their family language.

To conclude, the study reported here furthers our understanding of incomplete acquisition and attrition of the family language in young heritage speakers. The study applied a methodological framework which is commonly used in language attrition research investigating adult bilinguals who arrived in the host country after puberty. It seems that this approach can be useful in research on incomplete acquisition and language attrition in younger bilinguals. It is clear, however, that the results of free speech samples should be accompanied with the findings of other measures of vocabulary knowledge (e.g., controlled tests) to shed more light on the different aspects of heritage speakers' L1 lexical knowledge and the strongest factors of the lacunae they have in their family language due to incomplete acquisition and/or attrition. 


\subsection{Discussion of the quantitative investigation}

The quantitative investigation of the dissertation examines incomplete acquisition and attrition of young heritage speakers' vocabulary knowledge in their family language. The participants consisted of thirty 6-18 year old PersianEnglish bilinguals (14 boys and 16 girls; mean age: 10.3) who have been living in New Zealand for different lengths of time (mean: 6.9 years). There was an equal number of simultaneous and sequential bilinguals in this group. To obtain benchmark data of what the heritage speakers' vocabulary knowledge might have been like if they had grown up in the home country, a control group was recruited, comprised of thirty monolingual speakers of Persian in Iran who were matched with the heritage speakers in terms of age, gender, number of siblings and their family's socio-economic status.

The first study examines young heritage speakers', either simultaneous or sequential bilinguals, productive and receptive vocabulary knowledge in their family language compared to the matched monolingual counterparts. If there is a difference, the factors that account for this difference are investigated. These factors include current age, age at emigration, length of emigration, frequency of heritage language use and parents' attitude towards heritage language acquisition and maintenance. A verbal fluency task (VFT) and an auditory picture-word matching task were used to measure the heritage speakers' productive and receptive knowledge, respectively. Information about the bilinguals' demographic and socio-linguistic factors was collected through semi-structured interviews with their parents. The results showed that the heritage speakers were outperformed by the monolinguals in both vocabulary tests, but the gap was wider in the case of the simultaneous bilinguals; a finding in line with Montrul (2008). Of the factors investigated, the parents' attitude was found to be the strongest predictor of the simultaneous bilinguals' vocabulary knowledge, which highlights the role parents can play in the heritage language development of their children even if they are exposed to a majority language early on in life. On the other hand, the sequential bilinguals' vocabulary knowledge was associated mostly with age at emigration - the older the children were when they moved to the second language environment, the better their family language vocabulary tended to be.

Some researchers have argued that to judge how speakers use language naturally, free speech data should be collected (Schmid, 2011). To elicit free speech data from the heritage speakers, a film-retelling task was used. The second study in the quantitative investigation examines whether young heritage 
speakers, simultaneous and sequential bilinguals, differ from monolinguals with regard to lexical richness (lexical diversity and lexical sophistication) in their family language. It also weighs the influence of the demographic and/or sociolinguistic factors on the difference, if there is any. The lexical diversity was assessed by using MTLD (measure of textual lexical diversity), known as the least susceptible measure to text length (Koizumi, 2012). Lexical sophistication was measured by calculating the average frequency of all lemmas used by each participant in the corpus by all bilinguals and their matched monolinguals who completed the study. As expected, the monolinguals' narratives tended to manifest greater lexical richness according to both measures, but did most markedly so according to the lexical sophistication measure, suggesting that the latter is a better parameter in detecting the differences between heritage speakers and monolinguals. The heritage speakers' lexical richness was strongly associated with their age at emigration and the length of time they had been living in the host country. Neither the heritage speakers' frequency of heritage language use nor their parental attitudes towards heritage language acquisition and maintenance were found to be significant predictors of the bilinguals' lexical richness.

Taking the findings of these two studies together, it can be argued that this investigation has contributed to the growing body of literature in incomplete acquisition and attrition in young heritage speakers. Firstly, the biological age (at the time of testing) in the comparison of all results (i.e., productive lexical knowledge, receptive lexical knowledge, lexical diversity and lexical sophistication) of the heritage speakers with their matched controls turned out to be a strong predictor, indicating that the older heritage speakers as well as the older monolinguals had the higher lexical proficiency in their first language. While this finding was expected in the monolinguals, it is somewhat surprising in the case of the heritage speakers, given the pressure from the dominant language and the reduced opportunity for using the heritage language as they grow older in the host country. The older bilinguals, whether simultaneous or sequential, obtained better test results and displayed greater lexical richness than the younger heritage speakers. It can be argued that the heritage speakers in my research continue to develop their proficiency in Persian with limited input, mainly from their parents, in the host country, even though the sociolinguistic variables (i.e., heritage language use and parental attitudes towards heritage language) did not turn out to be significant predictors in the statistical analyses. This result also lends support to the effect of parental input in heritage language maintenance which has widely been recognized (see De Houwer, 1999; 
Fishman, 1991; King, Fogle \& Logan-Terry, 2008; Schwartz, 2010, to name a few).

In terms of the age effects on the results, the findings of both quantitative studies also showed that age at emigration significantly predicts the heritage speakers' productive and receptive lexical knowledge as well as their lexical richness. The strong effect of age at emigration illustrates that the older the heritage speakers were when they left the home country, the more proficient they are in their family language. The effect of age at emigration in my quantitative investigation is in line with some studies (e.g., Ammerlan, 1996; Pelc, 2001, Bylund, 2008, 2009) that showed its strong impact on incomplete acquisition and language attrition. However, this variable has received much less attention in studies of language attrition compared to its effect on second language learning (Bylund, 2009; Schmid, 2011).

Additionally, the analysis of simultaneous and sequential bilinguals provides evidence for Montrul's (2008, p. 60) hypothesis, arguing that "if language attrition occurs within early (pre-puberty) bilingualism, it will be more severe in simultaneous bilinguals (exposed to the two languages very early) than in sequential bilinguals (when the L1 was acquired before the L2)." As this hypothesis proposes, when heritage speakers are exposed to two languages during the critical period, their language acquisition and loss is a function of age and input (Gorman, 2010). However, vocabulary acquisition, unlike phonology and syntax, is more like an open-ended process which does not have a biological foundation as the Critical Period Hypothesis predicts (e.g., Davis \& Kelly, 1997; Bahrick et al., 1994). These studies described that language learners can acquire new vocabulary during their life span as they encounter new words, however the ability to learn new lexical items may deteriorate with age (Hoyer \& Lincourt, 1998). Therefore, I argue that the finding in this investigation, regarding the wider gap between the simultaneous bilinguals' results compared to the sequential bilinguals' with their monolingual counterparts, show the effect of limited exposure to the heritage language lexicon for simultaneous bilinguals. While the focus of this investigation is on Persian-English bilinguals in New Zealand, the results may apply to heritage speakers of other populations in different host countries.

Regarding methodology, this investigation has important implications for the existing literature and future research. As noted, far less attention has been paid to heritage speakers' vocabulary knowledge and the variables that influence it (Montrul, 2009). The available literature in incomplete acquisition and language attrition of home languages of heritage speakers is mainly based 
on the findings of studies exploring their grammatical proficiency (e.g., Montrul, 2008; Polinsky, 2006). The studies presented in this quantitative investigation examined the vocabulary knowledge of the participants who are still undergoing the process of vocabulary acquisition in their heritage language while at the same time (probably) losing some of it. Therefore, this research raises many questions in the area of lexical acquisition and loss in need of further research.

Moreover, the methodology applied in these two quantitative studies was commonly used in studies of first language attrition in adult bilinguals (see Schmid, 2011). Applying this methodology on young heritage speakers, whose knowledge of the family language is the outcome of incomplete acquisition and attrition (Montrul, 2008), may therefore provide a basis for future research in this area. Of the controlled tasks applied in the first study in this investigation, the matching task (APWMT) was found to be a better parameter in distinguishing the differences between heritage speakers and their matched controls than the VFT (verbal fluency task). This finding was surprising, since receptive knowledge tends to be retained longer than productive knowledge, while production requires a higher level of activation (Hulsen, 2000; Paradis, 2007, p. 125; Montrul 2008, p. 81). As a result, I expected the heritage speakers would fail more to produce words in their family language in the verbal fluency task than recognize the meaning of words as they encounter them in the matching task. This finding has two main implications. Firstly, it clarifies that the VFT seemed not to be an appropriate task in studies that aim to trace incomplete acquisition or attrition in young heritage speakers' productive knowledge. The application of this task in adult bilinguals in studies of language attrition needs to be reconsidered as well, as Schmid and Jarvis (2014) discussed. The other implication of this finding lies in the use of the auditory picture-matching task. The APWMT task turned out to be valid in distinguishing the difference between heritage speakers' receptive vocabulary knowledge with their monolingual controls'. With no use of written language, this auditory task enabled me to measure heritage speakers' receptive lexical knowledge bypassing the need for literacy in the family language.

As already mentioned, the Peabody picture-word matching task (PPVT) has frequently been used to measure the receptive vocabulary knowledge in children and adult bilinguals (e.g., Bialystok, Luk, Peets \& Yang, 2009). In this test, four pictures are presented to respondents and they are asked to choose the picture for a word spoken by an examiner. While the Peabody picturevocabulary test assesses respondents' knowledge by presenting four pictures for 
one oral word, the APWMT presents four word options for one picture instead - a correct option, a semantically related distractor, a phonologically related distractor and an unrelated distractor. Therefore, this matching task seems to assess participants' lexical recognition more than PPVT which may give participants visual clues in their word choice. This feature of the auditory matching task may also reduce the chance of guessing for participants in their replies. Therefore, the multiple-choice format of the APWMT test may provide a better measurement of receptive knowledge compared to the Peabody picturevocabulary matching task (PPVT). To apply the auditory matching task in the area of language acquisition as well as language loss, future research on the comparison of these two tests need to be undertaken to clarify which one is a better parameter in measuring the receptive vocabulary knowledge.

In terms of methodology, another contribution this investigation makes is showing that the lexical sophistication measure was more sensitive in detecting differences between the heritage speakers and their matched monolinguals than the lexical diversity measure. This finding has important implications for studies attempting to examine incomplete acquisition and attrition of family languages in young heritage speakers by investigating their vocabulary knowledge. It implies that studies of incomplete acquisition and attrition in young heritage speakers' family language should consider not only the variety (lexical diversity) but also the frequency (lexical sophistication) of the lexical items they use. In addition, the studies on language attrition in adult migrants can benefit from this finding and include a lexical sophistication measure in their methodology.

Following the literature on the role of the family in language maintenance and loss (e.g., Fishman, 1991; King, Fogle \& Logan-Terry, 2008; Schwartz, 2010), it was expected that sociolinguistic variables would be identified as strong predictors of the heritage speakers' proficiency in their family language. While I concluded that the effect of age shows indirectly that the sociolinguistic variables play a part in heritage language proficiency, the statistical results of this quantitative investigation did not provide support for this argument. The fact that the sociolinguistic variables did not turn out to play a significant role in all of the results of the quantitative investigation needs to be interpreted with caution, for at least two reasons. Firstly, it is plausible that their influence is overridden by the stronger effect of the demographic variables in the statistical computation. The second reason is the use of the parents' selfreported data, since the parents may have reported their desired beliefs rather than their actual daily practices and efforts in helping their children develop and 
maintain their heritage language. To tackle this issue, I launched the qualitative investigation, in case a more in-depth analysis of the interview data might reveal evidence of the influence of sociolinguistic variables (i.e., heritage language use and parental attitudes towards their children's heritage language acquisition and maintenance) on heritage speakers' vocabulary knowledge. 


\section{PART II:}

Heritage Language Acquisition and Maintenance:

A Qualitative Investigation 


\section{Chapter 5 : Part II}

\subsection{Introduction to the qualitative investigation}

As noted earlier, contrary to expectations, the sociolinguistic variables that were explored in the quantitative investigation did not turn out to be significant predictors of the heritage speakers' Persian proficiency. Accordingly, I launched a qualitative investigation to determine if a more indepth analysis of the interview data might reveal evidence of the influence of heritage language use and parental attitudes on heritage speakers' proficiency in their family language.

This chapter includes two qualitative studies on parental attitudes towards heritage language acquisition and maintenance for their children. The first study intends to fill the gap in examining parental attitudes in the context of family language policy by utilizing Spolsky's (2004) model of language policy as a methodological framework. Firstly, the gap in examining parental attitudes in the home context is discussed and it is argued why a model of language policy is used. After illustrating the participants' beliefs, practices and management towards Persian acquisition and maintenance, this study concludes that this model of language policy seems to provide a reliable methodological framework to use in examining parental attitudes in the family context. It was also found that the Iranian parents in this study were more committed to helping their children develop and maintain conversational fluency than literacy in their family language. This finding led me to conduct the second study in this qualitative investigation to examine parental attitudes towards heritage language literacy specifically. Similar to the first study, different components of language policy (beliefs, practices and management strategies) are discussed, this time in relation to literacy.

\subsection{The first qualitative study: Parental attitudes towards heritage language acquisition and maintenance ${ }^{3}$}

So far, there has been little discussion about how immigrant parents' attitudes towards acquisition and maintenance of their ethnic language for their

\footnotetext{
${ }^{3}$ This study has been submitted as the following article: Gharibi, K. \& Seals, C. A. (under review). Bridging family language policy and parental attitudes towards heritage language acquisition and maintenance.
} 
children should be examined. Drawing upon the literature, this study aims to contribute to research on family language policy by focusing on the examination of parental attitude towards heritage language acquisition and maintenance in the home context.

There is little agreement among researchers regarding theoretical and methodological approaches to the concept of attitude (Ó Riagáin, 2008), which is mainly due to a lack of agreement regarding its operationalization (Garrett, 2010). Traditionally, studies have often conflated attitudes and beliefs, using these two terms interchangeably, arguing that it is difficult to separate them in practice (e.g., Gibbons \& Ramirez, 2004; Yu, 2010). However, inconsistencies have been shown between immigrant parents' language ideologies and their practices (e.g., Lao, 2004; Schwartz, 2008). In light of these discrepancies, these questions arise: is it enough just to look at language beliefs in the examination of language attitudes? Are positive parental beliefs sufficient for preserving children's heritage language, without the addition of supporting practices and management? As discussed in the quantitative investigation, parental attitude did not turn out to be a strong predictor in the statistical analyses of all test results. Therefore, conducting this study may help shed light on the surprising outcome of the quantitative study.

Although attitudes and beliefs are related, they are not synonymous. While an attitude is a general evaluative orientation towards an object, a belief is narrower in scope and generally more cognitive in nature (Oskamp \& Schultz, 2005, p. 18). An attitude can be defined as preparation for behavior or a predisposition to respond in a particular way to an object (Allport, 1937, as cited in Oskamp \& Schultz, 2005, p. 8). Consequently, I argue that attitude as a construct has been simplified in studies that have examined language beliefs as a way to grasp the whole picture of language attitude, since they fail to show how people incline to behave in a certain situation.

In addition, in the direct approach to investigating attitudes (see Ó Riagáin, 2008, for a review), participants are asked to report their attitudes, and these reports are taken as truth. A methodological issue raised here is "whether subjects' verbal statements of their attitudes and behavioral reactions in concrete situations can both be interpreted as manifestations of the same underlying dispositions" (Ó Riagáin, 2008, p. 332). Consequently, there may be discrepancies between what they report they believe and their behavior (see Garret, Coupland \& Williams, 2004) that originates from their beliefs. 
This study attempts to fill the mentioned gap in examining parental attitudes towards heritage language maintenance. In the current research, "attitude" is considered as a multilayered construct which has beliefs as its core. By utilizing Spolsky's model of language policy (2004) as a lens and a methodological framework, this study aims to unpack the different layers of attitude as a construct. It also attempts to further complexify the multi-faceted, interwoven pieces of meaning that contribute to what I mean by "attitudes".

It should be noted that although the model of language policy is applied in this study to examine parental attitude, they are not used interchangeably for several reasons. Firstly, the model is used as a methodological framework by which I conceive of parental attitudes in the family context as a multilayered construct. In addition, this study relies on data from semi-structured interviews with parents, while exploring family language policy requires data from children as members of the family as well. Consequently, family language policy and parental attitudes are not considered as the same constructs in this research.

Therefore, attitude is explored in this study by utilizing the language policy model to uncover other layers of this multilayered construct. I anticipated that the qualitative approach to attitude is more likely to show the difference between participants' self-reported beliefs and their reported behavior in certain situations (Ó Riagáin, 2008). In the quantitative investigation, it was responses to Likert-scale type questions which were entered into the analyses. However, a qualitative investigation can shed light on details of what they reported in the interviews about their beliefs, practices and efforts.

Taking the above into consideration, language beliefs and attitudes are not used interchangeably in this study. The term "belief" is used to refer to what parents think about heritage language transmission and maintenance for their children (as opposed to what they do in their everyday life), while the components of language policy (namely beliefs, practices and management) all together are used as indirect indicators of the complex construct of attitude. In this study, I consider "attitude", which can take different forms in the context of family language policy, as a multilayered construct with beliefs as the first stratum and the core. While beliefs are necessary, they are not sufficient in showing the whole picture. Therefore, "practices" and "management" are considered as the next layers of this construct, as visualized in Figure 5.1, to understand how people conceive of attitudes. In presenting this, I do not intend to reduce Spolsky's model to attitudes; rather, I aim to evaluate and validate the application of this model as a lens in perceiving the complex construct of 
parental attitudes in the context of family. Thus, this study attempts to demonstrate if the model of language policy provides a reliable methodological framework for understanding parental attitudes in the context of family.

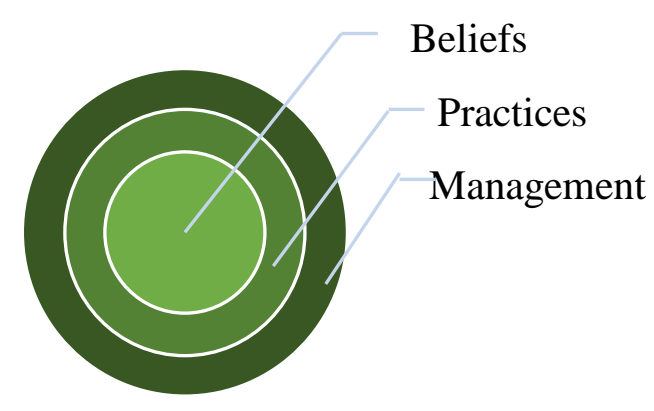

Figure 5.1: The multilayered construct of attitude in this study ${ }^{4}$

In addition, by focusing on Iranian immigrants in New Zealand, this study tries to contribute to the literature in two ways. Firstly, little research has been conducted on heritage language maintenance and loss among Iranian immigrants, and that which has been conducted mostly in the United States (e.g., Modarresi, 2001; Felling, 2006; Ramezanzadeh, 2010), which has the highest number of Iranian immigrants (Bozorgmehr, 1998). Furthermore, while New Zealand has a rich literature in the area of heritage language maintenance and loss (e.g., Hulsen, 2000; Bell, Harlow \& Stark, 2005; Seals, forthcoming, to name a few), little attention has been paid to small migrant populations such as Iranians in this country, with no institutional support for intergenerational transmission of their minority language (see the Introduction of the thesis).

The research questions in this study are as follows:

1. Do Iranian immigrant parents consider it important to pass their heritage language to their children?

\footnotetext{
${ }^{4}$ It should be noted that there are different ways of visualizing every construct; however, this is how I portray attitude as a multifaceted construct. This figure depicts beliefs as the central layer since practices and efforts are rooted in beliefs.
} 
2. What are Iranian immigrant parents' practices and efforts regarding their children's heritage language acquisition and maintenance?

3. Are their reported beliefs transferred to their daily practices and management strategies?

4. Does the model of language policy provide a reliable methodological framework for examining parental attitudes in the context of family?

\subsubsection{Findings}

The participants' beliefs about heritage language acquisition and maintenance for their children, their related practices and the parents' efforts to modify or influence language use in the home are presented in this section. These trends are discussed in relation to their fit with Spolsky's (2004) model of language policy.

\subsubsection{Language beliefs}

All adult participants in this study noted that they consider it important to use the heritage language in the home and pass it on to their children. They also reported strong beliefs in their responsibility to use the heritage language in the home. In addition, the majority of parents explicitly stated their belief that it would be their fault if their children developed only low proficiency in the heritage language. The most common reasons parents mentioned for pursuing heritage language maintenance included cultural identity, communication with the extended family, and advantages of bilingualism.

\section{Parents' reasons for heritage language maintenance}

Repeatedly, the parents expressed their strong beliefs that acquisition and maintenance of the heritage language enables their children to develop and keep their cultural identity as Iranians. It is not uncommon for immigrants to look at the heritage language as a vehicle for transmitting cultural identity to their children (e.g., Fishman, 1991; Cavallaro, 2005; Zhang \& Slaughter-Defoe, 2009), indicating that language is one of the most important keys to ethnic identity in multilingual situations. The participants also stated that their children's loss of the minority language would lead to the loss of their identity 
as Iranians, which supports previous findings that families associate heritage language attrition with the loss of cultural identity (e.g., Schecter \& Bailey, 2004; Lee, 2012). This is expressed in the example below from Naji, a 38 -year old mother of one:

$$
\begin{aligned}
& \text { ناجى: خوب /ين يه بجّه /يرانيه و فارسى زبان مادريشه. من فكر مى كنمر احه فارسى رو } \\
& \text { ياد نَيره، بعد يه مدت هيج تما يلى به /يران نداشته باشه . }
\end{aligned}
$$

Naji: Well, he's [my son's] Iranian, and Persian is his mother tongue. I think if he doesn't learn Persian, he won't have any connections to Iran eventually.

In the above excerpt, Naji reports her perception that developing ethnic identity occurs through learning the heritage language, and failing to acquire the heritage language leads to the loss of cultural identity (Lee, 2012). She believed that if her son does not learn his heritage language, he will lose his ties with the Iranian culture and cannot develop an Iranian identity. This result is in accordance with what Iranian-American parents reported in some studies on heritage language maintenance (e.g., Modarresi, 2001; Feling, 2006).

In previous studies (e.g., Guardado, 2002; Zhang \& Slaughter-Defoe, 2009), the terms "cultural identity" and "ethnic identity" have been used to refer to the identity of minority language speakers without necessarily considering proficiency in the heritage language, since there are monolingual speakers of the dominant societal language who may identify specifically with a heritage community but not with the heritage language. I argue that the aspect of identity that heritage speakers develop through the acquisition of their heritage language, whether while growing up or later in life, can be referred to by the term heritage language identity. This identity develops through the acquisition and maintenance of a speaker's heritage language and by having some levels of affiliation with, connection to, and investment in the heritage ethnic culture, occurring simultaneously with or as a result of heritage language acquisition (see Val \& Vinogradova, 2010).

In addition to shaping heritage language identity, all parents in this study stated that they would like their children to learn and maintain Persian to be able to communicate with their relatives back in the home country (see Fillmore, 1991; King \& Fogle, 2006; Park \& Sarkar, 2007). Bennett (1997) found similar results in her study that identified the use of a minority language with families in a home country as a strong motivation for language maintenance. This can 
be seen in the example below, where Arezou, a mother who left Iran thirteen years ago, expresses the same thoughts about her children:

$$
\begin{aligned}
& \text { آرزو: دوست دارم وقتى ميريم/ يران بتونن به فارسى ارتباط برقرار كنن كه مثل عضوى } \\
& \text { از خانواده باشن نه مثل يه غريبه. }
\end{aligned}
$$

Arezou: I would like them to be able to communicate in Persian when we visit Iran so that they would be like members of the family, not strangers.

In this excerpt, Arezou notes that by learning the heritage language, her children would be positioned more as members of the family in the home country, since they could communicate with their extended family; otherwise they would seem like strangers (see also Feling, 2006).

Additionally, some parents with low English proficiency in the current study want their children to learn Persian because they see their children's Persian use as a necessity for maintaining inner family communication. This is expressed below by Narges, a mother who was not very fluent in English:

$$
\begin{aligned}
& \text { نركس: ديَّه خودشون ميدونن كه /ين تنها راه /رتباط با بلدرو مادرشونه. خودشون }
\end{aligned}
$$

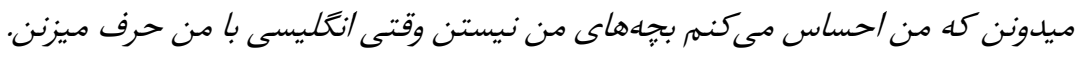

Narges: They would know that it is the only way to communicate with their parents. They already know that I feel like they are not my kids when they speak in English to me.

This quote highlights that communication between parents and children in immigrant families can be threatened if children do not learn the heritage language and if parents are not fluent in the dominant language. Without a common language of proficient communication, family dynamics suffer, and parents are aware of this (Zhang \& Slaughter-Defoe, 2009; Seals, 2013). Families also feel a common identity through a shared common language, which in turn facilitates a healthy family relationship within immigrant families (Fillmore, 1991). The ability to communicate with immediate and extended family is often considered one of the most important advantages of minority/heritage language maintenance (e.g., Kouritzin, 1999; Seals, 2013).

Parents also associated development and maintenance of the family language with bilingualism, which they saw as a privilege that will bring their children better career opportunities in the future (e.g., Guardado, 2002; King \& 
Fogle, 2006; Garcia, 2009). This is expressed by Arezou in the following statement:

$$
\text { آرزو: خوب هر جهى بيشتر زبان بلد باشن، ابرتونيتى بيشترى در آينده دارن. }
$$

Arezou: Well, if they know more languages, they will have more opportunities ${ }^{5}$ in the future.

Arezou notes that by learning and maintaining the heritage language, her children can take advantage of bilingualism in their future careers. In addition, one parent stated that "learning a language leads to learning a new world" (Sara, July 2013). They also referred specifically to the increased intelligence of bilinguals which is in keeping with research findings that bilinguals have substantially "more practice in analyzing meaning" than monolingual speakers, which results in higher intelligence (Cummins, 1989, p. 20). However, as Bialystok (2010) argues, learning and using two languages positively affects bilinguals' cognitive abilities (p. 569), leading to "mental flexibility, a superiority in concept formation, a more diversified set of mental abilities" (Peal \& Lambert, 1962, p. 20, as cited in Bialystok, 2010).

\section{Having regrets in the case of heritage language loss}

Additionally, the parents stated that they would regret if their children lost the ability to speak and understand their heritage language. This has been identified in applied linguistics as an indicator of parents' attitudes towards minority/heritage language maintenance (e.g., Cherciov, 2012). The reasons the participants mentioned for their regrets in the case of heritage language loss varied, however. Some participants tied language loss to the loss of family dynamics, especially with grandparents. Additionally, some parents with low English proficiency believe their communication with their children is hindered by family language loss (e.g., Zhang \& Slaughter-Dafoe, 2009). Some of them stated that their children would lose their "heritage language identities". In addition, a few parents, such as Minou, a 34-year old mother of one, mentioned the loss of the opportunity for bilingualism, shown in the example below:

\footnotetext{
${ }^{5}$ The bold words in the Persian quotations are instances of codeswitching and code-mixing to English.
} 


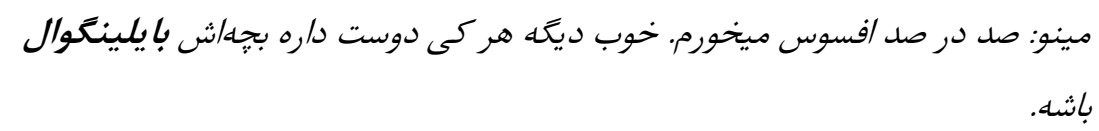

Minou: I would regret one hundred percent, since everyone would like their kid to be bilingual.

As Minou states in this excerpt, she would regret if her son lost the chance to be bilingual. She also expressed this as a shared idea among parents of heritage language speakers, therein building a joint community goal of bilingualism.

However, in the below example, Yousef, a post-doctoral fellow, replies that he does not believe it is possible for his son to lose Persian proficiency since he and his spouse have been trying very hard to keep up language maintenance:

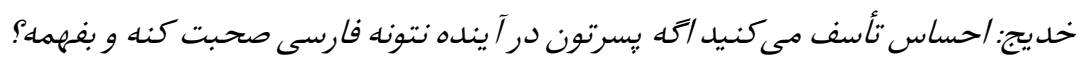

Khadij: Would you regret if your son could not speak and understand Persian in the future?

$$
\text { يوسف: نتونه توكار ما نيست، خانم. }
$$

Yousef: "Not being able to" is not an option for us, Miss.

This excerpt highlights Yousef's commitment to heritage language maintenance for his son, which is a sentiment reflected among many of the participants. Since his family had a very explicit policy for using Persian as the only language of the home, Yousef expressed certainty that his son would be able to maintain his skills in the heritage language.

In terms of heritage language maintenance in the families, a difficulty arose was that there were also some parents who were not fully aware of the gradual process of heritage language loss due to decreased use. They did not imagine that their children might lose their heritage language skills when they grow up (e.g., Fillmore, 2000) and denied this possibility by citing their own use of Persian in the home. Interestingly, these parents code-switched often during the interviews, and their children also frequently used English as one of the languages of the home (following parents' modeling) and these children did not have strong language abilities in Persian. Furthermore, the children of parents who used Persian-only at home appeared to have higher Persian proficiency than those whose parents code-switched or used two languages in 
the home setting (This is discussed further in the section about language practices, see also Figure 5.2).

There are contrasting views in the existing literature about the influence of code-switching by immigrant parents on their children's heritage language maintenance. For example, De Houwer (1999) argues that immigrant parents' own use of code-switching in parent-child interactions, which shows their relaxed attitude towards language choice, directly influences heritage speakers' minority language development. By using code-switching themselves, parents tend to let their children code-switch, and this leads to a gradual decrease of the use of the heritage language. However, Lanza (2001) discusses how a discursive approach to studying parent-child interactions can provide a more holistic picture of bilingual children who are socialized into code-switching and language-mixing, arguing that these language practices are not necessarily detrimental to the heritage language. Therefore, although it seems that in the present study, parents' code-switching and language mixing influenced their children's heritage language use and possibly proficiency, further empirical research is needed on the role of frequency of parental input in minority language acquisition (see De Houwer, 2007).

Finally, there were some parents who were aware of the gradual process of their children's heritage language loss, leading them to employ a family language policy promoting heritage language maintenance. Two parents explained that this is the main reason for encouraging their children to use Persian. Sara reflects on this in the example below:

$$
\text { البارا: شوهر من سى ساله خارج /ز كشوره، ولى فارسيش شايد /ز خيلىها /ينجا بهتر }
$$

Sara: My husband hasn't been in Iran for thirty years, but his Persian is much better than many Iranians here. This is why he's strict about using Persian, since he knows how fast a language can be lost due to disuse. He has seen this a lot.

Sara in this excerpt explains how her husband, who has been in nonPersian speaking countries for a long time, insists on using Persian in the home so that their children could acquire and maintain it. She also explains that her husband has seen many people lose a language due to lack of use. This quote shows that parents who are aware of possible gradual heritage language loss in 
their children are more likely to have an explicit language policy aiming to promote their children's sole use of the heritage language. It also reveals that parents' personal experiences with bilingualism are a main factor in shaping family language policies (King \& Fogle, 2006; Curdt-Christiansen, 2009).

It has been shown that parental language ideology operates as the underlying force in their decisions on what languages to practice in the home (Curdt-Christansen, 2009; 2013). Although all of the parents in the present study believe that their children should acquire and maintain their heritage language, the way they act in everyday life (language practices) to reach this goal does not always conform to their beliefs.

\subsubsection{Language practices}

\section{Persian use in the families}

All of the families in this study stated that Persian is used daily in their family settings. However, the amount of Persian use differs between and within the families. All the parents I interviewed use Persian with their spouses, except for one couple who reported communicating in Turkish and Persian almost equally with each other. Additionally, the extent to which the minority language is reportedly used in family domains differs between children communicating with their parents versus their siblings. Eleven parents stated that Persian is the only language they use when interacting with their children, but not all of them have an explicit policy for using the minority language at home. Some parents purposefully adopt a heritage language-only policy, aiming to help their children to develop and maintain Persian. However, the way they apply this policy in everyday life is not uniform across families according to the parents' reports.

Looking at heritage language maintenance along a continuum (see Guardado, 2002), five families have children with higher Persian proficiency than the others, as evidenced by the results of lexical tests in the quantitative investigation. Figure 5.2 visualizes this continuum based on the family language use and the children's heritage language proficiency. This continuum presents the general pattern amongst the families, but as with all language use, there are always exceptions. 


\begin{tabular}{|c|c|c|c|c|c|}
\hline $\begin{array}{c}\text { Language } \\
\text { use }\end{array}$ & 5 families & 7 families & 6 families & 2 families & $\begin{array}{c}1 \\
\text { family }\end{array}$ \\
\hline $\begin{array}{l}\text { Parents to } \\
\text { children }\end{array}$ & Persian & Persian & $\begin{array}{l}\text { Persian \& } \\
\text { English }\end{array}$ & $\begin{array}{l}\text { English \& } \\
\text { Persian }\end{array}$ & $\begin{array}{l}\text { English } \\
\text { \& Persian }\end{array}$ \\
\hline $\begin{array}{l}\overline{\text { Children to }} \\
\text { parents }\end{array}$ & Persian & $\begin{array}{l}\text { Persian \& } \\
\text { English }\end{array}$ & $\begin{array}{l}\text { Persian \& } \\
\text { English }\end{array}$ & $\begin{array}{l}\text { English \& } \\
\text { Persian }\end{array}$ & English \\
\hline
\end{tabular}

Figure 5.2: Heritage language maintenance and family language use continuum

For these five families, the heritage language-only policy was implicitly known to the children, who almost always followed it by using Persian when interacting with their parents at home, even when not explicitly told to do so. As Mehdi, a forty-year old father of one daughter, explains below, these children abide by this implicit policy:

$$
\text { مهلى: آلما مى دونه زبان خونه زبان فارسيه. بقولا نهادينه شده . }
$$

Mehdi: Alma knows that Persian is the language of the home. In other words, it has been internalized [for her].

Mehdi explains how the "heritage language-only policy" has been internalized for his daughter through practice, by always using the minority language in family settings as "the default language of the home" (Yu, 2010, p. 15). The parents with this policy also remarked that their children usually do not need to be encouraged to use the minority language. This is explained by Narges, a mother of two fluent Persian speakers, in the example below:

$$
\begin{aligned}
& \text { نركس: اصلا نيازى به تشويق نيست، جون خود به خود /ينا /ين كارو مىكنن. با /ينكه }
\end{aligned}
$$

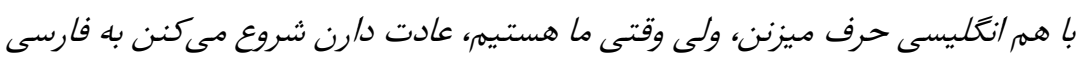

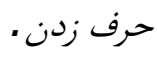

Narges: There is no need to encourage them at all because they do it regularly. Although they speak English with each other, they habitually switch to Persian when we are around.

This mother describes how their heritage language-only policy at home encourages her children to linguistically accommodate their parents, even 
though the children prefer to use the dominant language when communicating with each other (see Fishman, 1965). This can be explained with reference to Accommodation Theory (Giles \& Coupland, 1991, p. 60-61):

Accommodation is to be seen as a multiply-organized and contextually complex set of alternatives, regularly available to communicators in face-to-face talk. It can function to index and achieve solidarity with or disassociation from a conversational partner, reciprocally and dynamically.

As this example shows, children often choose to use their family language in their parents' presence to show solidarity (Seals, 2013).

In contrast to the five families already discussed, the rest of the participants who reported that they use Persian as the only language of the home also said that their children need to be explicitly reminded and encouraged to use the minority language. These families mentioned that their children often speak in English with their siblings despite the parents' encouragement to use Persian. This can also be justified by accommodation of the heritage speakers to their siblings (Seals, 2013).

In addition to parents who explicitly hold a heritage language-only policy, some parents stated that they use Persian when communicating with their children due to their own low levels of English proficiency. These participants also reported that their children, as heritage speakers, have always been aware of their parents' low levels of English proficiency even at preschool age, and this may be one reason they use their heritage language when communicating with their parents. Darya, who is not as proficient as her husband in English, illustrates this idea in the example below:

$$
\text { لوريا: با من بيشتر فارسى حرف ميزنه، ولى با باباش بعضى وقتا انغليسى همر حرف ميزنه. }
$$

Darya: He [my son] speaks in Persian with me, but he sometimes speaks in English with his dad because he knows that I don't know that much English. He just believes that his dad is an English teacher, and he knows English well.

In this excerpt, Darya describes how her son's awareness of his parents' English proficiency affects his language choice with his parents. This illustrates 
how children can accommodate to parents with different proficiency levels by alternately using either the heritage or societally dominant language.

Another example shows how "disaccomodation" can also be a factor in child language use. This example comes from one participant who reported that her six year old son asks her to use Google Translate every time he asks her the Persian meaning of an English word. Heritage language speaking children can therefore position their parents as speakers of Persian but not of English, thus leading to the children's doubts as to their parents' second language proficiency. Two parents further stated that one of the reasons they do not speak English with their children at home is that their English was judged negatively by their children who have high levels of English proficiency. Ava, a mother of two young daughters, describes why she does not use English with her daughters in the example below:

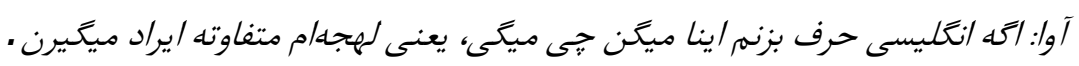

Ava: If I speak in English with them, they would ask what I'm saying, you know, I mean my accent is different, and they would criticize me.

As Ava emphasizes in this excerpt, the main reason why she does not use English when communicating with her children is that they position her as not proficient in English, thus leading to her discomfort with using English around them. This quote highlights the fact that the use of the heritage language by immigrant parents is sometimes not due to a deliberate language policy but instead due to a perceived lack of agency or ability.

Additionally, as shown above and below, some parents with Persianonly language policies at home curb their own English language use due to selfpositioning as not proficient in English. They intentionally do not use English at home in order not to expose their children to English with a Persian accent, which they consider to be non-native-like. These participants hold strong ideologies that their children should only learn English from English native speakers. Naji, a mother of a seven-year old son, who has a Persian-only policy in the home describes one of the reasons of this language practice as follows:

$$
\begin{aligned}
& \text { ناجى: با توجه به /ينكه آراد داره انغليسى رو تو مدرسه ياد ميكيره با لهجه درست }
\end{aligned}
$$

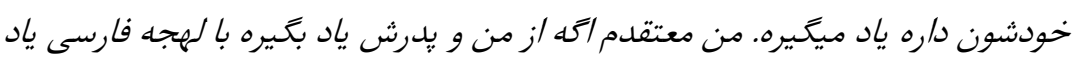

$$
\begin{aligned}
& \text { ميخيره. }
\end{aligned}
$$


Naji: Considering that Arad [my son] is learning English at school with the correct accent, I believe that if he learns English from me and his dad, it would be English with a Persian accent.

In this excerpt, Naji states that her son should learn "correct" English from native speakers, showing the effects of her own ideologies about language on her home language policy. Instead of supporting a 'World Englishes' (e.g., McArthur, 2001) view, she supports a nativist view of the language, which could possibly be a result of her own experiences living in a native-English speaking country, offering further proof that participants' own experiences become imbedded in the family language policies they establish (see CurdtChristiansen, 2009).

While about half of the participants (eleven families out of twenty-one) reported that they use the minority/heritage language as the only language of the home, ten parents noted that they use both English and Persian for their daily interactions in the family. These parents explained that although Persian is the preferred language of the home, they would like their children to feel free to use English when communicating with them if needed. Saba, a mother of one nineyear old daughter, expresses these thoughts in the excerpt below:

$$
\begin{aligned}
& \text { سبا: ما فارسى حرف مىزنيمر ولى بعضى وقتا /حساس مى كنم/ /و نياز داره كه به انتليسى } \\
& \text { حرف بزنه مثلا وقتى داره در مورد مدرسه تند تند تعريف مى كنه يه جيزى . }
\end{aligned}
$$

Saba: We speak in Persian, but sometimes I think that she needs to speak in English, like when she's talking fast about something that happened at the school.

Saba explains that she lets her daughter use English in some situations, showing parental accommodation to children. This provides further evidence that home language socialization is a two-way process, with parents socializing children and children socializing parents (e.g., Kim, 2008; Fogle, 2009; Fogle \& King, 2013).

In families with more than one child, the eldest child usually had higher proficiency in the heritage language, a trend that has been established in the literature (e.g., Seals, 2013). Since the older children often speak with their younger siblings in English, the younger children are socialized into using English and have fewer opportunities to practice speaking the heritage language. One of the heritage speakers who is the older sibling attributes her younger brother's lower Persian proficiency to herself: 


$$
\begin{aligned}
& \text { رها: رادين /ز من فارسى كمتر مى دونه، شايد به خاطره /ينه كه من بيشتر باهاش } \\
& \text { انَليسى حرف ميزنم تو خونه . }
\end{aligned}
$$

Raha: Radin knows less Persian than me, maybe because I speak in English with him at home.

In this excerpt, Raha shows awareness of the sibling-to-sibling preference for English in the home and considers that speaking in English with her younger brother reduces his chance of using Persian at home. She then extends this to say it might also be a reason of his lower proficiency in Persian. This mirrors previous studies (e.g., Fillmore, 1991; Kouritzin, 1999; Guardado, 2002; Seals, 2013) that indicate older siblings in immigrant families tend to communicate in the dominant language with younger siblings even though they may be fluent in the heritage language to some extent. Consequently, this reduces the opportunity for the younger siblings to practice and develop the heritage language.

If we look at the other end of the language maintenance continuum, there was just one parent who reported no deliberate efforts in practicing the minority/heritage language with his children in the home, although he considered it theoretically important to use and maintain it. This parent and his spouse use Persian and English at home when talking to their children, but the children speak with their parents only in English. These parents have a laissezfaire language policy (see Park, 2007), which supports the pattern of heritage speakers feeling more content to use the language in which they are more fluent, often the socially dominant language. Consequently, these children have often only developed receptive knowledge of Persian and have low productive abilities in Persian, as is the case for this family, explained by their father below:

$$
\text { حرف مىزنيد: ما به دو زبان به طور مساوى حرف مىزنيم باهاشون. وقتى به فارسى باهاشون ميدن و ميفهمن، ولى جواب نميتونن (به فارسى) بلن . }
$$

Saeed: We speak with them in two languages [Persian and English] equally. When we speak in Persian to them, they listen and understand well, but they can't reply back [in Persian].

In this excerpt, Saeed describes the laissez-faire language practice in their home, which led to his children not developing productive abilities in Persian. As he indicates, his children's receptive knowledge in Persian is considered good, while their productive abilities are low, such that they cannot talk to their parents in Persian. As stated by Park (2007), without parents' 
reinforcement, heritage speakers are less likely to choose the minority language as the language of the home, which in turn leads to lower productive abilities in the heritage language. The fact that these participants have positive beliefs towards heritage language use and maintenance for their children, but the children still do not develop strong productive abilities in the heritage language, indicates that positive beliefs are not enough to guarantee heritage language maintenance in their children.

\section{Iranian friends and Persian use}

Social networks have also been shown to have a major effect on the preservation or gradual loss of a language (García, 2003). In particular, there is a link between the size of social network in the heritage language and the outcome of language maintenance (e.g., Wei, 2000; Hulsen, de Bote \& Weltens, 2002). Following this, the number of Iranian friends and the social networks of the families were anticipated to have an effect on Persian maintenance for the heritage speakers in the current study.

All families in the present study have Iranian friends in New Zealand and noted that they spend more time with them than with their English-speaking friends, even though they may have more non-Iranian friends. Saba, a mother who left Iran about nine years ago, illustrates the amount of time she and her family spend with Iranian friends as follows:

$$
\text { سبا: ما ممكنه تعد/د كمترى دوست / يرانى داشته باشيمر ولى هر هفته داريمر همديكر رو }
$$

Saba: We may have fewer Iranian friends [than non-Iranians], but we see each other every week. Therefore, the number of our friends does not matter; the time that we spend together matters.

Saba highlights the fact that they spend more time with other Iranian families, even though they may have a larger number of non-Iranian friends. Saba and other participants visit their Iranian friends with the aim of their children developing a positive attitude towards the culture and home country, and in order to provide their children with opportunities to practice their heritage language. 
Regardless of intentions, however, all participants noted that their children usually speak in English with their Iranian peers. Naji describes heritage speakers' language use with peers in the example below:

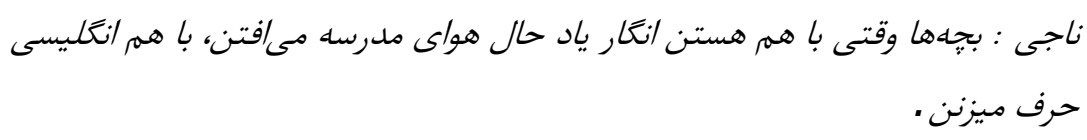

Naji: When children are hanging out, they feel like they're at school, and they speak in English together.

As emphasized in this excerpt, the heritage speakers interact with their Iranian peers in the dominant language like they do at school, reflecting the socialization they receive from their school peers and their accommodation to dominant societal language norms (see Fishman, 1965). Therefore, having friends from the home country did not seem to provide many opportunities for the heritage speakers in practice.

\section{Contact with the home country}

Contact with the home country has been identified as a means of measuring attitude towards the heritage language (e.g., Cherciov, 2012), and it has been found to be a strong predictor of first language proficiency among immigrants (e.g., Hulsen et al., 2002). Almost all participants in the present study had regular daily or weekly contact with their families and friends in Iran through phone or video calls. Additionally, all parents reported that they use social media every day to maintain contact with friends and family in the home country. Although the parents have frequent contact with Iran, they emphasized that their children have less. Hasti, a 34-year old mother of two, explains this as follows:

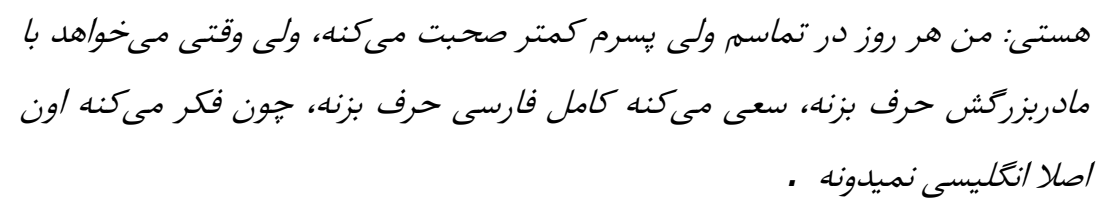

Hasti: I'm in touch [with Iran] every day, but my son talks [on the phone] less often. However, when he wants to talk to his grandma, he tries to speak completely in Persian, since he thinks that she doesn't know English at all. 
In this quote, Hasti describes that although she is in touch with the home country every day, her son rarely speaks with his grandparents, but when he does, he positions them as non-English speakers and adapts by attempting to use only Persian. Still, parents cannot consider contact with the home country as a main way to promote language development and maintenance for their children if the latter are not willing to engage in this regularly.

However, using the heritage language when visiting the home country has been identified as one of the best motivators for heritage language maintenance (Bennett, 1997; Hinton, 1999; Cherciov, 2012). The number of visits to Iran differed between the families who participated in this study. Some of them travelled to Iran every other year, while a few of them have not visited the home country since they had their children. All participants who visited Iran, however, reported that their children's heritage language proficiency increased quickly during visits to the home country. Narges illustrates this as follows:

$$
\begin{aligned}
& \text { نركس: رادين دو ساله بِيش كه /يران بوديم فوقالعاده فارسيش بهتر شد. خيلى تاثير } \\
& \text { داشت و هممون هم خيلى خوشحال بوديم به /ين خاطر . }
\end{aligned}
$$

Narges: Radin progressed in Persian extraordinarily two years ago when we went to Iran. It was very effective, and we were all happy because of this.

In the above excerpt, Narges expresses her family's positive opinion towards Persian development and maintenance practices. Additionally, considering the long distance between New Zealand and Iran, it cannot be claimed that the low number of visits to Iran shows negative attitudes of the families towards cultural identity and the heritage language maintenance in their children. However, each opportunity to visit Iran seems to be beneficial for promoting the children's heritage language development and use when they returned to New Zealand.

\section{Watching Persian movies and listening to Persian songs}

Almost all participants in this study mentioned that they listen to Persian songs almost every day, and their children sometimes sing with them. Listening to songs and watching movies in the heritage language exposes the children to Persian, and it might have a positive effect on their proficiency in the heritage language (e.g., Hinton, 1999; Cho \& Krashen, 2000; DeCapua \& Wintergerst, 2009). However, many of the younger siblings in this study who had lower 
levels of proficiency in their family language (as shown by their test results in Part I) were reported to be hardly interested in playing and listening to songs in Persian on their own, showing that greater proficiency in the minority language invites more input, while lower levels of proficiency promote less heritage language use amongst heritage speakers (Pearson, 2007).

A few parents explained that they try to watch Persian television weekly in order to expose their children to the heritage/minority language. They stated that, in addition to heritage language maintenance, they want their children to know about their culture and the country they came from. Narges, whose daughter and son are fluent in Persian, explains one of the reasons as follows:

$$
\begin{aligned}
& \text { نركس : ما هر شب موقع شام خوردن سريال /يرانى ميبينيم. يه علتى كه زبان فارسى } \\
& \text { بجه ها خوبه همينه . }
\end{aligned}
$$

Narges: We watch Iranian TV series every night when we have dinner. This is one of the reasons that their Persian is good.

Narges in this excerpt reports that they watch movies in Persian every night at dinner time, and she associates this positively with her children's Persian proficiency, a sentiment echoed by a few families in the study. Therefore, parents contextualize the heritage language in terms of cultural representations and use cultural artifacts as a means to deliver this contextualized use of language to their children.

\subsubsection{Language management}

As discussed before, language management is defined here as any effort people make to modify their language practices. In operationalizing attitude for the present study, encouraging children to use the minority language and correcting their Persian when they make a mistake were included in the management component.

\section{Encouraging children to use the heritage language}

All parents in the present study reported they encouraged their children to use the heritage language in various ways. As mentioned, in families with a heritage language-only policy, parents reported less trouble reminding their children to speak in Persian because their children know to switch to Persian 
when speaking to their parents and often with their siblings when their parents are around.

Additionally, some parents' strategy for encouraging their children to use the heritage language is to pretend not to understand when their children talk to them in English. These participants stated that their children are aware that the parents are reminding them to use Persian. This refers to a "minimal grasp strategy" (Lanza, 1997), which has proved influential in promoting minority language use in children. Mehdi, who uses this strategy, illustrates this in the example below:

$$
\begin{aligned}
& \text { مهلدى: آلما وقتى وارد مهدكودى شد، علاقه زيادى نشون داد كه به انتليسى حرف بزنه }
\end{aligned}
$$

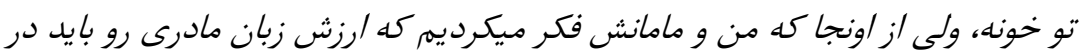

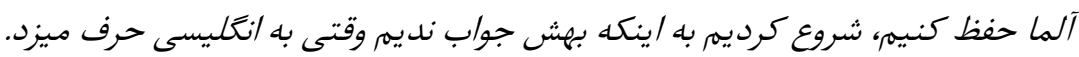

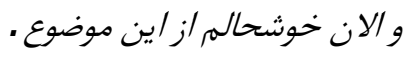

Mehdi: When Alma started kindergarten, she got interested in speaking English at home, but since her mum and I thought that we should maintain the value of the mother tongue for Alma, we started not responding to her when she spoke in English, and I am happy now because of this decision.

Mehdi describes the challenge he and his wife faced when their daughter started schooling. They decided not to reply to her English usage so that she would be forced to use the heritage language, therein rewarding heritage language use in the home.

Considering children's reluctance to talk on Skype with relatives in Iran, as described in the previous section, few participants in this study tried to help their children develop Persian proficiency through contact with the home country. However, one parent reported asking her nephew living in London to speak in Persian with her son every Sunday through Skype, aiming to provide her son with the opportunity to use and hear his heritage language. She illustrates this in the example below:

$$
\begin{aligned}
& \text { بهار: ديدم كاوه داره فارسى يادش ميره، جند وقته شروع كرده ساندىها به فارسى با }
\end{aligned}
$$

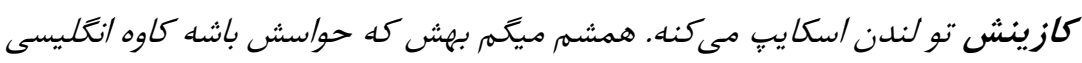

$$
\begin{aligned}
& \text { حرف نزنه. }
\end{aligned}
$$


Bahar: Because I saw Kaveh losing his Persian, he's started Skyping with his cousin who lives in London on Sundays. I keep telling him [the cousin] to be careful not to let Kaveh speak in English.

In this excerpt, Bahar describes her efforts to encourage her son's Persian use and maintenance. As part of these efforts, she also transfers the role of language manager to her nephew by asking him to 'be careful not to let Kaveh speak in English'. This also effectively governs the cousin's language usage because he must watch his own language use in order to then govern Kaveh's.

Some parents also use innovative methods to encourage their children to use only the heritage/minority language at home. One parent who has a Persian-only policy at home and whose son is fluent in Persian stated that they have to pay a 10 cent fine if they use English words when speaking Persian in the home.

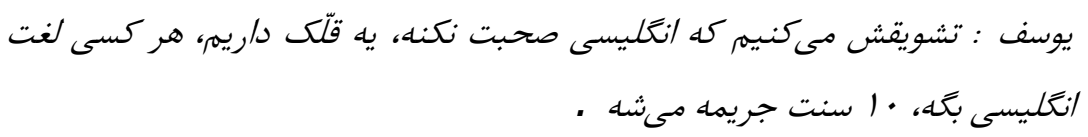

Yousef: We encourage him not to speak English. We have a piggy bank. If anyone uses an English word [at the home], she or he has to pay a 10 cent fine.

This approach to family language policy management is promising, as research indicates that parents who use more positive and entertaining methods to encourage their children to use their heritage language are more successful in heritage language maintenance for their children (e.g., Guardado, 2002).

Additionally, some parents reportedly explain the importance of heritage language use and the benefits of being bilingual or communicating with the home country to their children, who then consequently understand the effect of heritage language use with the family. Thus, meta-negotiation of family language policy by parents with their children can have a great effect on the outcome of heritage language proficiency. Some parents stated that talking to their children about the importance of using Persian with them facilitates heritage language use in the home environment. Furthermore, parents who display explicit positive attitude towards the heritage language can influence the children's heritage language use and proficiency (see Li, 2006). 


\section{Correcting heritage speakers' Persian}

In addition to supporting language use, the majority of parents reported that they explicitly correct their children's Persian regularly right after a mistake. Few of the parents believed that correcting their children would negatively affect their use of the heritage language. Parirokh was one of the few parents worried about this, however, and describes her reasoning in the example below:

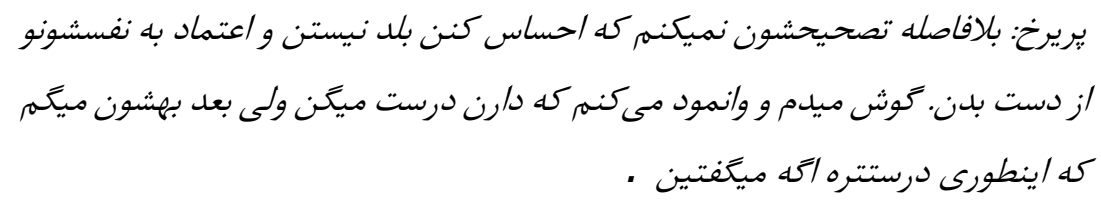

Parirokh: I don't correct them immediately [right after they make a mistake] to make them feel they don't know Persian and lose their self-confidence. I listen and pretend they are speaking correctly. However, I tell them afterwards it would be better if they had said it this way.

In this excerpt, Parirokh justifies why she does not correct her daughters' mistakes in Persian right away. Instead, in an effort to protect their confidence in using the heritage language, she chooses to use delayed feedback. However, it is important to note that whether the parents choose immediate or delayed feedback, they still find it important to provide some form of correction, again showing the importance they place on standardized language forms. Additionally, almost all of the parents were aware of the fact that some of the mistakes their children make are due to grammatical interference of English as the socially dominant language. For example, the children sometimes translate English to Persian word by word when they speak in the heritage language without adjusting the syntax. Therefore, parents' corrective feedback is also an attempt to curb interference from the L2.

\section{Other sources of language management}

Further studies have found that heritage speakers' teachers who are from the new country can play a crucial role in motivating children to learn and maintain their family language (e.g., Lee, 2012). In New Zealand, education has two school levels: primary education (year 1 to year 8) for children 5 to 12 years old, and secondary education (year 9 to year 13) until the age of 17/18. English, 
te reo Māori, and New Zealand Sign Language are the official languages of the country. However, the language of schooling is primarily English, with some Māori medium schools, based on Māori culture and values. Schools offer an additional language in the curriculum in years 7 through 10. Chinese, Japanese, French, German, Spanish, Latin, Samoan and Māori are some of the common additional languages in New Zealand schools, depending on schools' available resources (Ministry of Education, 2015). Persian, however, is not currently offered in New Zealand schools or any other educational contexts in the country, making home language use even more critical for maintenance.

In the current study, the children's teachers in New Zealand seem to play a key role in the families' language policy choices within the home. Nine parents stated that they were told by their children's teachers to use their heritage language to help them develop and preserve it. This speaks to teachers' awareness that heritage speakers tend to use the dominant language at home when they start schooling and become more fluent in the dominant language as they continue schooling (e.g., Hinton, 1999; Seals, 2013). Sepehr, whose daughter has strong Persian proficiency, illustrates the role of teachers in the example below:

$$
\begin{aligned}
& \text { سبهر: معلماش به ما ادوايز ميكردن كه نكران انَليسى نباشين، نَكران فارسى باشين. } \\
& \text { با اينكه باران تو انخليسى مشكل داره به هيج وجه سعى نكنين باهاش انغليسى حرف } \\
& \text { ·زنين }
\end{aligned}
$$

Sepehr: Her teachers advised us not to worry about English [when she started schooling]. They advised worrying about Persian. They told us not to try to speak in English with Baran at the home, even though she had problems speaking it.

Sepehr explains that they were encouraged by their daughter's teachers to use Persian at home when their daughter started schooling, showing teachers' awareness of home language loss. Additionally, another parent mentioned that their son's teacher recommended asking their son every day to retell the lessons he learned at school in Persian for them in order to increase the opportunity of practicing the minority language. These examples highlight the value that immigrant parents can put in feedback received from their children's teachers and the influence of teachers on parents' home language management.

Furthermore, one parent explained how his son's attitude towards Persian use changed when his school organized an international event and asked the students, who were heritage speakers from different countries, to bring the 
flags of their countries to the event and sing a song in their minority languages. After this event at school, the child who used to ask his parents not to speak Persian in front of his friends at school started using Persian with his parents at home even when his friends were around.

The above examples show how institutions that value and validate minority languages and cultures play an important role in heritage language maintenance. They can influence heritage speakers' attitudes towards their family language and their decisions regarding its acquisition and use. These institutions include those inside heritage language communities such as weekend schools, as well as mainstream institutions such as public schools ( $\mathrm{Li}$, 2006). Therefore, schools and representatives such as teachers play a crucial role in heritage language maintenance, especially in a multilingual society such as New Zealand.

In addition to teachers and schools, participants also noted that their monolingual English-speaking New Zealander friends advise them frequently to value this opportunity and raise their children bilingually. Arezou illustrates this in the example below:

$$
\text { تا زرزو: نيوزيلنديها هم مرتبا ميكن سعى كنيد بجههاتون زبان خودتونو ياد بَّيرن كه دو }
$$

Arezou: We are usually told by New Zealanders to try to make our children learn our language so that they would know two languages [eventually].

Arezou explains how their language use in the home is influenced by monolingual English speakers in New Zealand. This shows the value that heritage/minority language speakers place in the opinions of native members of their new society, regardless of whether or not those members are monolingual. Investing in the practices that their friends find valuable is an important determinant in how the Persian families choose to manage language use in their homes. As New Zealand is a society which values multilingualism, many parents are fortunate to have well-informed input from teachers and friends as to the value of maintaining the heritage language. While parents' own views and experiences have much influence on their beliefs, practices, and management of their children's heritage languages, positive and supportive input from a society that values multilingualism also plays a major role. 


\subsubsection{Conclusion of the study on parental attitudes towards heritage language acquisition and maintenance}

In this part of the qualitative study, I have presented an investigation of Iranian immigrants' attitudes towards their children's heritage language acquisition and maintenance. By utilizing Spolsky's (2004) model of language policy, I have attempted to present an appropriate methodological framework for examining the complexity of parental attitudes towards heritage language acquisition and maintenance. In doing so, I have argued that it is not sufficient to consider only language beliefs in measuring language attitudes of immigrant parents towards their children's heritage language maintenance. Rather, language practices and management efforts must also be taken into account.

The findings of this study reveal that the participants, Iranian immigrants in New Zealand, have both positive beliefs towards their culture and minority language, as well as strong intentions to pass on the heritage language to their children. I also found that those who put much effort into their children's heritage language maintenance as well as those whose children have low-level proficiency in the heritage language, strongly believe that it is their responsibility to help their children to acquire and preserve proficiency in the heritage language by using it at home.

In addition to exploring parental attitudes by using the model of language policy as a lens, this study aimed to investigate whether the parents' beliefs transfer to their family practices and management. Similar to previous studies (e.g., Schwartz, 2008), discrepancies were revealed between the parents' reported beliefs, and their reported language use and management. For instance, the parents who stated that they would like to pass on the heritage language to their children, did not reportedly make much efforts to help their children acquire it. One possible reason for the inconsistencies is that individuals do not always act based on what they believe (or "practice what they preach"). Even for parents in the present study who have positive beliefs about heritage language maintenance, transferring them into practice may not occur for a variety of reasons. I argue that the relationship between language beliefs and language practices is "not linear nor unidirectional" (Borg, 2006, p. 275). It is not "linear" because of the intervening factors or obstacles that hinder parents from acting based on their beliefs. In this case, the parents, despite their positive beliefs towards heritage language maintenance, might not be able to practice regular heritage language use with their children due to their busy schedules or children's resistance. The relationship is not "unidirectional", because language 
beliefs are also affected by practices. In other words, while language practices and management efforts are influenced by the language beliefs parents hold towards heritage language maintenance, their beliefs may change due to their family language use during the course of raising their children. For instance, even if they believe they should use their ethnic language at home to pass it on to their children, they may not continue using their ethnic language when their children adopt the habit of using the dominant language after they start schooling, especially if the parents do not have enough time and energy to invest in their family language use. In addition, some studies have shown that heritage speakers' agency may influence their parents' ideologies and practices (e.g., Luykx, 2005; Fogle, 2009; Fogle \& King, 2013). Consequently, parents' strong beliefs concerning heritage language use may change as a result of their children's agency. Additionally, immigrant parents vary in their "impact belief" (De Houwer, 1999), which is the degree to which parents see themselves as capable and responsible for shaping their children's language (King et al., 2008, p. 912). Parents who have strong impact beliefs certainly are more able "to create a supportive environment" (De Houwer, 1999, p. 90) to facilitate heritage language use in the home setting when they face challenges. Considering the fact that language beliefs are also affected by language practices and management, I visualize Spolsky's model as in Figure 5.3.

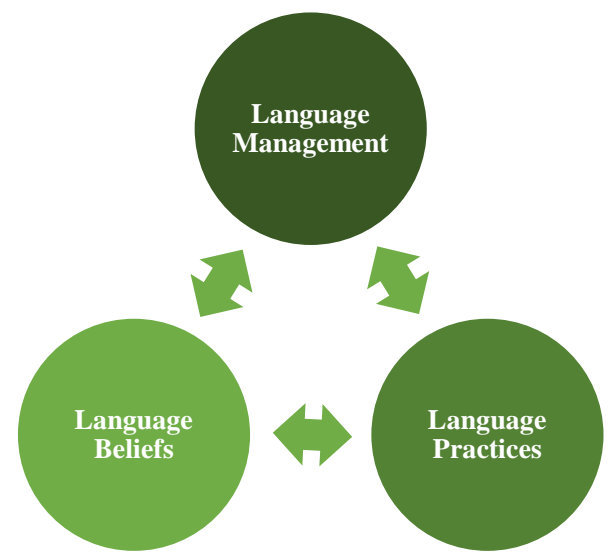

Figure 5.3: Visualization of Spolsky's (2004) model of language policy in this study

Furthermore, the dynamic nature of "attitudes" results in their changeability over people's lifetimes. The attitudes immigrants hold towards their heritage language and culture are not constant during their emigration years. Since the changes in parents' attitude are strongly influenced by their 
willingness to transmit the minority language to their children, longitudinal studies can yield a more complete picture of parents' attitudes towards heritage language transmission and maintenance.

In summary, positive parental beliefs do not guarantee heritage language maintenance. Measuring attitudes towards heritage language acquisition and maintenance should not only consider the beliefs individuals have about the heritage language, but also their language practices and management. In addition, studies that seek to find the impact of parental attitudes on heritage language acquisition and maintenance in young bilinguals should not rely on a quantitative investigation of parents' self-report data by itself. This qualitative analysis shed additional light on the rather unexpected finding of the quantitative investigation that parental attitudes did not seem to make a significant difference in various aspects of the heritage speakers' lexical proficiency. This unexpected outcome was mainly due to the small number of the participants in the quantitative investigation. The other reason might be because of the fact that the Likert-scale responses through the sociolinguistic questionnaire were not fine-grained enough to find relatively subtle betweenfamily differences in beliefs, practices and components as different layers of attitude.

Having conducted the first qualitative study, I found that the majority of Iranian parents in this study desired only for their children to have high conversational skills in Persian. In addition, as mentioned in Chapter 4, I deleted literacy as a variable in the quantitative studies since not many heritage speakers were Persian literate, although their results of lexical tests and lexical richness were found to be high comparatively. Conducting a study on what parents believe about Persian literacy and practice in relation to Persian literacy acquisition and maintenance can shed light of the indicated results from the quantitative section. Consequently, a need was raised to look more closely into the parents' attitudes towards their children's acquisition and maintenance of Persian literacy. 


\subsection{The second qualitative study: Parental attitudes towards heritage language literacy acquisition and maintenance ${ }^{6}$}

While having heritage language literacy abilities has been shown to play an integral role in heritage language maintenance (e.g., Schwartz, 2008; Hashimoto \& Lee, 2011; Zhang \& Koda, 2011; Kim \& Pyun, 2014), the development of heritage language literacy has remained under-researched (see Lee, 2013). Intergenerational transmission of heritage language literacy is a challenging task for immigrant parents. Commonly, immigrant parents report helping their children develop heritage language abilities through use in the home setting (e.g., Park \& Sarkar, 2007; Zhang \& Slaughter-Defoe, 2009; Nesteruk, 2010). However, previous research has almost exclusively focused on how this leads to the development of communicative competence (i.e., oral proficiency) in heritage speakers (e.g., Kondo, 1997; Lao, 2004); literacy development has been rarely investigated. Compared to oral proficiency, transmission of literacy skills in a heritage language is usually seen as a more difficult task (Tse, 2001a, 2001b; Lee, 2013), and families usually rely on community-based heritage language schools. However, when there is a lack of school support for heritage language education, responsibility for maintenance efforts falls to parents (Hinton, 1999) and this is also the case for Iranian immigrants in New Zealand.

Contrary to Krashen's (1996) concern that bilingual education is under attack, bilingual and mother tongue education have gained noticeable ground in the past decade (Brinton, Kagan \& Bauckus, 2008; Garcia, 2009; Wright, Boun \& Garcia, 2015, to name a few). This has been spurred on by the fact that a positive correlation has been shown between the development of minority/ heritage languages and societally dominant languages. For example, Cummins' interdependence hypothesis $(1979,1984)$ and model of Common Underlying Proficiency (CUP) (1981) support the idea of cross-linguistic transfer in languages (i.e., transfer of skills across languages). The interdependence hypothesis suggests that second language development is facilitated by the strong foundation of the first language (Cummins, 2000). In addition, common underlying proficiency "refers to the cognitive/academic proficiency that underlies academic performance in both languages" (Cummins, 2000, p. 38). Additionally, Krashen (1996) argues that literacy skills positively transfer

\footnotetext{
${ }^{6}$ This study has been submitted as the following article: Gharibi, K. \& Seals, C. A. (under review). Parental attitudes towards heritage language literacy acquisition and maintenance.
} 
across languages (even when languages do not share the same scripts such as Chinese and English). This strong correlation between literacy skills in first and second languages in bilinguals has commonly been documented in the literature (e.g., Cummins, 2000, 2007; Bialystok, 2001; Baker, 2011). As a result, the general ability to read and write in a heritage language facilitates the development of literacy skills in the societally dominant language as well.

The research on positive transfer has also led to research on parental attitudes towards bilingual education (e.g., Lao, 2004), which includes immigrant parents' efforts in starting community language schools (e.g., Shibata, 2000) and parents' roles in promoting heritage language literacy practices in home settings (e.g., Li, 2006). This research has revealed that a majority of immigrant parents would like their children to develop heritage language literacy skills. However, there are very few studies on immigrant families residing in areas where there are no community-based schools available (see Hashimoto \& Lee, 2011 for an exception). There have been even fewer studies focusing on immigrant parents' perceptions of the need to develop heritage language literacy for their children. The current study aims to contribute to these gaps by investigating what immigrant parents believe about developing heritage language literacy skills for their children in a geographical area where there are no heritage language community-based schools available.

The research questions addressed in this study on parental attitudes towards heritage language literacy acquisition and maintenance for their children are as follows:

1. What are Iranian immigrant parents' perceptions of heritage language literacy?

2. What are Iranian immigrant parents' beliefs, practices, and efforts regarding their children's literacy in the heritage language?

3. What are the challenges parents face in helping their children's heritage language literacy development and maintenance?

\subsubsection{Findings}

The participants' beliefs about heritage language literacy acquisition and maintenance for their children, their related practices and the parents' efforts to modify or influence language use in the home are presented in this section. These trends are discussed in relation to their fit with Spolsky's (2004) model 
of language policy as a methodological framework to explore parental attitude as a multilayered construct (as discussed in Section 5.2).

\subsubsection{Language beliefs}

\section{Lack of community-based heritage language schools}

Some heritage speakers in this study started schooling back in the home country prior to immigration and had some standard Persian literacy skills when they left the home country. However, the majority of children who were born in or moved to New Zealand before beginning school could not read and write in Persian. The parents of these heritage speakers commonly reported that they would like their children to learn Persian literacy skills, but they thought it was impossible because of lack of heritage language schools in their current cities of residence, a major barrier for immigrant parents (e.g., Li, 2006):

$$
\begin{aligned}
& \text { فرهاد: من كه خيلى دوست دارم ولى من كه نمىتونم يعنى نمىشه. اته كلاس بود }
\end{aligned}
$$

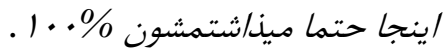

Farhad: I would like it a lot [to teach them] but I can't, I mean it's not possible. If there was a class here, I would send them for sure, $100 \%$.

This excerpt highlights the fact that Farhad believes the main reason for his children's heritage language illiteracy is a lack of Persian classes. However, he would like his children to develop Persian literacy skills if possible. Additionally, he expresses his perceived inability to teach his children Persian reading and writing, a worry shared by a majority of the participants in the study.

\section{Perceived inability in heritage language literacy teaching}

The parents of the bilinguals who were born in or immigrated to New Zealand prior to schooling repeatedly stated that they do not possess the skills to teach their children reading and writing in the minority language. However, they all reported that they support the idea of their children's literacy in the heritage language:

$$
\begin{aligned}
& \text { ناجى : با توجه به / ينكه / ينجا مدرسه نداريم، من خودم بايد شروع كنه. ولى مشكلى كه }
\end{aligned}
$$

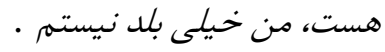


Naji: Considering the fact that there is no [Persian] school here, I have to start by myself. However, the problem is that I don't know much.

Naji in the above quote shows her awareness of the fact that since there is no community-based heritage language school available, the only way to help her son develop literacy skills in Persian is to become a home heritage language teacher (e.g., Zhang \& Slaughter-Defoe, 2009). However, she expresses her perceived inability to teach her child literacy skills. Additionally, she, as the majority of parents, was unsure when the best time for teaching Persian literacy is since their children just started learning English literacy at schools:

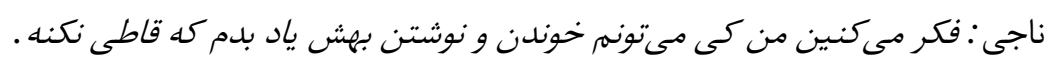

Naji: When do you think I can teach him Persian literacy, so that he does not get confused?

The above example shows that many immigrant parents do not have enough pedagogical knowledge or accurate information about dual language acquisition to help their children develop heritage language literacy. Consequently, immigrant parents need to be provided with educational resources and community-based programmes to get the answers to their questions.

\section{Becoming home heritage language teachers}

Although the majority of parents of the heritage speakers who were born in New Zealand felt unable to teach Persian literacy, there were a few parents who considered it really important and did their best to teach their children. The below quote shows one of these parents' belief about the importance of heritage language literacy for his son:

$$
\text { خديج: براتون مهمه آريا بتونه به فارسى حرف بزنه و بفهمه در آينده }
$$

Khadij: Is it important to you that Aria would be able to speak and understand Persian in future?

$$
\text { يوسف: و بخونه و بنويسه . }
$$

Yousef: And to read and write in Persian. 
Yousef's answer clearly shows that for him, developing Persian literacy skills is as important as conversational fluency. He explained later that he and his wife would like their son to be able to not only converse in Persian but also to be literate in the heritage language. This parent's high expectations of his child's abilities in the heritage language led to their explicit Persian-only family language policy and efforts to teach his son literacy in the heritage language. Compared to other parents in the current study, the fact that Yousef considers literacy skills as essential as conversational fluency in the heritage language is the main reason that led him to help his son develop these Persian skills. Conversely, the majority of parents desired only for their children to have high conversational skills in Persian, and they were mostly pleased if their children could speak in Persian with speakers from the home country. This example clearly shows that parents' ideologies (i.e., beliefs) shape visible and invisible language planning in the home setting for heritage speakers (CurdtChristiansen, 2009).

Although Yousef's son has been developing high proficiency in Persian literacy, his father still mentions lack of enough script material in Persian in the libraries. Yousef stated while his son is very interested in reading books, he can only do his daily reading and writing homework in Persian, and his reading for pleasure is limited to English books.

\section{The need for community-based heritage language schools}

The immigrant parents in this study, the majority of whom would like their children to develop and maintain literacy skills in the heritage language, reported that because of their perceived inability in teaching Persian and also lack of resources, they deeply feel the need for community-based Persian classes for their children. This is described in the following example by Sara, whose children had some Persian literacy prior to immigration:

$$
\begin{aligned}
& \text { سارا: من كرفتارم و كوتاهى مى كنه، به خاطر همين احساس نياز به يه آدم خارج از }
\end{aligned}
$$

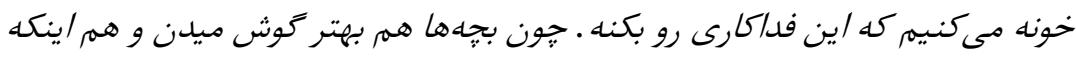

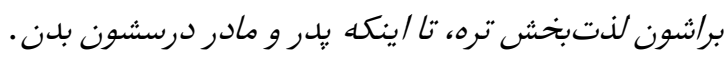

Sara: I am busy and I neglect [to practice Persian literacy with my children], for this reason we feel the need for someone outside of the home to make this sacrifice. Compared to having 
their parents teaching them [Persian literacy], the children would obey better and it would also be more enjoyable for them.

Sara states that the main reason she feels the need for a Persian teacher is that she cannot put what she sees to be enough effort into helping her children maintain Persian literacy skills because of her busy schedule. She also believes that the outcome of her children's proficiency would be better if they had someone other than their own parents as teachers of Persian. The choice of words by Sara (such as sacrifice) shows that she believes that the Iranian community should invest their time and effort to help the children develop and/or preserve their heritage language literacy. Taking this parent's choice of words into account to unpack the interwoven pieces of attitude as a multifaceted construct support the argument that it helps to consider how individuals report their attitude in addition to what they say.

\section{Heritage language literacy maintenance}

Some parents of children who started schooling back in the home country and had some Persian literacy when they moved to New Zealand, noted the importance of their children maintaining these skills. Thus, these parents expect their children to be able to read and write in Persian even if it is difficult to read and if spelling mistakes occur in writing. In addition, due to a lack of institutional support and community based schools, they believe that they are responsible for helping their children maintain the literacy skills they acquired prior to immigration as displayed in the example below:

$$
\text { مرضيه: خوشبختانه بجهها باسواد بودن كه ما /ومديم/ ينجا. ما فقط بايد حفظش كنيمر . }
$$

Marzieh: Fortunately, [my] children were [Persian] literate when we immigrated here. We should just maintain it.

In the above example, Marzieh, a mother of two heritage speakers who started schooling in Iran prior to emigration explains that she is pleased her children already knew Persian literacy when they left the home country. She also expresses her belief that it is parents' responsibility to help their children preserve literacy skills in the family language ("we should"). Furthermore, she expressed her worries about her children losing Persian literacy skills while in New Zealand. However, she stated that she is certain that her children are "old enough" not to lose their conversational fluency. 
Some parents described the importance of their children's Persian literacy maintenance by comparing them to other families without strong efforts to maintain their children's literacy skills, as Sara describes in the below example:

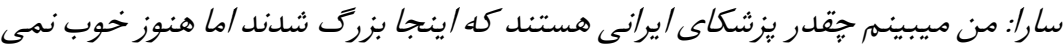

$$
\begin{aligned}
& \text { تونند فارسى بخونند و بنويسند، با /ينكه بلدر و مادرشون مقيد بودند . }
\end{aligned}
$$

Sara: I see many Iranian doctors who grew up here, but they still cannot read and write in Persian well, although their parents were committed [to Persian language maintenance].

This shows that parents "detect flaws" in other immigrant parents' bilingual parenting and try to avoid those in their own family language policy (King \& Fogle, 2006, p. 703). Sara in the above excerpt gives an example of unsuccessful Persian literacy maintenance to illustrate her ideology regarding the importance of it for her children. This example also illustrates her awareness that parents' commitment to heritage language use does not guarantee the development and maintenance of heritage language literacy for heritage speakers.

\section{The need to develop heritage language literacy}

While the parents in this study reported that they would like their children to have high levels of fluency as well as cultural knowledge, few of them believed that literacy can be a vehicle for both. Heritage speakers can develop cultural knowledge through learning to read and write, while being provided with many opportunities to improve their conversational proficiency in Persian in the host country. The incremental process of literacy development and the socialization heritage speakers go through with their teacher and coethnic peers provides them with opportunities to increase their conversational fluency in their ethnic language. In addition, the content of written material in their home language as well as access to the literature can help children to be familiar with cultural norms, and this can result in the development of their cultural knowledge.

As mentioned previously, I conducted this research on literacy when I found that the majority of participating Iranian immigrants consider conversational fluency in Persian a comparatively more important skill than literacy for their children. In addition to conversational fluency, I found that this 
immigrant community would reportedly like their children to have high cultural knowledge. The majority of parents in this study emphasized that they would like their children to learn some values in the Iranian culture (such as respecting the elders), and they commonly invest in teaching their children some aspects of their ethnic culture. To report their attempts in this regard, some of these parents stated that they tell their children cultural stories from Persian literature to highlight cultural values for them. To illustrate this point, Bahar, a single mother, explained how important it is for her to use written literature in Persian in teaching her son Persian values:

$$
\begin{aligned}
& \text { بهار: من دوست دارم كالجرال استورى ياد بكيره. براى كاوه تعريف مى كنهر هر شب }
\end{aligned}
$$

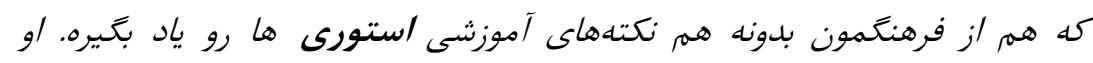

$$
\begin{aligned}
& \text { هم خيلى دوست داره . }
\end{aligned}
$$

Bahar: I would like him to learn [our] cultural stories. I tell

Kaveh [cultural stories] every night to learn about our culture as well as the moral of the stories. He loves it so much.

The example above demonstrates how some parents in this study apply Persian literature to increase their children's cultural knowledge, a priority in their upbringing. Heritage speakers can also develop cultural knowledge through written material in their family language when they are able to access it by using their literacy skills, a fact the majority of parents were not aware of. This understanding of developing cultural knowledge through literacy was shared by a few parents, as shown by Parirokh in the following example:

$$
\begin{aligned}
& \text { بريرخ: بهشون ميكم /صلا دلم نميخواد /ون /دبياتى كه من ميدونم شما /ز دست بديد. }
\end{aligned}
$$

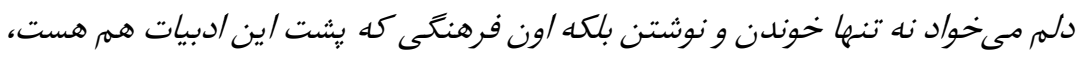

$$
\begin{aligned}
& \text { ياد بَّيرند . }
\end{aligned}
$$

Parirokh: I tell them I don't want them to lose the [Persian] literature that I know. I want them to learn not only reading and writing, but also the culture behind the [Persian] literature.

Parirokh is aware of the fact that developing heritage language literacy skills enables her children to learn about the literature of the heritage language and heritage culture, which develops their cultural knowledge in their ethnic language. She also emphasized that her children could become familiar with cultural values through Persian literature by learning how to read and write their heritage language. This quote is a strong example of the argument that literacy enables heritage speakers to develop cultural knowledge. Therefore, it can be 
suggested that the Iranian parents in the current study would like their children to have cultural knowledge, even if they do not believe it can be accessed through literacy development.

Overall, most of the Iranian parents in the study reported not putting much deliberate efforts into helping their children learn Persian literacy skills, despite the fact that they consider heritage language literacy very important for their children. Although they stated a lack of community-based schools as the main reason, I argue that it can at least in part be attributed to their beliefs about literacy. The majority of parents in this study viewed literacy just as an ability to encode and decode texts, and they were not aware of the role it can play in increasing their children's conversational proficiency as well as cultural knowledge. Accordingly, the parents may not feel that their children need to develop heritage language literacy skills in their new environment. Therefore, it can be argued that if the immigrant parents view literacy as a way to develop conversational fluency and cultural knowledge constructed by negotiation and communication in the language as well as cultural norms and practices in socially appropriate situations, they are likely to invest more in the development and maintenance of heritage language literacy for their children.

Furthermore, while immigrant parents in this study commonly reported that they would like their children to learn Persian literacy, some of them mentioned that their children do not feel the need to invest in learning heritage language literacy as long as they live in New Zealand. Narges' daughter, Raha, does not feel she needs to learn Persian literacy skills in her current environment:

$$
\text { رها: احساس مي كنهم لازم ندارمش، شايد اته مى خواستهم برم/يران و اونجا درس بخونمه }
$$

Raha: I feel I don't need it. I might keep learning it, if I wanted to go to Iran to study. However at the moment, I don't [keep up learning].

The above example can be explained through investment theory (Norton, 1997; 2000; 2013). This theory "offers a way to understand learners' variable desires to engage in social interaction and community practices" (Norton, 2013, p. 8). Raha feels that as long as she lives in New Zealand and there is no authentic need for using Persian literacy, she does not need to invest in developing Persian literacy skills because she does not believe she will gain any necessary symbolic capital (Bourdieu, 1989) as a result. Bourdieu (1989, p. 
23) defines symbolic capital as "the power granted to those who have obtained sufficient recognition to be in a position to impose recognition". In other words, learning Persian does not give Raha social prestige in the host country as she believes. Raha did not consider learning Persian literacy a credit in New Zealand and as a result she did not continue to put efforts in learning it. Heritage speakers are motivated to develop literacy skills only if they perceive an authentic need or gain in the use of heritage language literacy (Tse, 2001a, 2001b; Hashimoto $\&$ Lee, 2011). Also relevant is the notion of imagined community (Anderson, 1991; Norton, 2001; Pavlenko \& Norton, 2007) which can be defined as "groups of people, not immediately tangible and accessible, with whom we connect through the power of imagination" (Norton, 2013, p. 8). Considering her ideal imagined community in New Zealand, Raha does not see any advantage in developing skills she may not need to use in the second language environment as a community she imagines herself living in the future. Additionally, the fact that the majority of parents intend to stay in the second language environment and feel no need to invest in Persian literacy teaching for their children, can be analyzed through the lens of investment theory.

\section{The perception of bilingualism and biliteracy}

Another finding of this study was the difference between the Iranian parents' beliefs towards biliteracy and bilingualism compared to those of immigrant parents in other communities. Unlike the Japanese parents in Hashimoto and Lee's study (2011), the participants in this study did not consider heritage language literacy to be a prerequisite for their children's bilingualism. In their study, the parents believed that their children "could not be bilingual without being biliterate" (Hashimoto \& Lee, 2011, p. 176). The majority of the Iranian parents, unlike the mentioned Japanese parents, believed that their children only need to be able to speak and understand the language. In the example below, Saeed's children only developed receptive knowledge in Persian, mainly because he and his spouse use Persian and English at home when talking to their children, and their children speak with their parents only in English (see Figure 5.2). Yet Saeed believes that his children are bilingual, as shown in the example below:

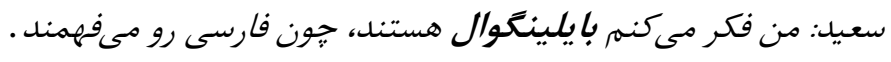

Saeed: I think they are bilingual since they understand Persian. 
While Saeed in the above example considers receptive ability in the heritage language as the only skill for his children to be considered bilingual, it is interesting to note that a parent in Hashimoto and Lee's (2011) study was skeptical about his children's bilingualism although they were "near nativelike" in Japanese oral proficiency with not very high heritage language literacy skills (p. 177). This finding reveals that the participants in the current research commonly consider oral fluency as the only prerequisite for being considered bilingual, while the participants in Hashimoto and Lee (2011), used biliteracy and bilingualism interchangeably throughout the interviews. On the other hand, there were few parents who considered literacy as a requirement for their children to be considered bilingual, as illustrated in the following example:

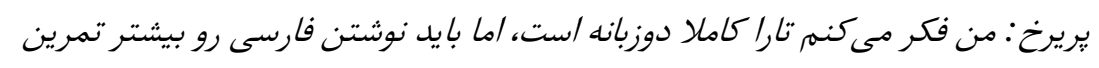

Parirokh: I think Tara is completely bilingual, however she needs to work on her Persian writing.

This example exemplifies that while this mother considers her daughter bilingual, she believes that her daughter needs to invest more in her literacy skills. Tara herself further explained that she needs to read books in Persian to maintain her literacy skills as well as to increase her vocabulary knowledge (Tara, June 2013). The above quotes revealed that the immigrant parents in this study have different views about the required heritage language skills (i.e., speaking, listening, reading and writing) for bilingualism. However, the majority of them do not necessarily conceive of biliteracy as a prerequisite for bilingualism.

Although the parents in the present study reported mostly that they believe their children should acquire and maintain their heritage language, this does not seem to extend to their practices regarding helping their children to develop literacy skills in their family language. However, as shown in the following sections, parents who do believe that literacy skills are also important do not always have practices and management strategies that conform to their beliefs.

\subsubsection{Language practices}

The findings of family practices regarding heritage language literacy illustrate that the majority of parents were not actively involved in purposeful 
heritage language activities for their children. However, they had mostly positive beliefs towards their children's developing heritage language literacy skills. The parents of heritage speakers who started schooling back in the home country and had some Persian literacy prior to immigration, reportedly encouraged their children to preserve their literacy skills. To do this, some parents gave them daily or weekly homework. These parents' efforts in teaching and maintaining their children's literacy skills in Persian can be explained by using the investment theory (Norton, 1997; 2000; 2013). The parents who are likely to go back to the home country choose to invest in Persian literacy because of the "imagined community" (Anderson, 1991) they envisage for their children.

While it was found that, in practice, the majority of parents in this study do not have time for this, a few of the parents who plan to go back to the home country were actively engaged with their children's Persian literacy maintenance, for the purpose of catching up with the school curriculum in Iran when they return. The majority of parents whose children were born in or moved to New Zealand before their schooling age reportedly taught their children the Persian alphabet and a few simple words, but they stated that they stopped mostly because of their busy schedules:

$$
\begin{aligned}
& \text { سبا: ما بارسال شروع كرديم ياد دادن حروف فارسى بهش. اما حقيقتش به دليل شلوغى }
\end{aligned}
$$

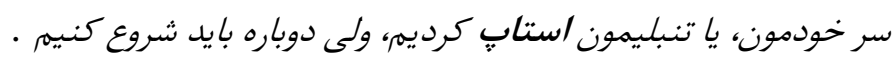

Saba: We started teaching her Persian characters last year, but to be honest, we stopped because of our busy schedule or our laziness. We should start again though.

Saba's choice of words implies that the reason for not investing in their children's heritage language literacy teaching is not only their busy schedule but also their lack of energy and motivation. There was just one heritage speaker who moved to New Zealand at the age of two whose parents have been teaching him Persian literacy since he was six. He was able to read and write even difficult texts in Persian. He also had higher scores in the test results and relatively narrow gap in comparison with his monolingual benchmark in the quantitative investigation. He had daily homework in Persian, and it was clear how much time and effort the parents spent on his homeschooling in Persian. It is interesting to note that the father was a postdoctoral fellow in education and has enough knowledge to teach his son the literacy skills. Therefore, this case agrees with prior findings that higher educated immigrant parents are more 
likely to foster biliteracy than parents with little education (e.g., Portes \& Hao, 1998).

\subsubsection{Language management}

\section{Overcoming the challenges of heritage language literacy development}

As discussed, some parents in the current study who would have liked to encourage their children to develop Persian literacy did not manage to teach them because of perceived inabilities or busy schedules. One of the ways these parents found for their children to still develop literacy skills is through visiting the home country. A few parents hired Persian tutors during their visits to Iran to teach their children reading and writing in the family language, as explained by Alborz in the following example:

$$
\text { البرز: ما /يران كه رفتيم، فارسى كلاس اول رو براش دو ماه معلم خصوصى كرفتيم. }
$$

Alborz: We hired a tutor for her for two months during our visit to Iran.

The above example is a good strategy for those parents who have the adequate resources and wish to invest in biliteracy for their children, but do not or cannot teach their children themselves. Additionally, the findings show that some heritage speakers seem to become self-motivated to learn Persian literacy when visiting the home country, as described by Narges in the example below:

$$
\begin{aligned}
& \text { نركس: حتى /يران كه بوديمه دختر برادرم داشت به رادين ياد ميداد الفابت رو. دوست } \\
& \text { هم داشت ولى وقتى بركشتيم/ ينجا ادامه نداد. شايد كوتاهى /ز ماست . }
\end{aligned}
$$

Narges: When we were visiting Iran, my niece was teaching Radin some of the alphabet. Although he loved it, he did not keep up when we came back here. It is probably our fault.

Narges in the above example describes how visiting Iran helped her son to learn Persian literacy from his peers in the extended family. However, she notes that her son did not continue to invest in heritage language literacy skills upon returning, likely because Persian literacy was not seen as needed for his imagined self in New Zealand. The same parent reported that her daughter believes she primarily developed Persian literacy knowledge during their visits to Iran: 


$$
\text { ايران كه رفتي رها يه ترم رفته كلاسه فارسى ينجا، اما ميكَه اصلا حساب نمىشه. ميكَه بيشتر }
$$

Narges: Raha went to a Persian class for one term, but she says it doesn't count. She says she learned [Persian literacy] mainly when we went to Iran.

As the above example shows, although Raha went to a former community-based Persian class in New Zealand for one term, she attributed her Persian literacy skills to her Iranian peers during visits to Iran, which shows the importance of peer socialization in language learning investment. Raha's investment was influenced by her local peer groups, and thus her imagined community in each location. There were not any community heritage language schools in New Zealand at the time of the current study, but a few heritage language classes are held in different cities in the country occasionally by members of the community. Raha in the example above used to go a Persian class for heritage speakers by a member of the Iranian community for one term in her city of residence. This also highlights the role community members can play in heritage language maintenance when there is no institutional support for heritage languages (Cunningham-Anderson \& Anderson, 2004; Shibata, 2000).

\section{Lack of enough resources}

In addition to parents' busy schedule as a difficulty in helping their children develop their heritage language literacy skills, lack of appropriate teaching material and books was another reported challenge in teaching and maintaining heritage speakers' Persian literacy. Some parents stated that they brought DVDs from Iran for their children to learn Persian reading and writing, but their children only used them a few times. The parents also reported a lack of books and written materials in Persian. They noted that while they brought some Persian books from Iran to New Zealand each time they went to visit, the children stopped reading them after a few times:

$$
\begin{aligned}
& \text { سارا: كتاب كه يه مقدار با خودشون آوردن ولى جون خوندن ديًاه مجددا برنميكردن }
\end{aligned}
$$

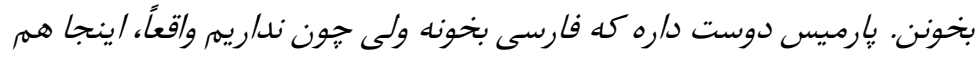

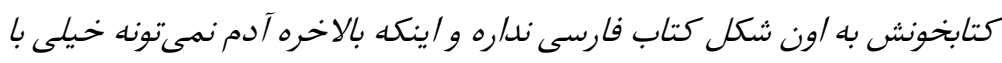

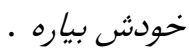


Sara: They [my children] brought some books with them, but they don't read them more than once. Parmis would like to read in Persian, but we really don't have any [books]. There are not many books in Persian in the library here. It's also not possible to bring many books [during each visit].

In this excerpt, this mother explains that her children brought some books from the home country back to New Zealand, but they hardly read them more than once. She also refers to her daughter's willingness to read in Persian, but she does not have enough access to Persian books, since there are not many Persian books at the libraries in New Zealand. Sara also notes that they cannot bring home many Persian books each time they visit Iran. As mentioned, Yousef, who taught his son reading and writing in Persian, also commented on a lack of Persian books, although his son is keen to read books. Limited access to materials and resources is one of the main challenges parents face even if they are very committed to teaching their children literacy skills (Hashimoto \& Lee, 2011).

\section{Lack of incentives for heritage speakers to develop Persian literacy}

One of the challenges reported by the participants was that their children were reluctant to invest in developing literacy skills in their heritage language. As discussed, it seems that many heritage speakers do not see any use for learning Persian literacy in the second language environment and thus do not invest in it. Heritage speakers engage in developing ethnic language literacy skills if they perceive an authentic need for that (Hashimoto \& Lee, 2011). One way to facilitate heritage language literacy in bilinguals is to persuade them to become involved in various literacy related-activities (Kim \& Pyun, 2014). To do this, some parents tried to encourage their children to write a poem or a text in Persian and to read it for other families when they had a gathering, which seemed motivational for children to improve their Persian literacy.

Heritage speakers should also be provided with opportunities to use their heritage language literacy skills in the family and community. These opportunities help them feel the need to develop and maintain their literacy skills, as seen in the following example:

$$
\text { تونست . بون روز تو انجمن /يرانيها، به تارا كفتند/سم/ /ونهايى كه بول دادند رو بنويس. }
$$


Parirokh: At Iranian Community, the other day Tara was asked to write the names of people who donated [in Persian]. She could.

This parent was pleased that her daughter, who had Persian literacy skills prior to immigration, maintained her writing skills and was able to use her literacy skills when needed. This example is an illustration of the role communities can play in providing heritage speakers with incentives to develop and/or maintain their literacy skills and also with opportunities to use those skills (Chao, 1997; Shibata, 2000; Li, 2005). Ethnic communities "promote both instrumental and integral motivations to develop the language through utilization and participation in cultural activities and to foster the family's ethnic identity and value" (Shibata, 2000, p. 472). Therefore, communities can not only facilitate opening heritage language schools by providing funding, recruiting teachers and other requirements (Cunningham-Anderson \& Anderson, 2004), but also create environments for heritage speakers to socialize with their co-ethnic peers and adults, resulting in development of their conversational fluency as well as cultural knowledge.

\subsubsection{Conclusion of the study on parental attitudes towards heritage language literacy acquisition and maintenance}

The present study examines Iranian immigrant parents' perceptions of heritage language literacy for their children. In addition, following the first qualitative study, it utilized Spolsky's (2004) model of language policy as a methodological framework to conceive of parental attitude as a multilayered construct. Consequently, it explores their practices, beliefs, and management strategies regarding their children's heritage language literacy acquisition and maintenance.

The findings from the current study revealed that Iranian immigrants, like other communities (e.g., Kondo, 1997; Sakomoto, 2006), are more committed to developing their children's oral proficiency through the use of the heritage language at home, compared to developing heritage language literacy. While literacy in the heritage language was not viewed as a key skill to most parents, conversational fluency was viewed by them as very important. Accordingly, acquisition and maintenance of heritage language literacy was very uncommon for the heritage speakers, and the parents believed that this was due to a lack of community-based heritage language schools in the host country. 
As previously noted, I could not include heritage language literacy as a variable in the inferential statistics in the quantitative investigation, because few bilinguals were able to read and write in the heritage language. However, the Persian-literate heritage speakers had higher scores in the test results as evidenced in the quantitative investigation. While one of the heritage speakers who were able to read and write in Persian had highest scores on the test results, some Persian-illiterate bilinguals did not have enough tokens in their speech samples to be considered in the lexical diversity and sophistication analyses mainly due to their low heritage language proficiency.

As this research shows, there are meaningful differences between heritage language speakers' conversational fluency and their literacy abilities. While some of them had high conversational proficiency in their heritage language, they were not able to read or write in Persian (i.e., low literacy abilities). Although the majority of parents reportedly consider lack of heritage language community-based schools as the main reason for their children's Persian illiteracy, it seems that this originates from their perception of literacy. The majority of them viewed literacy merely as the ability to read and write, seeming to be unaware of the fact that being able to read and write in family languages provides heritage speakers with opportunities to develop their conversational proficiency as well as cultural knowledge in the process of learning reading and writing in the heritage language, although they would like their children to have high levels of both. While they desire for their children to have high communicative competence and cultural knowledge as members of the Iranian community, they did not consider heritage language literacy very important for them. Consequently, they were not aware of the role literacy can play in heritage language maintenance.

In addition to raising immigrant parents' awareness of the role literacy can play in heritage language maintenance, this study argues for a change in parental approaches to literacy development and maintenance for heritage speakers. How immigrant parents in this study viewed literacy (as merely the ability to read and write) made them neglect the socialization heritage speakers go through in the incremental process of literacy development with their teacher and co-ethnic peers. This socialization encourages investment in the heritage language community and imagined heritage language self, which has the potential to lead to greater conversational fluency, cultural knowledge and literacy development.

Parents' affiliation with heritage language literacy development and maintenance can also be investigated through the concept of investment 
(Norton, 2000) which can be used as a "significant explanatory construct" (Cummins, 2006, p. 59) in this contribution. It seems that the "imagined community" (Anderson 1991) parents envision for their children in the future can be a good predictor of their investment in heritage language literacy development and maintenance. In other words, parents choose to promote investment in conversational fluency and cultural knowledge within the home, as they see this as tied to heritage language speaker identity, while they see literacy as unrelated and not part of their children's imagined identities as heritage language speakers and legitimate members of the diaspora community.

This study also explores the challenges the participants go through regarding their children's heritage language literacy acquisition and maintenance. In addition to the parental beliefs about literacy skills as well as lack of heritage language community-based schools, lack of resources such as heritage language written material and time was another challenge resulting in Persian illiteracy of heritage speakers.

Finally, this study has implications for small immigrant communities residing in areas with no or few heritage language schools available. Community-based schools can play an influential role in heritage language acquisition and maintenance. Although these schools suffer difficulties such as lack of appropriate teaching material and trained teachers (Kondo, 1997; Lee, 2002), immigrant parents in this study rely on them for their children's heritage language literacy development and maintenance. Community-based schools not only provide heritage speakers with literacy education in their family language, but also with an environment they can socialize with their teachers and co-ethnic peers (see Lee, 2013) and develop their conversational fluency and cultural knowledge. These schools can also provide reading materials for children as well as the guidance and knowledge immigrant parents need in helping their children with heritage language literacy acquisition. Heritage language literacy development deserves further attention from immigrant communities, heritage language researchers, and educators alike.

\subsection{Discussion of the qualitative investigation}

The qualitative investigation of the dissertation examines Iranian parents' attitudes towards their children's heritage language acquisition and maintenance. The participants consisted of twenty-four parents who have been living in New Zealand between 1-30 years. Their children, who were my main 
participants in the quantitative investigation, were thirty 6-18 year old PersianEnglish bilinguals (14 boys and 16 girls) with different lengths of stay in the host country. The parents who participated directly in the study were mostly mothers (seventeen mothers and seven fathers).

The first study in this investigation explores immigrant parents' attitudes towards their children's heritage language development and maintenance. Scholars have not reached an agreement on the operationalization of attitude (Ó Riagáin, 2008; Garrett, 2010). This qualitative study has aimed to present an expanded methodological framework for examining parental attitudes in the context of family. Spolsky's (2004) model of language policy was employed as a lens to illustrate the multifaceted construct of attitude. As visualized in Figure 5.1 , attitude in this study is conceived of different interwoven layers of beliefs, practices and management. The data - which were extracted from the semistructured interviews with the parents - were explored to grasp a holistic picture of parental attitude by taking the parents' beliefs, practices and efforts towards heritage language into consideration.

The findings revealed that the Iranian immigrants in New Zealand have positive beliefs towards their culture and minority language, as well as strong intentions to pass on the heritage language to their children. It was also found that those who put much effort into their children's heritage language maintenance as well as those whose children have low level proficiency in Persian strongly believe that it is their responsibility to help their children acquire and preserve proficiency in the heritage language by using it at home. Cultural identity, communication with the extended family, and advantages of bilingualism were the reasons the parents reported for heritage language maintenance and their regret in the case of heritage language loss. Knowing these reasons can certainly assist communities and educators who aim to support heritage language acquisition and maintenance in multicultural societies.

Persian has been used in all the families as one of the main languages of the home, but the amount of heritage language use differed between and within the families. The majority of the parents used the heritage language as the main language of the home to communicate with their children, however not all of them had a policy for heritage language use in the family. In those families who had a heritage language-only policy, the parents believed that this policy has been internalized for their children and they use Persian as the default language of the home. This internalized Persian-only policy led the children in some of these families to reportedly speak in the heritage language with their parents and even with their siblings in the presence of their parents. Some of the parents 
who often use their minority language, though with no explicit language policy, had to use Persian as the language of parenting due to their low level of proficiency in English as the societally dominant language. Their children are reportedly aware of their parents' low English proficiency and choose to use their heritage language conversing with them. An implication of this finding is that language use in immigrant families is not always determined by a clear family language policy. In the case of these families, their "no-policy policy" (Fishman, 2006) is in favor of heritage language maintenance, since they use their ethnic language as the main language of the home due to their low English proficiency rather than a family language policy. Furthermore, this finding implies that parents' proficiency in the dominant language of their host country should be taken into account in studies of family language policy.

There were also parents who believed that their children need to use the majority language in the family context and they give them this sense of freedom to choose the language for communication with family members. In these families, the heritage speakers generally had lower proficiency in Persian (as evidenced by the test scores in the quantitative investigation) as a result of less opportunity to practice it. Of the families participating in this study, there was just one family whose children had developed receptive proficiency in the heritage language as well as very limited productive knowledge.

Social network was explored as a part of the language practice component. Although the Iranian immigrants spend more time with their friends from the home country, it seems that it does not provide the heritage speakers with many opportunities to practice Persian, since the children reportedly converse in English with their co-ethnic peers as they also do at school. Visiting the home country was noted as having a fast positive impact on children's Persian proficiency. However, as soon as they return to the host country, they usually start to lose the proficiency they developed during their visit. Having phone and video calls with the home country as well as watching Persianspeaking movies, despite its impact on heritage language acquisition and maintenance, were not commonly applied by the families in this regard. A practical implication of these findings is that immigrant families can invest more in their children's exposure to their heritage language by providing them with any possible opportunities through social network, visiting home country, contacts with their home country and watching movies in their ethnic language.

The role of encouraging the children to use Persian, which was considered a part of the language management component in the model of language policy, was highlighted when the heritage speakers started their 
schooling. The majority of the parents faced challenges with family language use at this time, since the children tended to use English at the home as they did at school with their peers. Another interesting finding of this study was the impact of teachers on heritage language maintenance in New Zealand. The parents of these children stated that they were advised by their children's teachers as well as (other) monolingual English speaking New Zealanders to keep using Persian at home to raise their children bilingually. This finding clearly shows that bilingualism seems to be valued in New Zealand education and society (e.g., Bell, Harlow \& Stark, 2005; Ward \& Masgoret, 2008). This finding highlights the role school teachers can play in promoting heritage language use in immigrant families. It also suggests that Iranian immigrant parents in New Zealand seem to acknowledge advice from their children's school teachers in their decisions regarding family language use. Additionally, it clarifies immigrant families' need for language consultants to help them with heritage language use in the family, including their children's heritage language acquisition and maintenance. This need was also raised when the parents had many questions on different aspects of teaching their children how to read and write in Persian with no heritage language community schools available.

Although parental language ideology has been identified as the underlying force in parental decisions on family language use (CurdtChristansen, 2009; 2013), there are discrepancies between parental language ideologies and family language practices in this study. In light of these inconsistencies between parents' beliefs and their actual family language practices and efforts to preserve the heritage language, this study suggests that analyses of migrant language attitudes towards heritage language maintenance should not only consider their beliefs towards minority language maintenance, but also their language practices and management. The first study in the qualitative investigation demonstrated that the model of language policy provides a methodological framework for understanding parental attitudes in the context of family. Having conducted this study, I found that the majority of Iranian parents in this study desired only for their children to have high conversational skills in Persian. This finding led me to look into the parents' attitudes towards acquisition and maintenance of heritage language literacy for their children.

The second study in the qualitative investigation aimed to examine how immigrant parents conceive of developing heritage language literacy skills for their children in New Zealand (with no institutional support for Persian and few community-based schools), where the responsibility for Persian literacy 
acquisition and maintenance rests on parents' shoulders (Hinton, 1999). Following the first study in this investigation, the parents' beliefs, practices and management strategies were explored to see how they shape the basis of their attitudes towards their children's heritage language literacy acquisition and maintenance.

The findings revealed that although the majority of parents would like their children to learn how to read and write Persian, the development and maintenance of Persian literacy was not very common in the heritage speakers, which the parents attributed largely to the lack of community-based heritage language schools in the host country. It was also found that while conversational fluency in Persian and Iranian cultural knowledge was continuously positioned as being extremely important for the heritage language speaking children, it was not seen as connected to traditional literacy. The parents did not commonly see literacy bringing their children the outcomes that they would like them to develop (i.e. communicative proficiency and cultural skills). Otherwise, they would be likely to invest more in their children's heritage language literacy education.

Furthermore, a perceived inability was reported by the majority of the parents in this study in becoming heritage language teachers, which was the only way to support their children's literacy in New Zealand without institutional support for Persian. Because of this perceived inability in teaching Persian and also lack of resources, such as time and written materials in the heritage language, the participants deeply feel the need for community-based Persian classes for their children. This study, additionally, argues that the parents' practices and efforts in heritage language literacy development and maintenance can be explained through the concept of investment (Norton, 2000). It seems that parents invest in their children's Persian literacy acquisition and maintenance based on the "imagined community" (Anderson, 1991) they envision for their children in the future. In other words, parents choose to promote investment in communicative skills and cultural knowledge within the home, as they see this as tied to heritage language speaker identity, while they see literacy as unrelated and not part of their children's imagined identities as heritage language speakers.

Considering both studies, the qualitative investigation of the dissertation has a number of important implications. First and foremost, the two studies called for more attention to the multifaceted nature of "attitude" in studies that aim to examine this construct. The findings of both studies suggest that this multilayered construct has been simplified in studies that use beliefs and 
attitudes interchangeably, resulting in their failure to collect data to represent peoples' attitudes.

In addition, the second study revealed that literacy is not just the ability to read and write (as viewed in traditional approaches). When literacy is viewed as a social act, it provides heritage speakers with opportunities to develop their communicative skills through communication and negotiation in their family language with their co-ethnic adults and peers. It also helps them access the literature in their heritage language to build up their cultural knowledge. If immigrant parents and communities view the cultural knowledge heritage speakers can develop through developing literacy, they would likely invest more in heritage language literacy acquisition and maintenance for their children.

Finally, a practical implication of this investigation is in the use of interview data. As mentioned earlier, the first qualitative study was launched to examine if a more in-depth analysis of the interview data might reveal evidence of the influence of heritage language use and parental attitudes on heritage speakers' proficiency in their family language, something which was not clearly shown in the quantitative investigation. Conducting a qualitative investigation in conjunction with a quantitative investigation portrays a clearer image of the heritage speakers' proficiency as well as their parents' beliefs, practices and efforts in relation to Persian acquisition and maintenance. A further methodological implication of this project is that mixed-method analysis of heritage language acquisition and maintenance provides us with more reliable results. It may be argued that in the quantitative investigation of this dissertation, the sociolinguistic variables did not turn out as significant predictors of the heritage speakers' Persian proficiency because the quantitative product of the interview data were investigated. However, in the qualitative analysis, analyzing how the participants negotiated their beliefs, experiences, practices and efforts over the interviews helped to grasp a more holistic picture of the impact of parental attitudes and heritage language use on heritage speakers' family language proficiency. 
CONCLUSION 


\section{Chapter 6 : Conclusion}

This final chapter outlines the theoretical, methodological and practical contributions of this project and discusses some directions for future research.

\subsection{Implications of this research project}

Conducting a quantitative analysis on heritage speakers' lexical knowledge in conjunction with a qualitative investigation of their parents' attitude towards heritage language acquisition and maintenance made this research project unique in the literature, to my knowledge. Among the contributions of this research project, an important implication is to support the use of mixed-method studies to provide us with a more accurate and holistic image of incomplete acquisition, attrition and maintenance of heritage speakers' competence in their family language. As noted earlier, I began my $\mathrm{PhD}$ with the quantitative investigation on incomplete acquisition and attrition for Iranian heritage speakers in New Zealand. Conducting this investigation provided me with a clear overview of different proficiency levels of the heritage speakers compared to each other and to their matched monolinguals as well. The quantitative investigation used the parents' responses to Likert-scale questions of the socio-linguistic questionnaire. These questions concerned the parents' self-reported beliefs, practices and efforts in helping their children to acquire and/or maintain their family language, a compound variable for parental attitude. However, it failed to demonstrate a very clear picture of the influential factors in incomplete acquisition and attrition of their family language. Contrary to the expectations, the compound variable of parental attitude from Likert-scale responses did not correlate strongly with all lexical proficiency scores (i.e., productive and receptive vocabulary knowledge, lexical diversity and lexical sophistication) of the children. Therefore, I hypothesized that this might be due to the fact that the socio-linguistic questionnaire as such was not sensitive enough as an instrument to uncover the differences between parental attitude that were expected to predict children's lexical proficiency. The other reasons are rooted in the limitations of this project. One was the small number of the participants in each group: thirty heritage speakers and thirty matched monolingual speakers. Because of the small communities of Iranians in different cities in New Zealand, I could recruit adequate number of participants for statistical analysis; however, it did not provide enough variability in the sociolinguistic data. 
Consequently, a need for a qualitative investigation was raised to dig into the data to understand the impact of the heritage speakers' Persian use in the second language environment and the parents' attitudes towards heritage language acquisition and maintenance. Although relying on parents' self-report data is another limitation of this project, the qualitative investigation, compared to the quantitative investigation, helped to understand how these immigrant parents' beliefs, practices and management strategies in relation to the heritage language lead to their children's different proficiency. Its detailed analysis of how the parents reported their beliefs, practices and efforts during the interviews in addition to their answers to the Likert-scale questions yielded a finer-grained picture of parental attitudes which helped detect differences between parents' attitudes that were not captured in the form of questionnaire responses.

Investigating the heritage speakers' competence in the family language through a quantitative analysis along with a qualitative analysis of their parents' attitudes allowed me to grasp a thorough understanding of their heritage language development in the second language environment. None of these investigations by themselves could have provided the holistic picture of the heritage speakers' proficiency in their family language and the impact of family environment on incomplete acquisition, attrition and maintenance of their home language. In addition, the qualitative data gave me the opportunity to explore the parents' attitudes towards heritage language literacy acquisition and maintenance for their children, a variable I could not include in the purely quantitative study because there were few heritage speakers in the sample who were Persian literate. It also helped me to speculate about potentially influential factors for heritage language acquisition/maintenance that could inform largerscale quantitative or qualitative work in future. As a result, an enriched sociolinguistic questionnaire for investigation of parental attitudes or family language policies can be created based on the qualitative analysis. Factors such as negotiation of family language policy with heritage speakers can be added to the questionnaire, since the qualitative analysis has shown that the children of the parents who reportedly negotiate the importance of heritage language acquisition in the family happened to have higher Persian lexical proficiency. So, qualitative findings can help fine-tune quantitative research instruments, and this is how a research discipline advances.

While in Part I on incomplete acquisition and attrition, I examined the competence of the heritage speakers compared to other bilinguals and their matched monolinguals, in Part II on heritage language acquisition and maintenance, the ways in which the heritage speakers differ in their home 
language proficiency as a result of their parents' attitudes were explored. Therefore, in this research project, I not only explored what is missing in the heritage speakers' competence in their family language from the attrition perspective, but also I investigated what they gained in their home language in the host country with limited input and output (from the additive perspective). This innovative methodology to investigate heritage speakers' vocabulary knowledge quantitatively along with a qualitative study to explore their parents' attitudes provided a very clear image of the heritage speakers' competence as well as their family environment as the main place they are exposed to input in their home language.

Incomplete acquisition and attrition of heritage languages are underresearched (Montrul, 2008; Schmid, 2011). As discussed in Chapter 2, the literature on incomplete acquisition or attrition in heritage speakers is mainly based on studies that examined their grammatical competence (e.g., Montrul, 2008; Polinsky, 2006), and fairly little attention has been paid to their vocabulary knowledge (Montrul, 2009). The quantitative investigation on young heritage speakers' vocabulary knowledge has further contributed to the literature in these areas of research. Additionally, one of the major implications of this quantitative investigation lies in its methodology. As previously mentioned, the methodology applied in this investigation has commonly been used in studies of language attrition in adult bilinguals (see Schmid, 2011). Applying the same methodology in studies of language attrition in young heritage speakers may therefore provide a basis for future research in this area. In addition, it certainly helps to compare and contrast language attrition in adult and young bilinguals.

Teasing apart different young bilinguals as simultaneous and sequential heritage speakers is another contribution the quantitative investigation makes. As discussed, Montrul (2008, p. 98) asserts, it is important to distinguish between simultaneous and sequential bilingualism when investigating processes of incomplete acquisition and attrition in childhood. Studies on simultaneous and sequential bilinguals by exploring the influence of input in relation to age, contribute to a gap in the literature on the role of input and age on heritage language acquisition as was addressed in some studies (e.g., Unsworth \& Blom, 2010; Unsworth, 2016). The studies in the quantitative investigation also showed the different influential factors in the simultaneous and sequential bilinguals' vocabulary knowledge in their family language. Parental attitude turned out as the strongest predictor in simultaneous bilinguals, while the sequential bilinguals' lexical knowledge was mainly associated with their age 
at emigration. An important implication of this finding is highlighting the role immigrant parents can play in heritage language acquisition and maintenance even when their children were born in or immigrated to the host country at a young age.

Devising the auditory task to measure heritage speakers' receptive knowledge in their family language is another contribution of the first quantitative study. This test, in addition to its auditory format which makes it more appropriate in examining the receptive knowledge of target-languageilliterate test takers, was found to be a better parameter in distinguishing the differences between heritage speakers and their matched controls than the VFT (verbal fluency task). It should be noted that this finding implies that the VFT seemed not to be an appropriate task in measuring the productive knowledge in studies that aim to trace incomplete acquisition or attrition in young heritage speakers. This finding is supported by the fact that some monolingual participants in this study had lower scores on the VFT task than the heritage speakers, although they were certainly competent native speakers. According to the literature (Hulsen, 2000; Paradis, 2007, p. 125; Montrul 2008, p. 81), the productive knowledge of bilinguals compared to their receptive recognition of word meaning is expected to be more susceptible to attrition. While applying the verbal fluency task (VFT) in studies of language attrition in young bilinguals should be investigated more, it appears that this study raised a need to reassess its application as a test of young heritage speakers' productive vocabulary knowledge (see also Schmid \& Jarvis, 2014, p. 16). Picture-naming task which is also commonly used to measure accuracy and speed of participants in studies of language attrition (see Schmid, 2011) may be a better task in assessing productive knowledge of young heritage speakers.

The second quantitative study on lexical richness also contributes to the field of incomplete acquisition and language attrition. As already discussed, studies on first language attrition in adult bilinguals (e.g., Schmid, 2007, Schmid \& Keijzer, 2009; Schmid \& Dusseldrop, 2010) previously examined their participants' lexical diversity as well as the results of some controlled tasks (such as verbal fluency tasks, picture-naming tasks, picture-word matching tasks and grammaticality judgment tasks). This study revealed that lexical sophistication is a better parameter in distinguishing the differences between bilinguals and monolinguals in studies on language attrition and incomplete acquisition. This finding implies that studies of incomplete acquisition and attrition in young heritage speakers' family language as well as adult bilinguals should consider not only the variety (lexical diversity) but also the frequency 
(lexical sophistication) of the lexical items they use to examine the traces of incomplete acquisition and attrition in their participants.

Both quantitative studies showed the impact of age at emigration on the results of the sequential bilinguals' vocabulary knowledge, which contributes to the literature. The older they were when they left the home country, the higher their lexical proficiency is likely to be in Persian lexicon. However, according to the literature, this finding is not unexpected (Ammerlaan, 1996; Hulsen, 2000; Montrul, 2009; Montrul \& Foote, 2014). A surprising implication of this investigation is the association of current age and the young participants' heritage language proficiency. This investigation revealed a positive correlation between age and the results of controlled test and lexical richness of the participants, implying that the older participants, whether heritage speakers or monolinguals, were more likely to have higher productive and receptive lexical knowledge as well as more diverse and sophisticated lexicons. This result suggests that the heritage speakers, either simultaneous or sequential bilinguals, have continued to develop their family language in the second language environment, likely thanks to the input from their parents. Although the statistical analyses did not show the effect of sociolinguistic variables on all the test results, this finding indirectly supports the effect of heritage language use and parental attitude (as operationalized in this research) on heritage language proficiency in young bilinguals.

Regarding the qualitative investigation, its main contribution lies in presenting a reconceptualized framework for examining parental attitudes towards heritage language acquisition and maintenance. Part II of this dissertation complexifies attitude as a multilayered construct, for which more data should be collected to grasp its interwoven pieces of meaning. Showing the discrepancies between parental beliefs versus their practices and efforts towards Persian acquisition and maintenance for their children, this investigation highlights that parental beliefs should be accompanied with supporting practices and efforts to guarantee heritage language acquisition and maintenance. Additionally, Chapter 5 discusses the challenges immigrant families face in transferring their beliefs to daily practices and management strategies in helping their children develop communicative competence and literacy abilities in the heritage language, particularly when they reside in a second language environment with no institutional support for intergenerational transmission of their minority language (see Graded Intergenerational Disruption Scale in Fishman, 1991). The detailed overview of the families' beliefs, practices and 
efforts provides practical implications for immigrant parents who intend to raise their children bilingually.

Raising immigrant parents' awareness on the critical role they can play in raising their children bilingually is another important contribution of the qualitative investigation. This investigation showed that they can help their children acquire their home language naturally by merely using it in their households. The detailed analysis of different sub-components of their family language policies outlined different opportunities that immigrant parents can use to expose their children to their heritage language. In addition, it was conceived that immigrant parents' positive beliefs are not enough for acquisition and maintenance of their ethnic language by their children. If they liked their children to develop some levels of proficiency in their heritage language, they should add supporting practices and efforts to their positive beliefs towards ethnic language acquisition and maintenance. The role of teachers of mainstream schools in host countries has also been indicated in this investigation. This finding raises a need for making educators and teachers in majority language education aware about their role in instilling positive attitudes towards ethnic language acquisition and maintenance, if multilingualism is valued in a host country.

Another important contribution of the qualitative investigation is highlighting the role of literacy in improving conversational fluency and cultural knowledge. The second study in this investigation indicated that heritage speakers can develop communicative skills and cultural knowledge through verbal as well as written communication in their family language if they become literate in their home language. In view of that, this study highlighted that heritage language literacy is not just the ability to read and write, since heritage speakers can develop the cultural and social knowledge through the development of their literacy abilities in their home language. Therefore, it was concluded that if immigrant parents, educators, communities and researchers adopted this approach to literacy as a vehicle for conversational fluency as well as cultural knowledge, they would be likely to invest more in heritage language education.

Another implication of this research project was comparison of an immigrant community in different host countries. Iranians have been found to be able to help their children to acquire their ethnic language in the United States and Sweden, where the Iranian immigrant communities are much larger than in New Zealand. This project showed that, despite the small size of this community in New Zealand and the virtual absence of educational support of ethnic 
language schooling, this community is quite successful at raising their young members with good Persian proficiency, as documented by the results of the lexical tests and lexical richness in the quantitative investigation. As mentioned, some heritage speakers had scores as high as their matched monolingual speakers. On the downside, while the participating Iranian parents appeared to help their children acquire conversational fluency, they do not invest enough in heritage language literacy education for their children. It seems that heritage language education has been disregarded by these parents due to lack of community language schools as they reported.

All in all, this mixed-method project with quantitative analysis of heritage speakers' lexical knowledge and qualitative analysis of their parents' attitudes has contributed to the growing field of incomplete acquisition, attrition and maintenance of heritage languages in different aspects.

\subsection{Directions for further research}

Incomplete acquisition and attrition of home languages in young heritage speakers are under-researched areas. As previously discussed, the available literature on incomplete acquisition and attrition in young bilinguals is mainly based on investigations on their grammatical knowledge. This project provides a starting point for future research examining incomplete acquisition and attrition of heritage speakers' vocabulary knowledge. While the quantitative investigation of this research has shed light on some aspects of the fields of incomplete acquisition and attrition, it has certainly raised many questions in need of further research. The main limitation of Part I of this research was the small number of the heritage speakers, which was mainly due to the small number of Iranian immigrants in New Zealand. Therefore, future studies using the same experimental set up with higher numbers of participants are very welcome. It would be interesting to see if the same influential factors in simultaneous and sequential bilinguals turn out as strong predictors as was found out in the current research.

Furthermore, the methodological framework applied in Part I needs to be adopted and retested in future studies on incomplete acquisition and attrition of family languages to establish its appropriateness in studies on young heritage speakers' lexical knowledge and some of its implications can be explored in future research. The verbal fluency task (VFT) in studies of language attrition in young bilinguals should be investigated more to better understand the need 
to reassess its application in studies on young heritage speakers' productive knowledge. Future research, in addition, can determine the validity of the auditory picture-word matching task, which turned out to be a good parameter in weighing the receptive knowledge in my participants. Additionally, future research could consider conducting investigations on lexical richness by using Read's (2000) model. As a result, along with exploring lexical diversity and lexical sophistication, lexical density and the frequency of lexical errors (Read, 2000) of participants' speech samples might provide a more comprehensive overview of heritage speakers' lexical richness in their family language.

As noted earlier, Montrul (2008) argues that the best way to tease apart gradual processes of incomplete acquisition and attrition is by conducting longitudinal studies. She also asserts that it is important to distinguish simultaneous and sequential bilingualism for research on incomplete acquisition and language attrition in childhood (p. 98). Hence, longitudinal research on simultaneous and sequential bilinguals would certainly allow the fields of incomplete acquisition and attrition in heritage speakers to grow and provide answers to many questions regarding the incremental process of acquisition and attrition of heritage languages.

One of the main limitations of this study, as previously discussed, was relying on the parents' self-report data, which might not be an adequate tool for identifying the aspects of language attrition (Schmid, 2011, p. 102) and language maintenance. It is highly recommended for future research to triangulate the interview data with observational data through recording naturally-occurring conversations in the family context of heritage speakers to gain deeper insights into parental attitudes towards heritage language maintenance. In addition, future investigation on attitudes to language could adopt the methodological framework applied in this study- utilizing the model of language policy, to be able to further develop it as a valid framework in examinations of language attitudes. Additionally, the role literacy can play in heritage language acquisition and maintenance for young bilinguals in different immigrant communities deserves more attention by scholars exploring heritage language maintenance and loss.

This research has contributed not only to the field of heritage language maintenance in Iranian immigrants, but it also added to the rich literature on minority language maintenance in New Zealand. Since there is no institutional support for Persian education, and there are not many community-based Persian classes in this country either, the responsibility of heritage language maintenance certainly rests on immigrant parents' shoulders. As previously 
noted, Iranian immigrants have not commonly been studied in different host countries (except in the United States, with the highest number of Iranian immigrants). More research would be welcome to obtain a clear picture of their beliefs, practices and efforts in terms of heritage language acquisition and maintenance for their bilingual children in different host countries.

\subsection{Final word}

Having conducted this project on incomplete acquisition, attrition and maintenance of heritage speakers' family language, I aimed to achieve two main purposes. Firstly, I aimed to contribute to the literature of the fields of incomplete acquisition, language attrition and language maintenance of heritage speakers. In addition, I strove to make practical implications in the areas of heritage language acquisition and maintenance and to help immigrant parents who would like to raise their children bilingually. In sum, I hope this research can make a change in young heritage speakers' lives and help them to not lose their opportunity of bilingualism as they grow up. 


\section{REFERENCES}

Al-Sahafi, M. A. (2010). The dynamics of language maintenance among Arabic-speaking Muslim immigrant families in New Zealand (Unpublished doctoral dissertation). University of Auckland, New Zealand.

Al-Sahafi, M. A., \& Barkhuizen, G. (2006). Language use in an immigrant context: the case of Arabic in Auckland. New Zealand Studies in Applied Linguistics, 12(1), 51-69.

Ammerlaan, T. (1996). You get a bit wobbly...: Exploring bilingual lexical retrieval processes in the context of first language attrition (Unpublished doctoral dissertation). Katholieke Universiteit, Nijmegen, The Netherlands.

Anderson, B. (1991). Imagined communities: Reflections on the origin and spread of nationalism. New York: Verso.

Atoofi, S. (2013). Linguistic markers of affect in heritage Persian: A linguistic anthropological study among Persian heritage language students and their teachers. Iranian Studies, 46(6), 877-901.

Bahrick, H. P., Hall, L. K., Goggin, J. P., Bahrick, L. E., \& Berger. S. A. (1994). Fifty years of language maintenance and language dominance in bilingual Hispanic immigrants. Journal of Experimental Psychology: General, 123(3). 264-283.

Baker, C. (2011). Foundations of bilingual education and bilingualism. Multilingual matters.

Barkhuizen, G. (2006). Immigrant parents' perceptions of their children's language practices: Afrikaans speakers living in New Zealand. Language awareness, 15(2), 63-79.

Barkhuizen, G. P., \& Knoch, U. (2005). Missing Afrikaans: 'linguistic longing' among Afrikaans-speaking immigrants in New Zealand. Journal of Multilingual and Multicultural Development, 26(3), 216-232.

Bedford, R., Bedford, C., Ho, E., \& Lidgard, J. (2002). The globalisation of international migration in New Zealand: Contribution to a debate. New Zealand Population Review, 28(1), 69-97.

Bedore, L. M., Pena, E. D., Summers, C. L., Boerger, K. M., Resendiz, M. D., Greene, K., \& Gillam, R. B. (2012). The measure matters: Language 
dominance profiles across measures in Spanish-English bilingual children. Bilingualism: Language and Cognition, 15(03), 616-629.

Bell, A., Harlow, R., \& Starks, D. (2005). Languages of New Zealand. Wellington: Victoria University Press.

Benmamoun, E., Montrul, S., \& Polinsky, M. (2010). White paper: Prolegomena to heritage linguistics. Harvard University, 12, 26-43.

Bennett, E. J. (1997). Attitude of the second generation Dutch in Australia to language maintenance and ethnic identity. In J. Klatter \& S. Kroon (Eds.), Dutch overseas: studies in maintenance and loss of Dutch as an immigrant language (pp. 51-68). Tilburg: Tilburg University Press.

Ben-Rafael, M., \& Schmid, M. S. (2007). Language attrition and ideology: Two groups of immigrants in Israel. In B. Köpke, M. S. Schmid, M. Keijzer \& S. Dostert (Eds.), Language attrition: Theoretical perspectives (pp. 205-226). Amsterdam/Philadelphia: John Benjamins.

Benton, R. (2001). RLS in Aotearoa / New Zealand 1989-1999. In J. A. Fishman (ed.), Can threatened languages be saved? Reversing language shift, revisited: A 21st century perspective, (pp. 423-450). Clevedon: Multilingual Matters.

Berardi-Wiltshire, A. (2009). Italian identity and heritage language motivation: five stories of heritage language learning in traditional foreign language courses in Wellington, New Zealand (Unpublished doctoral dissertation). Massey University, New Zealand.

Bialystok, E. (2001). Bilingualism in development: Language, literacy, and cognition. Cambridge University Press.

Bialystok, E. (2010). Bilingualism. Wiley interdisciplinary reviews: cognitive science, 1(4), 559-572.

Bialystok, E., Luk, G., F. Peets, K., \& Yang, S. (2010). Receptive vocabulary differences in monolingual and bilingual children. Bilingualism: Language and Cognition, 13(04), 525-531.

Bohman, T. M., Bedore, L. M., Peña, E. D., Mendez-Perez, A., \& Gillam, R. B. (2010). What you hear and what you say: Language performance in Spanish-English bilinguals. International Journal of Bilingual Education and Bilingualism, 13(3), 325-344. 
Bonin, P., Barry, C., Méot, A. \& Chalard, M. (2004). The influence of age of acquisition in word reading and other tasks: A never ending story? Journal of Memory and language, 50, 456-476.

Bonin, P., Fayol, M., \& Chalard, M. (2001). Age of acquisition and word frequency in written picture naming. The Quarterly Journal of Experimental Psychology, 54 A (2), 469-489.

Borg, S. (2006). Teacher cognition and language education: Research and practice. London: Continuum.

Bourdieu, P. (1989). Social space and symbolic power. Sociological theory, 7(1), 14-25.

Bozorgmehr, M. (1998). From Iranian studies to studies of Iranians in the United States. Iranian Studies, 31(1), 4-30.

Brinton, D., Kagan, O., \& Bauckus, S. (Eds.). (2008). Heritage language education: A new field emerging. Routledge.

Bylund, E. (2009a). Effects of age of L2 acquisition on L1 event conceptualization patterns. Bilingualism: Language and Cognition, 12(3), 305-322.

Bylund, E. (2009b). Maturational constraints and first language attrition. Language learning, 59(3), 687-715.

Cabo, D. P. Y., \& Rothman, J. (2012). The (Il) logical problem of heritage speaker bilingualism and incomplete acquisition. Applied Linguistics, $33 / 4,450-455$.

Cavallaro, F. (2005). Language maintenance revisited: An Australian perspective. Bilingual Research Journal, 29(3), 561-582.

Chao, T. H. (1997). Chinese Heritage Community Language Schools in the United States. ERIC Digest, ED409744.

Charmaz, K. (2014). Grounded Theory in Global Perspective Reviews by International Researchers. Qualitative Inquiry, 20(9), 1074-1084.

Cherciov, M. (2012). Investigating the impact of attitude on first language attrition and second language acquisition from a Dynamic Systems Theory perspective. International Journal of Bilingualism, 17(6), 716733. 
Cho, G., \& Krashen, S. (2000). The role of voluntary factors in heritage language development: How speakers can develop the heritage language on their own. ITL, Review of Applied Linguistics 127-128, 127-140.

Crezee, I. (2008). I understand it well, but I cannot say it proper back: language use among older Dutch migrants in New Zealand (Unpublished doctoral dissertation). Auckland University of Technology, New Zealand.

Crezee, I. (2012). Language shift and host society attitudes: Dutch migrants who arrived in New Zealand between 1950 and 1965. International Journal of Bilingualism, 16(4), 528-540.

Cui, Bao-Hui. 2012. The differential attitudes of parents and children towards Chinese as a heritage language in a New Zealand context (Unpublished MA Thesis). University of Auckland, New Zealand.

Cummins, J. (1979). Linguistic interdependence and the educational development of bilingual children. Review of educational research, 49(2), 222-251.

Cummins, J. (1984). Bilingualism and special education: Issues in assessment and pedagogy. Clevedon: Multilingual Matters.

Cummins, J. (1989). Language and literacy acquisition in bilingual contexts. Journal of Multilingual \& Multicultural Development, 10 (1), 17-31.

Cummins, J. (1991). Interdependence of first-and second-language proficiency in bilingual children. In E. Bialystok (Ed.), Language processing in bilingual children, (pp. 70-89). Cambridge: Cambridge University Press.

Cummins, J. (2006). Identity texts: The imaginative construction of self through multiliteracies pedagogy. In O. Garcia, T. Skutnabb-Kangas \& M. Torees-Guzman (Eds.), Imagining multilingual schools: Languages in education and glocalization (pp. 51-68). Clevedon, UK:

Multilingual matters.

Cummins, J. (2007). Rethinking monolingual instructional strategies in multilingual classrooms. Canadian Journal of Applied Linguistics/Revue canadienne de linguistique appliquée, 10(2), 221240. 
Cummins, J. (2000). Language, power, and pedagogy: Bilingual children in the crossfire. (Vol. 23). Multilingual Matters.

Cunningham-Andersson, U., \& Andersson, S. (2004). Growing up with two languages: A practical guide. New York: Routledge.

Curdt-Christiansen, X. L. (2009). Invisible and visible language planning: Ideological factors in the family language policy of Chinese immigrant families in Quebec. Language Policy, 8(4), 351-375.

Curdt-Christiansen, X. L. (2013). Family language policy: Sociopolitical reality versus linguistic continuity. Language Policy, 1(12), 1-6.

Curdt-Christiansen, X. L. (2013). Negotiating family language policy: Doing homework. In M. Schwartz, \& A. Verschik (Eds.), Successful Family Language Policy: Parents, Children and Educators in Interaction (pp. 277-295). Netherlands: Springer.

Curdt-Christiansen, X. L. (2014). "Family language policy: Is learning Chinese at odds with leaning English in Singapore." In X. L. CurdtChristiansen \& A. Hancock (Eds.), Learning Chinese in diasporic communities: Many pathways to being Chinese, (pp. 35-58).

Amsterdam: John Benjamins.

Curdt-Christiansen, X. L. (2016). Conflicting language ideologies and contradictory language practices in Singaporean multilingual families. Journal of Multilingual and Multicultural Development, 1-16.

Davis, S. M., \& Kelly, M. H. (1997). Knowledge of the English noun-verb stress difference by native and nonnative speakers. Journal of Memory and Language, 36(3), 445-460.

de Bot, K. \& Clyne, M. (1994). A 16-year longitudinal study of language attrition in Dutch immigrants in Australia. Journal of Multilingual \& Multicultural Development, 15(1). 17-28.

de Bot, K., Gommans, P., \& Rossing, C. (1991). L1 loss in an L2 environment: Dutch immigrants in France. In H. W. Seliger \& R. M. Vago (Eds.), First language attrition (pp. 87-98). Cambridge:

Cambridge University Press.

De Houwer, A. (1990). The acquisition of two languages from birth: A case study. Cambridge, UK: Cambridge University Press. 
De Houwer, A. (1995). Bilingual language acquisition. In P. Fletcher \& B. MacWhinney (Eds.), The handbook of child language (pp. 219-250). Oxford, UK: Blackwell.

De Houwer, A. (1999). Environmental factors in early bilingual development: The role of parental beliefs and attitudes. In G. Extra \& L. Verhoeven (Eds.), Bilingualism and migration (pp. 75-96). Berlin: Mouton de Gruyter.

De Houwer, A. (2007). Parental language input patterns and children's bilingual use. Applied Psycholinguistics, 28 (3), 411-424.

DeCapua, A., \& Wintergerst, A. C. (2009). Second-generation language maintenance and identity: A case study. Bilingual Research Journal, 32(1), 5-24.

Dijkstra, T., Miwa, K., Brummelhuis, B., Sappelli, M., \& Baayen, H. (2010). How cross-language similarity and task demands affect cognate recognition. Journal of Memory and language, 62(3), 284-301.

Durán, P., Mavern, D., Richards, B., \& Chipere. N. (2004). Developmental trends in lexical diversity. Applied Linguistics, 25 (2). 220-242.

Fallgatter, A. J., M. Roesler, L. Sitzmann, A. Heidrich, T. J. Mueller \& W. K. Strik. (1997). Loss of functional hemispheric asymmetry in Alzheimer's dementia assessed with near-infrared spectroscopy. Cognitive Brain Research, 6(1). 67-72.

Felling, S. (2006). Fading Farsi: Language, Policy, Ideology, and Shift in the Iranian American Family (Unpublished doctoral dissertation). Georgetown University, Washington, DC.

Field, A., Miles, J., \& Field, Z. (2012). Discovering statistics using R. SAGE.

Fillmore, L. W. (1991). When learning a second language means losing the first. Early childhood research quarterly, 6(3). 323-346.

Fillmore, L. W. (2000). Loss of family languages: Should educators be concerned? Theory into practice, 39(4), 203-210.

Fishman, J. A. (1965). Who speaks what language to whom and when? La Linguistique, 1(Fasc. 2), 67-88. 
Fishman, J. A. (1991). Reversing language shift: Theoretical and empirical foundations of assistance to threatened languages Vol. (76).

Clevedon/Philadelphia: Multilingual matters.

Fishman, J. A. (2006). Language policy and language shift. In T. Ricento (Ed.), An introduction to language policy: Theory and method, (pp. 311-328), New York: Blackwell.

Fogle, L. W., \& King, K. A. (2013). Child agency and language policy in transnational families. Issues in Applied Linguistics, 19.

Fogle, L.W. (2009). Language socialization in the internationally adoptive family: Identities, second languages, and learning. (Unpublished doctoral dissertation). Georgetown University, Washington, DC.

Fromkin, V. A. (1987). The lexicon: Evidence from acquired dyslexia. Language, 1-22.

García, M. (2003). 2. Recent research on language maintenance. Annual Review of Applied Linguistics, 23, 22-43.

Garcia, O. (2009). Education, multilingualism and translanguaging in the 21st century. Social justice through multilingual education, 140-158.

García, Ofelia. (2009). Bilingual Education in the 21st Century: A Global Perspective. Malden, MA and Oxford: Basil/Blackwell.

Garrett, P. (2010). Attitudes to language. New York: Cambridge University Press.

Garrett, P., Coupland, N., \& Williams, A. (2003). Investigating language attitudes: Social meanings of dialect, ethnicity and performance. University of Wales Press.

Genesee, F., Paradis, J., \& Cargo, M. (2004). Dual language development and disorders: A handbook on bilingualism and second language learning. Baltimore, MD: Brookes.

Gibbons, J., \& Ramirez, E. (2004). Different Beliefs Beliefs and the Maintenance of a Minority Language. Journal of Language and Social Psychology, 23(1), 99-117.

Giles, H., \& Coupland, N. (1991). Language: Contexts and consequences. Philadelphia, PA: Open University Press. 
Gorman, L. (2010). Rev. of Incomplete acquisition in bilingualism: Reexamining the age factor by Silvina Montrul, Heritage Language Journal, 7 (2), 187-191.

Grosjean, F. (2001). The bilingual's language modes. In J. L. Nicol (Ed.), One Mind, Two Languages: Bilingual Language Processing (pp. 1-22). Oxford: Blackwell.

Guardado, M. (2002). Loss and maintenance of first language skills: Case studies of Hispanic families in Vancouver. Canadian Modern Language Review/La Revue canadienne des langues vivantes, 58(3), 341-363.

Harris, J. R. (1995). Where is the child's environment? A group socialization theory of development. Psychological review, 102(3), 458.

Harris, M., Yeeles, C., Chasin, J., \& Oakley, Y. (1995). Symmetries and asymmetries in early lexical comprehension and production. Journal of Child Language, 22(01), 1-18.

Hashimoto, K., \& Lee. J. S. (2011). Heritage-language literacy practices: A case study of three Japanese American families. Bilingual Research Journal 34(2): 161-184.

Hinton, L. (1999). Involuntary language loss among immigrants: AsianAmerican linguistic autobiographies. In J. Alatis and A. Tan (Eds): Language in Our Time: Bilingual Education and Official English, Ebonics and Standard English, Immigration and the Unz Initiative. Georgetown University Round Table on Languages and Linguistics 1999 (pp. 203-252). Washington, DC: Georgetown University Press.

Hoffman, L., Templin, J., \& Rice, M. L. (2012). Linking outcomes from Peabody Picture Vocabulary Test forms using item response models. Journal of Speech, Language, and Hearing Research, 55(3), 754-763.

Hoyer, W. J., \& Lincourt. A. E. (1998). Ageing and the Development of Learning. In M. A. Stadler \& P. A. Frensch (Eds.), Handbook of implicit learning (pp. 445-470). Thousand Oaks, CA, US: SAGE.

Hulsen, M. E. H. (2000). Language loss and language processing: Three generations of Dutch migrants in New Zealand. Nijmegen: Katholieke Universiteit Nijmegen. 
Hulsen, M., de Bot, K., \& Weltens, B. (2002). 'Between two worlds'. Social networks, language shift, and language processing in three generations of Dutch migrants in New Zealand. International Journal of the Sociology of Language, 27-52.

Hutz, M. (2004). Is there a natural process of decay? A longitudinal study of language attrition. In M. S. Schmid, B. Köpke, M. Keijzer \& L. Weilemar (Eds.), First language attrition: Interdisciplinary perspectives on methodological issues (pp. 189-207).

Amsterdam/Philadelphia: John Benjamins.

Irwin, K. (1989). Multicultural education: The New Zealand response, New Zealand Journal of Educational Studies, 24(1), 3-18.

Iwashita, N., Brown, A., McNamara, T., \& O’Hagan, S. (2008). Assessed levels of second language speaking proficiency: How distinct? Applied linguistics 29(1). 24-49.

Izura, C., \& Ellis. A. W. (2004). Age of acquisition effects in translation judgement tasks. Journal of Memory and Language, 50, 165-181.

Izura, C., \& Ellis. A. W. (2002). Age of acquisition effects in word recognition and production in first and second languages. Psicológica 23, 245-282.

Jahani, C. (2004). Language attitudes and language maintenance among Iranian immigrants in Sweden. Orientalia Suecana, 53, 93-111.

Johri, R. (1998). Stuck in the middle or clued up on both? Language and identity among Korean, Dutch and Samoan immigrants in Dunedin (Unpublished doctoral dissertation), University of Otago, New Zealand.

Junker, D. A., \& Stockman, I. J. (2002). Expressive vocabulary of GermanEnglish bilingual toddlers. American Journal of Speech-Language Pathology,11(4), 381-394.

Kim, C. E., \& Pyun, D. O. (2014). Heritage language literacy maintenance: a study of Korean-American heritage learners. Language, Culture and Curriculum, 27(3), 294-315.

Kim, J. (2008). Negotiating multiple investments in languages and identities: The language socialization of Generation 1.5 Korean-Canadian university students (Unpublished doctoral dissertation). University of British Columbia. 
Kim, J., \& Starks, D. (2005). Language diaries: A case study of language use in the New Zealand Korean community. In A. Bell, R. Harlow \& D. Starks (Eds.), Languages of New Zealand (pp. 343-369). Wellington: Victoria University Press.

Kim, S. H. (2007). First language attrition in a second language learning environment: the case of Korean-English late bilinguals (Unpublished doctoral dissertation). University of Auckland, New Zealand.

King, K. A., \& Fogle, L. W. (2013). Family language policy and bilingual parenting. Language Teaching, 46(02), 172-194.

King, K. A., Fogle, L. W., \& Logan-Terry, A. (2008). Family language policy. Language and Linguistics Compass, 2(5), 907-922.

King, K., \& Fogle, L. (2006). Bilingual parenting as good parenting: Parents' perspectives on family language policy for additive bilingualism. International Journal of Bilingual Education and Bilingualism, 9(6), 695-712.

Kipp, S., Clyne, M., \& Pauwels, A. (1995). Immigration and Australia's language resources. AGPS.

Koizumi, R. (2012). Relationship between text length and lexical diversity measures: can we use short texts of less than 100 tokens. Vocabulary Learning and Instruction, 1(1), 60-69.

Koizumi, R., \& In'nami, Y. (2013). Vocabulary knowledge and speaking proficiency among second language learners from novice to intermediate levels. Journal of Language Teaching and Research, 4(5), 900-913.

Kondo, K. (1997). Social-psychological factors affecting language maintenance: Interviews with Shin Nisei university students in Hawaii. Linguistics and education, 9(4), 369-408.

Kopeliovich, S. (2013). Happylingual: A family project for enhancing and balancing multilingual development. In Schwartz, M., \& Verschik, A. (Eds.), Successful Family Language Policy: Parents, Children and Educators in Interaction (pp. 249-275). Netherlands: Springer.

Köpke, B. (2007). Language attrition at the crossroads of brain, mind, and the society. In B. Köpke, M. S. Schmid, M. Keijzer \& S. Dostert (Eds.), Language attrition: Theoretical perspectives (pp. 9-38). Amsterdam/Philadelphia: John Benjamins. 
Köpke, B., \& Schmid, M. S. (2009). L1 attrition and the mental lexicon. In A. Pavlenko (Ed.), The Bilingual Mental Lexicon (pp. 209 - 238). Bristol/Buffalo/Toronto: Multilingual Matters.

Köpke, B., \& Schmid. M. S. (2004). First Language Attrition: The next phase. In M. S. Schmid, B. Köpke, M. Keijzer \& L. Weilemar (Eds.), First language attrition: Interdisciplinary perspectives on methodological issues (pp. 1-45). Amsterdam/Philadelphia: John Benjamins.

Kouritzin, S. G. (1999). Face [t] s of first language loss. New York: Routledge.

Krashen, S. D. (1996). Under attack: The case against bilingual education. Culver city, California: Language Education Associates.

Lanza, E. (1997). Language mixing in infant bilingualism: A sociolinguistic perspective, Clarendon: Oxford Univeristy Press.

Lanza, E. (2001). Bilingual first language acquisition: A dicourse perspective on language contact in parent-child interaction. In J. Cenoz, \& F. Genesee (Eds.), Trends in bilingual acquisition, 1, (pp. 201-229). Amesterdam/ Philadelphia: John Benjamins.

Lanza, E., \& Svendsen, B. A. (2007). Tell me who your friends are and I might be able to tell you what language (s) you speak: Social network analysis, multilingualism, and identity. International journal of bilingualism, 11(3), 275-300.

Lao, C. (2004). Parents' attitudes toward Chinese-English bilingual education and Chinese-language use. Bilingual Research Journal: The journal of the National Association for Bilingual Education, 28(1), 99-121.

Laufer, B., \& Nation. I. S. P. (1995). Vocabulary size and use: Lexical richness in L2 written production. Applied Linguistics 16(3). 307-322.

Lee, B. Y. (2012). Heritage language maintenance and cultural identity formation: the case of Korean immigrant parents and their children in the USA. Early Child Development and Care, 183(11), 1576-1588.

Lee, J. S. (2002). The Korean language in America: The role of cultural identity in heritage language learning. Language Culture and Curriculum, 15(2), 117-133. 
Lee, J. S. (2013). Literacy and Heritage Language Maintenance. In C. A. Chapelle (ed.), The Encyclopedia of Applied Linguistics (pp. 1-6), Blackwell Publishing Ltd.

Lenneberg, E. H. (1967). Biological foundations of language. New York: John Wiley.

Li, G. (2006). The role of parents in heritage language maintenance and development: Case studies of Chinese immigrant children's home practices. In K. Kondo-Brown, (Ed.), Heritage language development: Focus on East Asian immigrants (pp. 15-31). Amsterdam/Philalephia: John Benjamins.

Li, M. (2005). The role of parents in Chinese heritage-language schools. Bilingual Research Journal 29 (1), 197-207.

Luykx, A. (2005). Children as socializing agents: Family language policy in situations of language shift. In ISB4: Proceedings of the 4th International Symposium on Bilingualism (pp. 1407-1414). Somerville, MA: Cascadilla Press.

Malvern, D., \& Richards, B. (2013). Measures of lexical richness. In C. A. Chapelle (Ed), The Encyclopedia of Applied Linguistics. Blackwell Publishing Ltd.

McArthur, A. (2001). World English and World Englishes: Trends, tensions, varieties, and standards. Language Teaching, 34. 1-20.

McCaffery, J. J., \& Tuafuti, P. (2003). Samoan Children's Bilingual Language and literacy development. Bilingual children's language and literacy development. In R. Barnard \& T. Glynn (eds.), Bilingual Children's language and literacy development, 80-107. Clevedon: Multilingual Matters.

McCarthy, P. M. The Gramulator. https://umdrive.memphis.edu/pmmccrth/public/software/software_inde x.htm (14 May, 2014.)

McCarthy, P. M., \& Jarvis. S. (2007). vocd: A theoretical and empirical evaluation. Language Testing, 24(4), 459-488.

McCarthy, P. M., \& Jarvis. S. (2010). MTLD, vocd-D, and HD-D: A validation study of sophisticated approaches to lexical diversity assessment. Behavior Research Methods, 42(2). 381-392. 
McLaughlin, B. (1978). Second-language acquisition in childhood. Hillsdale, NJ: Elbaum.

Megerdoomian, K. (2009). Heritage Persian characteristics and needs. In STARTALK Persian teacher's workshop for professional curriculum and materials development. University of Pennsylvania, Philadelphia.

Meisel, J. M. (1989). Early differentiation of languages in bilingual children. In K. Hyltensta, \& L. Obler (Eds.), Bilingualism across the lifespan: Aspects of acquisition, maturity and loss (pp. 13-40), Cambridge, UK: Cambridge University Press.

Ministry of Education. (2015). Education in New Zealand 2013 2017. Wellington: Learning Media.

Modarresi, Y. (2001). The Iranian community in the United States and the maintenance of Persian. International journal of the sociology of language, 93-116.

Montrul, S. (2002). Incomplete acquisition and attrition of Spanish tense/aspect distinctions in adult bilinguals. Bilingualism: Language and Cognition, 5(01), 39-68.

Montrul, S. (2008). Incomplete acquisition in bilingualism: Re-examining the age factor. Amsterdam/Philadelphia: John Benjamins.

Montrul, S. (2009). Lexical knowledge and access in Spanish heritage speakers: Theoretical and Pedagogical Issues. Paper presented at The Third Heritage Language Summer Institute, June 21-26, University of Illinois, Urbana-Champaign.

Montrul, S. (2012). Is the heritage language like a second language? EuroSLA Yearbook 12(1), 1-29.

Montrul, S. (2013). Bilingualism and the heritage language speaker. In T. K. Bhatia \& W. C. Ritchie (Eds.), The Handbook of Bilingualism and Multilingualism (pp. 168-189). Balckwell Publising Ltd.

Montrul, S. (2016). The acquisition of heritage languages. United Kingdom: Cambridge University Press.

Montrul, S., \& Foote, R. (2014). Age of acquisition interactions in bilingual lexical access: A study of the weaker language of L2 learners and heritage speakers. International Journal of Bilingualism, 18(3), 274303. 
Montrul, S., \& Polinsky. M. (2011). Why not heritage speakers? Linguistic Approaches to Bilingualism, 1(1), 58-62.

Naghdi, A. (2010). Iranian diaspora: with focus on Iranian immigrants in Sweden. Asian Social Science, 6(11), 197.

Nakanishi, N. (2000). Language maintenance and language shift in the Japanese community of Auckland: A study of the interaction between the sojourners and the immigrants (Unpublished MA Thesis). University of Auckland, New Zealand.

Namei, S. (2008). Language choice among Iranians in Sweden. Journal of Multilingual and Multicultural Development, 29(5), 419-437.

Nation, I. S. P. (2006). How large a vocabulary is needed for reading and listening? The Canadian Modern Language Review, 63, 59-82.

Nation, I. S. P., \& Beglar, D. (2007). A vocabulary size test. The Language Teacher. 31(7), 9-13.

Nesteruk, O. (2010). Heritage language maintenance and loss among the children of Eastern European immigrants in the USA. Journal of Multilingual and Multicultural Development, 31(3), 271-286.

Nicoladis, E. (2003). Cross-linguistic transfer in deverbal compounds of preschool bilingual children. Bilingualism: Language and Cognition, 6, 17-31.

Nicoladis, E. (2006). Cross-linguistic transfer in adjective-noun strings by preschool bilingual children. Bilingualism: Language and Cognition, 9(01), 15-32.

Norton, B. (1997). Language and identity. TESOL Quarterly, 31(3), 409-429.

Norton, B. (2000). Identity and language learning: Gender, ethnicity and educational change. Harlow, UK: Pearson Educated Limited.

Norton, B. (2001). Non-participation, imagined communities and the language classroom. In M. Breen (Ed.), Learner contributions to language learning: New directions in research (pp. 159-171). London: Peason Education Limited.

Norton, B. (2013). Identity and language learning: Extending the conversation. Multilingual matters. 
O’ Riagáin, P. (2008). Language attitudes and minority languages. In J. Cenoz \& N. H. Hornberger (Eds.), Encyclopaedia of language and education, Volume 6: Knowledge about language (pp. 329-342). New York: Springer.

O'Grady, W., Schafer, A. J., Perla, J., Lee, O., \& Wieting., J. (2009). A psycholinguistic tool for the assessment of language loss: The HALA project. Language Documentation and Conservation, 3(1), 100-112.

Okita, T. (2002). Invisible work: Bilingualism, language choice and childrearing in intermarried families (Vol. 12).

Amsterdam/Philadelphia: John Benjamins.

Oskamp, S., \& Schultz, P. W. (2005). Attitudes and opinions. Mahwah, NJ: L. Erlbaum Associates.

Paradis, J. (2007). Early bilingual and multilingual acquisition. In P. Auer and L. Wei (Eds.), Handbook of multilingualism and multilingual communication (pp. 15-44). Berlin/ New York: Mouton de Gruyter.

Paradis, J., \& Genesee, F. (1996). Syntactic acquisition in bilingual children: Autonomous or independent? Studies in Second Language Acquisition, 18 (01), 1-25.

Paradis, J., Nicoladis, E., Crago, M., \& Genesee, F. (2011). Bilingual children's acquisition of the past tense: A usage-based approach. Journal of Child Language, 38(03), 554-578.

Paradis, M. (2004). A neurolinguistic theory of bilingualism. Amsterdam/Philadelphia: John Benjamins.

Paradis, M. (2007). L1 attrition features predicted by a neurolinguistic theory of bilingualism. Language attrition. In B. Köpke, M. S. Schmid, M. Keijzer \& S. Dostert (Eds.), Language attrition: Theoretical perspectives (pp. 121-133). Amsterdam/Philadelphia: John Benjamins.

Park, C. Y. (2007). Maintaining Korean as a heritage language (Unpublished doctoral dissertation). Arizona State University.

Park, S. H. (2000). A sociolinguistic and social psycholinguistic study of Korean communities in New Zealand: Language maintenance and second language learning (Unpublished doctoral dissertation). Victoria University of Wellington, New Zealand. 
Park, S. M., \& Sarkar. M. (2007). Parents' attitudes toward heritage language maintenance for their children and their efforts to help their children maintain the heritage language: A case study of Korean-Canadian immigrants. Language, culture and curriculum, 20(3), 223-235.

Pavlenko, A., \& Norton, B. (2007). Imagined communities, identity, and English language learning. In J. Cummins and C. Davison (Eds.), International handbook of English language teaching (pp. 669680). New York: Springer.

Payesteh, B. (2015). Language Input and Outcomes in Bilingual PersianEnglish Children Attending an Immersion Preschool (Unpublished doctoral dissertation). University of Minnesota.

Pearson, B. Z. (1998). Assessing lexical development in bilingual babies and toddlers. International journal of bilingualism, 2(3), 347-372.

Pearson, B. Z. (2007). Social factors in childhood bilingualism in the United States. Applied Psycholinguistics, 28(03). 399-410.

Pearson, B. Z., Fernández, S. C., Lewedeg, V., \& Oller, D. K. (1997). The relation of input factors to lexical learning by bilingual infants. Applied Psycholinguistics, 18(01), 41-58.

Pelc, L. A. (2001). L1 lexical, morphological and morphosyntactic attrition in Greek-English bilinguals (Unpublished doctoral dissertation). New York: CUNY.

Peters, M. \& Marshall, J. (1989). Te Reo o Te Tai Tokerau: language evaluation and empowerment, New Zealand Journal of Educational Studies, 24 (1), 14-157.

Pilkington, J. (1990). Mixed marriages and language maintenance: some Samoan data. Wellington Working Papers in Linguistics, Vol. 1, 28-36.

Polinsky, M. (1997). American Russian: Language loss meets language acquisition. In W. Browne, E. Dornische, N. Kondrashova \& D. Zec (Eds.), the Formal Approaches to Slavic Linguistics. Cornell Meeting (pp. 370-406). Ann Arbor, MI: Michigan Slavic Publications.

Polinsky, M. (1997). American Russian: Language loss meets language acquisition. In Wayles Browne, Ewa Dornische, Natasha Kondrashova and Draga Zec (Eds.), the Formal Approaches to Slavic Linguisitics. Cornell Meeting (pp. 370-406). Ann Arbor, MI: Michigan Slavic Publications. 
Polinsky, M. (2006). Incomplete acquisition: American Russian. Journal of Slavic Linguistics, 14(2). 191-262.

Polinsky, M. (2007). Reaching the end point and stopping midway: different scenarios in the acquisition of Russian. Russian Linguistics, 31(2), 157-199.

Polinsky, M. (2011). Reanalysis in adult heritage language. Studies in Second Language Acquisition, 33(02), 305-328.

Portes, A., \& Hao, L. (1998). E pluribus unum: Bilingualism and loss of language in the second generation. Sociology of Education, 269-294.

Ramezanzadeh, F. S. (2010). Unveiling the veiled and veiling the unveiled: Revealing the underlying linguistic ideologies and their impact on Persian language loss and maintenance among second-generation Iranian-American college students (Unpublished doctoral dissertation). The University of Utah.

Read, J. (2000). Assessing vocabulary. Cambridge: Cambridge University Press.

Revis, M. S. (2015). Family Language Policies of Refugees: Ethiopians and Colombians in New Zealand (Unpublished doctoral dissertation). Victoria University of Wellington, New Zealand.

Roberts, M. L. (1999). Immigrant language maintenance and shift in the Gujarati, Dutch and Samoan communities of Wellington. (Unpublished doctoral dissertation). Victoria University of Wellington, New Zealand.

Roberts, M. L. (2005). Immigrants' attitudes to language maintenance in New Zealand. In Allan Bell, Ray Harlow \& Donna Starks (eds.), Languages of New Zealand (pp. 248-270). Wellington: Victoria University Press.

Ronowicz, E. (1999). Methodological issues of testing language attrition in children in a natural bilingual environment. Poznan Studies in Contemporary Linguistics, 35, 105-117.

Rothman, J. (2007). Heritage speaker competence differences, language change, and input type: Inflected infinitives in heritage Brazilian Portuguese. International Journal of Bilingualism, 11(4), 359-389. 
Rothman, J. (2009). Understanding the nature and outcomes of early bilingualism: Romance languages as heritage languages. International Journal of Bilingualism, 13(2), 155-163.

Sakamoto, M. (2006). Balancing L1 maintenance and L2 learning: Experiential narratives of Japanese immigrant families in Canada. In K. Brown (Ed.), Heritage language development: Focus on East Asian languages (pp. 33-56). Amsterdam/The Netherlands: John Benjamins.

Schecter, S. R., \& Bayley, R. (2004). Language socialization in theory and practice. International Journal of Qualitative Studies in Education, 17(5), 605-625.

Schmid, M. S. (2002). First language attrition, use and maintenance: The case of German Jews in Anglophone countries. Amsterdam/Philadelphia: John Benjamins.

Schmid, M. S. (2004). First language attrition: The methodology revised. International journal of Bilingualism, 8, 239-255.

Schmid, M. S. (2007). The role of LI use for LI attrition. In B. Köpke, M. S. Schmid, M. Keijzer \& S. Dostert (Eds.), Language attrition:

Theoretical perspectives (pp. 135-154) Amsterdam/Philadelphia: John Benjamins.

Schmid, M. S. (2011). Language attrition. New York: Cambridge University Press.

Schmid, M. S. The Language Attrition Website. Retrieved April 22, 2013, from http://www.let.rug.nl/languageattrition/

Schmid, M. S., \& Dusseldorp, E. (2010). Quantitative analyses in a multivariate study of language attrition: the impact of extralinguistic factors. Second Language Research, 26(1), 125-160.

Schmid, M. S., \& Fägersten, K. B. (2010). Disfluency markers in L1 attrition. Language Learning, 60 (4), 753-791.

Schmid, M. S., \& Jarvis, S. (2014). Lexical access and lexical diversity in first language attrition. Bilingualism: Language and Cognition, 17(4), 729748.

Schmid, M. S., \& Keijzer, M. (2009). First language attrition and reversion among older migrants. International Journal of Sociology of Language, 200, 83-101. 
Schwartz, M. (2008). Exploring the relationship between family language policy and heritage language knowledge among second generation Russian-Jewish immigrants in Israel. Journal of Multilingual and Multicultural Development, 29(5), 400-418.

Schwartz, M. (2010). Family language policy: Core issues of an emerging field. Applied Linguistics Review, 1(1), 171-192.

Schwartz, M., \& Verschik, A. (2013). Successful Family Language Policy: Parents, Children and Educators in Interaction. Dordrecht/ New York: Springer.

Schwartz, M., Kozminsky, E., \& Leikin, M. (2009). Toward a Better Understanding of First Language Vocabulary Knowledge: The Case of Second-Generation Russian-Jewish Immigrants in Israel. Diaspora, Indigenous, and Minority Education 3(4), 226-244.

Seals, C. A (forthcoming). Pasifika heritage languages in New Zealand. In O. Kagan, M. Carreira, and C. Chik, (Eds). A Handbook on Heritage Language Education: From Innovation to Program Building. Routledge.

Seals, C. A. (2013). Te Espero: Varying child bilingual abilities and the effects on dynamics in Mexican immigrant families. Issues in Applied Linguistics, 19, 119-142.

Sedighi, A. (2010). Teaching Persian to Heritage Speakers. Iranian Studies, 43(5), 683-697.

Segalowitz, N. (2010). Cognitive bases of second language fluency. New York: Routledge.

Serratrice, L. (2013). The bilingual child. In T. K. Bhatia \& W. C. Ritchie (Eds.), The Handbook of Bilingualism and Multilingualism (pp. 85108). Balckwell Publising Ltd.

Shibata, S. (2000). Opening a Japanese Saturday school in a small town in the United States: Community collaboration to teach Japanese as a heritage language. Bilingual Research Journal, 24(4), 465-474.

Snodgrass, J. G., \& Vanderwart, M. (1980). A standardized set of 260 pictures: norms for name agreement, image agreement, familiarity, and visual complexity. Journal of experimental psychology: Human learning and memory, 6(2), 174-215. 
Soesman, A. (1997). An experimental study on native language attrition in Dutch adult immigrants in Israel. In J. Klatter and S. Kroon (Eds.), Dutch overseas: studies in maintenance and loss of Dutch as an immigrant language (pp. 181-194). Tilburg: Tilburg University Press.

Sohrabi, B. (1992). Trends of Iranian Migration into Sweden. Stockholm: Stockholm

Sohrabi, B. (1997). Ethnolinguistic vitality and patterns of communication among the second generation of Iranian immigrants in Sweden. International Journal of the Sociology of Language, 128, 45_71.

Spolsky, B. (2004). Language policy. Cambridge : Cambridge University Press.

Spolsky, B. (2012). Family language policy-the critical domain. Journal of Multilingual and Multicultural Development, 33(1), 3-11.

Spolsky, B., \& Shohamy, E. G. (1999). The languages of Israel: Policy, ideology, and practice (Vol. 17). Multilingual Matters.

Staehr, L. S. (2009). Vocabulary knowledge and advanced listening comprehension in English as a foreign language. Studies in Second Language Acquisition, 31(4), 577-607

Starks, D., \& Youn, S. H. (1998). Language maintenance in the Auckland Korean community. Many Voices, 12, 8-11.

Statistics New Zealand, 2013 ethnic group profiles: Iranians.

(http://www.stats.govt.nz/Census/2013-census/profile-and-summaryreports/ethnicprofiles.aspx ?request_value $=24766 \&$ tabname $=$ Populationandgeograph y). Accessed on 11/01/ 2015.

Strauss, A. L. \& Corbin. J. M. (1998). Basics of Qualitative research: Techniques and Procedures for Developing Grounded Theory (2nd ed.). Thousand Oaks, CA: Sage.

Street, B. V. (2000). Literacy events and literacy practices: Theory and practice in new literacy studies. In M. Martin-Jones \& K. Jones (Eds.), Multilingual literacies: Reading and writing different worlds (pp. 1730). Amsterdam/Philadelphia: John Benjamins.

Street, B. V. (2005). Literacies across educational contexts: Mediating learning and teaching. Philadelphia: Caslon Publishing. 
Sun, S. (1999). The New Zealand-Born Chinese Community of Auckland: Aspects of Language Maintenance and Shift. Hong Kong Journal of Applied Linguistics, 4(2), 1-14.

Tannenbaum, M., \& Howie, P. (2002). The association between language maintenance and family relations: Chinese immigrant children in Australia. Journal of multilingual and multicultural development, 23(5), 408-424.

Taumoefolau, M., Donna Starks, Davis, K., \& Bell, A. (2002). Linguists and language maintenance: Pasifika languages in Manukau, New Zealand. Oceanic Linguistics 41(1). 15-27.

Tawalbeh (forthcoming). Language use and attitudes amongst the Iraqi community in Wellington (Unpublished doctoral dissertation). Victoria University of Wellington. New Zealand.

Tomasello, M., \& Bates, E. (2001). Language development: The essential readings. Blackwell.

Tomiyama, M. (1999). The first stage of second language attrition: A case study of a Japanese returnee. Second language attrition in Japanese contexts, 59-79.

Tomiyama, M. (2000). Child second language attrition: A longitudinal case study. Applied Linguistics, 21(3), 304-332.

Tse, L. (2001a). Resisting and reversing language shift: Heritage-language resilience among US native biliterates. Harvard Educational Review, 71(4), 676-709.

Tse, L. (2001b). Heritage language literacy: A study of US biliterates. Language Culture and Curriculum, 14(3), 256-268.

Tucker, G. R. (1998). A global perspective on multilingualism and multilingual education. In J. Cenoz \& F. Genesee (Eds.), Beyond bilingualism: Multilingualism and multilingual education (pp. 3-15). Clevedon, UK: Multilingual Matters.

Unsworth, S. (2013). Current issues in multilingual first language acquisition. Annual Review of Applied Linguistics, 33, 21-50.

Unsworth, S. (forthcoming). Quantity and quality of input in bilingual language development. In E. Nicoladis, \& S. Montanari (Eds.), 
Lifespan perspectives on bilingualism, (pp. 136-196), Mouton de Gruyter/APA.

Unsworth, S., \& Blom, E. (2010). Comparing L1 children, L2 children and L2 adults. In E. Blom, \& S. Unsworth (Eds.), Experimental methods in language acquisition research, 27 (pp. 201-222), Amsterdam/Philadelphia: John Benjamins.

Val, A., \& Vinogradora, P. (2010). What is the identity of a heritage speaker? Heritage Berief Collection. Washington, DC: Alliance for the Advancement of Heritage Languages, Center for Applied Linguistics.

Valdés, G. (2000). Introduction. Spanish for Native Speakers, Volume I.

AATSP Professional Development Series Handbook for teachers K-16. New York: Harcourt College.

Vermeer, A. (2000). Coming to grips with lexical richness in spontaneous speech data. Language testing, 17(1), 65-83.

Vermeer, A. (2004). Vocabulary size in Dutch L1 and L2 children. In P. Bogaards \& B. Laufer (Eds), Vocabulary in a second language: Selection, acquisition, and testing (pp. 173-189).

Amsterdam/Philadelphia: John Benjamins:

Walker, R. (1989). Māori identity. In D. Novitz \& B. Willmott (Eds.). Culture and Identity in New Zealand. Wellington: Government Print.

Walker, U. (2011). Linguistic diversity as a bridge to adjustment: Making the case for bi/multilingualism as a settlement outcome in New Zealand. Language policy for the multilingual classroom: Pedagogy of the possible, 149-173.

Ward, C. \& Liu. J. H. (2012). Ethno-cultural conflict in Aotearoa/New Zealand: Balancing indigenous rights and multicultural responsibilities. In Dan Landis \& Rosita D. Albert (Eds.), Handbook of ethnic conflict, 45-69. Dordrecht/New York: Springer.

Ward, C., \& Masgoret, A. M. (2008). Attitudes toward immigrants, immigration, and multiculturalism in New Zealand: A social psychological analysis. International Migration Review, 42(1), $227-$ 248.

Wei, L. (2000). Towards a critical evaluation of language maintenance and language shift. Sociolinguistica, 14, 142-147. 
Wright, W. E., Boun, S., \& Garcia, O. (2015). The handbook of bilingual and multilingual education. John Wiley \& Sons.

Yan, S., \& Nicoladis, E. (2009). Finding le mot juste: Differences between bilingual and monolingual children's lexical access in comprehension and production. Bilingualism: Language and Cognition, 12(03), 323335 .

Yilmaz, G., \& Schmid. M. S. (2012). L1 accessibility among Turkish-Dutch bilinguals. The Mental Lexicon, 7(3), 249-274.

Yu, S. (2010). How much does parental language behaviour reflect their language beliefs in language maintenance? Journal of Asian Pacific Communication, 20(1), 1-22.

Zhang, D., \& Koda, K. (2011). Home literacy environment and word knowledge development: A study of young learners of Chinese as a heritage language. Bilingual Research Journal: The Journal of the National Association for Bilingual Education, 34(1), 4-18.

Zhang, D., \& Slaughter-Defoe, D. T. (2009). Language attitudes and heritage language maintenance among Chinese immigrant families in the USA. Language, culture and curriculum, 22(2), 77 


\section{APPENDICES}

\section{Appendix A}

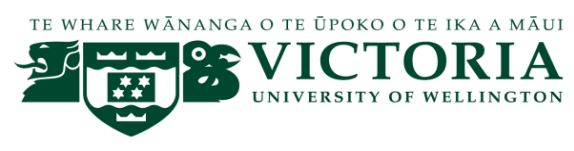

\section{Information Sheet}

Title: L1 Vocabulary Knowledge in Young Iranian Bilinguals in New Zealand To: Parents

My name is Khadij Gharibi and I am currently a $\mathrm{PhD}$ student in Applied Linguistics in the Department of Linguistics and Applied Language Studies at Victoria University of Wellington. I am conducting this research on the knowledge of vocabulary in your child's mother tongue. The Victoria University of Wellington Human Ethics Committee has granted ethical approval for this research.

You are invited to participate in my research. I would visit you and your child just once. First, I would like to interview you (and your spouse) about your family background and language use based on a questionnaire. It would take 15-20 minutes. Firstly, I invite your child to produce as many words as possible from a particular category such as animals, food, clothes in Persian within 60 seconds. Then, I invite her/him to do an auditory picture-word matching task. In this task, a picture is presented on a computer screen and your child is invited to listen to recorded Persian words and to press a key as soon as they hear the name of the corresponding picture. The next test is a film retelling task. Your child will watch an episode of "Tom and Jerry" and then I invite her/him to retell the story in Persian.

All of the tasks together take about one hour. I will also invite you to do the same tasks. I would like to audio record you and your child, but this would be done with your consent. I will turn off the recorder if your child wants to have a break. The data collected through this project will be used for comparing the use and knowledge of Persian by bilinguals and monolinguals and findings will be presented in my thesis, at seminars, conferences or in publications.

Pseudonyms will be used in this study and contributions will be anonymised. During the project all data will be stored securely. Only my supervisors and I will have access to the data. All recordings will be destroyed two years after the 
completion of the research project. Your participation in this project is completely voluntary. You may withdraw until May 1st, 2014. If you choose to withdraw, your recordings will be removed from the data. If you have any questions about this research project, please feel free to ask me. My contact details are at the end of this sheet. Thank you very much for your time and help.

\section{Khadij Gharibi \\ Khadij.Gharibi@vuw.ac.nz}

Tel: 4638947

Office: Von Zedlitz 406

Frank Boers

(Primary Supervisor)

Frank.Boers@vuw.ac.nz

Tel: 4635604

Office: Von Zedlitz 409 


\section{Appendix B}

\section{TE WHARE WÃNANGA O TE ŨPOKO O TE IKA A MĀUi \\ 59菌8: VICTORIA \\ * * C UNIVERSity OF WELLINGTON}

\section{اطلاعات تحقيق}

عنوان تحقيق: دانش وازكانى زبان اول در دوزبانه ها نىجوان ايرانى در نيوزيلند

به: والدين

نام من خديجه غريبى است و من در حال حاضر دانشجوى دكترا در رشته زبانشناسى كاربردى در گروه

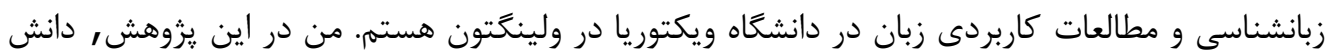

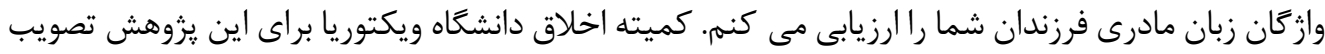

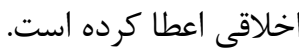

از شما براى شركت در اين تحقيق سياسكذارى ميكنم. من شما و فرزندتان را فقط يك بارملاقات مى كنم.

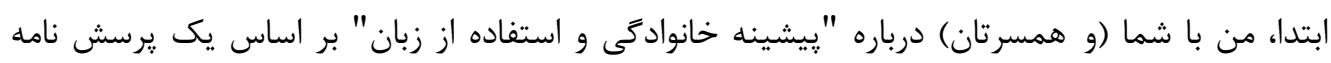

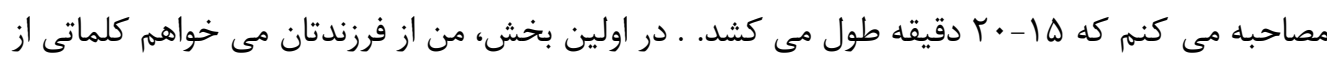

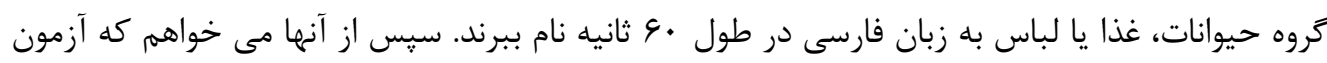

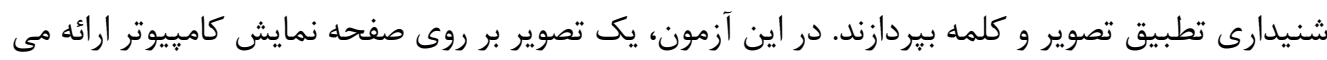

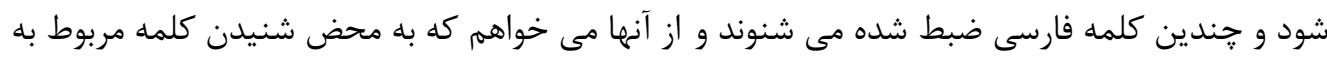

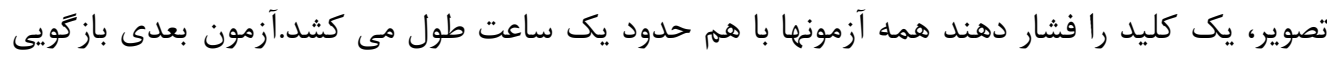

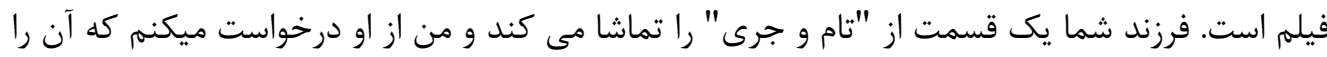

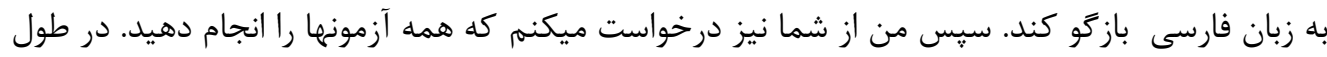

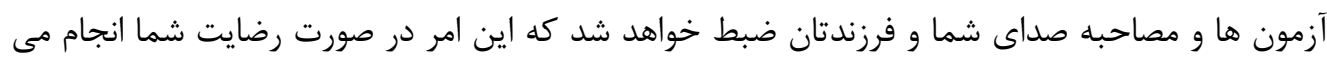

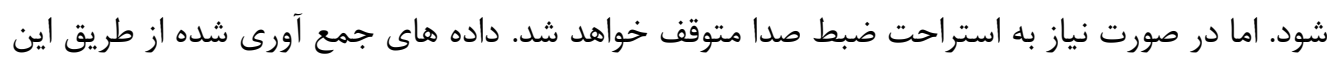
يروزه براى مقايسه استفاده و دانش زبان فارسى دو زبانه ها ويك زبانه ها استفاده خواهد شد و يافته هاى

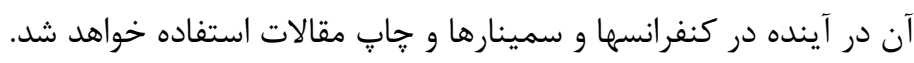

همه داده ها در اين مطالعه با نام غير واقعى ثبت مى شود، و بدون ذكر نام شما و فرزندتان ارائه خواهد شد. در طى اين يروزه همه داده ها به صورت ايمن ذخيره مى شود. تنها من و اساتيد راهنما دسترسى به به داده

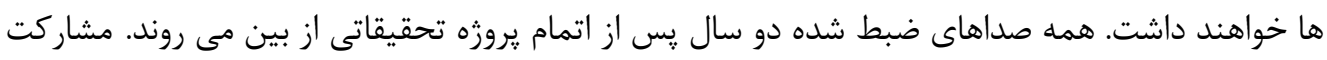

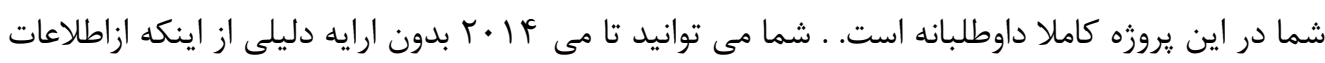


مربوط به شما و فرزندتان در اين تحقيق استفاده شود، صرف نظر كنيد. در اين صورت، داده هاى شما حذف

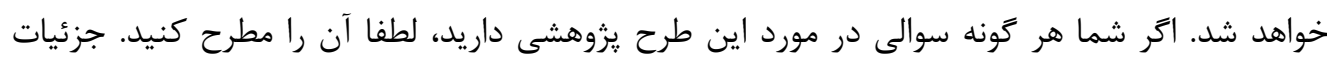

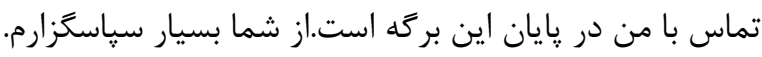

$$
\text { فرانك بورز }
$$

Frank.Boers@vuw.ac.nz

تلفن : F\&

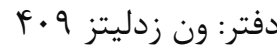

خديجه غريبى

Khadij.Gharibi@vuw.ac.nz

ت تلفن :

دفتر: ون زدليتز 


\section{Appendix C}

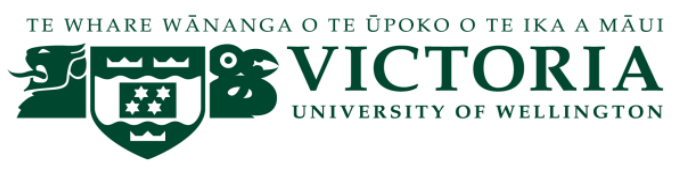

\section{Information Sheet}

Title: L1 Vocabulary Knowledge in Young Iranian Bilinguals in New Zealand To: Participants (over 16)

My name is Khadij Gharibi and I am currently a PhD student in Applied Linguistics in the Department of Linguistics and Applied Language Studies at Victoria University of Wellington. I am conducting this research on the knowledge of vocabulary in your children's mother tongue. The Victoria University of Wellington Human Ethics Committee has granted ethical approval for this research.

You are invited to participate in my research and I would appreciate that. I would visit you and your parents just once. First, I would like to interview you and your parents about your family background and Language use based on a questionnaire. It would take 15-20 minutes. The first part is a film retelling task. You will watch an episode of "Tom and Jerry" and then I invite you to retell the story in Persian. Then I ask you to produce as many words as possible from a particular category such as animals, food, clothes in Persian within 60 seconds. Then, I invite you to do an auditory picture-word matching task. In this task, a picture is presented on a computer screen and I ask you to listen to recorded Persian words and to press a key as soon as you hear the name of the corresponding picture.

All of the tasks together take about one hour. I will also invite your parents to do the same tasks. I would like to audio record you and your parents, but this would be done with your consent. I will turn off the recorder if you or your parents want to have a break. The data collected through this project will be used for comparing the use and knowledge of Persian by bilinguals and monolinguals and findings will be presented in my thesis, at seminars, conferences or in publications.

Pseudonyms will be used in this study and contributions will be anonymised. During the project all data will be stored securely. Only my supervisors and I will have access to the data. All recordings will be destroyed two years after the 
completion of the research project. Your participation in this project is completely voluntary. You may withdraw until May 1st, 2014. If you choose to withdraw, your recordings will be removed from the data. If you have any questions about this research project, please feel free to ask me. My contact details are at the end of this sheet. Thank you very much for your time and help.

Khadij Gharibi

Khadij.Gharibi@vuw.ac.nz

Tel: 4638947

Office: Von Zedlitz 406

Frank Boers

(Primary Supervisor)

Frank.Boers@vuw.ac.nz

Tel: 4635604

Office: Von Zedlitz 409 


\title{
Appendix D
}

\section{TE WHARE WĀNANGA O TE ŪPOKO O TE IKA A MĀUI \\ 50 VICTORIA \\ * * +2 university of Wellington}

\author{
اطلاعات تحقيق \\ عنوان تحقيق: دانش وازكانى زبان اول در دوزبانه ها نوجوان ايرانى در نيوزيلند \\ به: شركت كنندكان
}

نام من خديجه غريبى است و من در حال حاضر دانشجوى دكترا در رشته زبانشناسى كاربردى در گروه

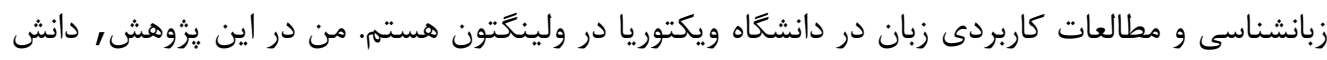

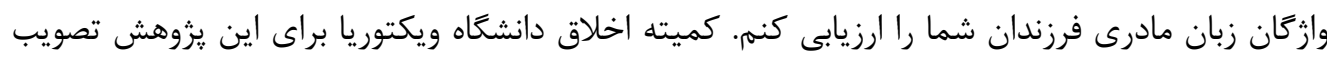

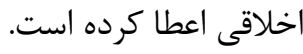

از شما براى شركت در اين تحقيق سياسخذارى ميكنم. من شما و والدينتان را فقط يك بارملاقات مى كنم.

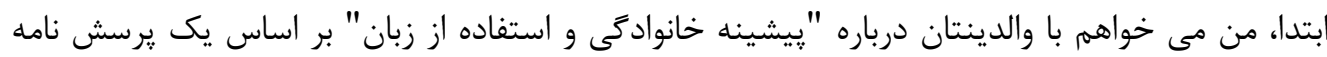

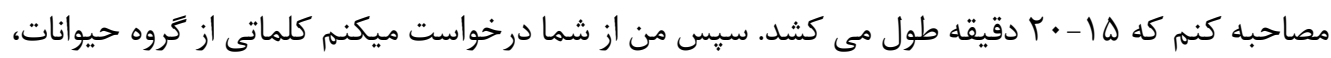

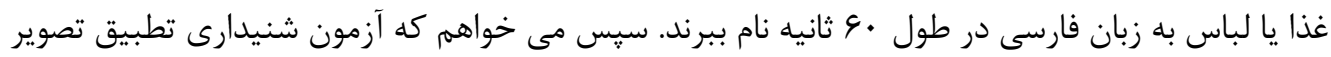

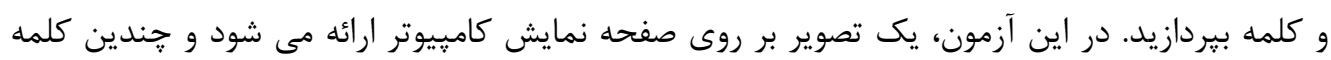

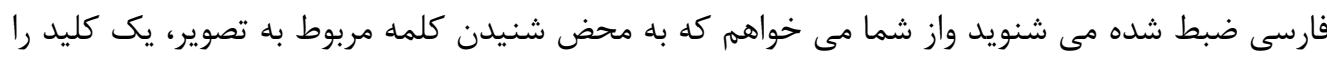

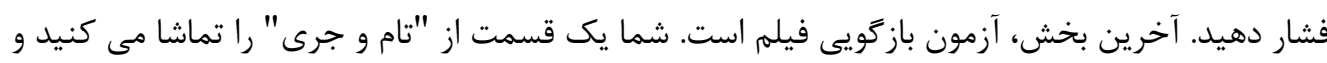

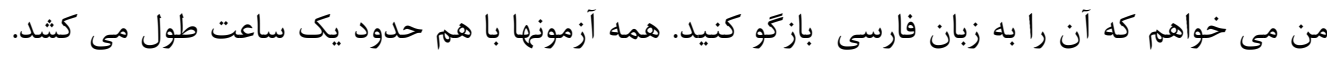

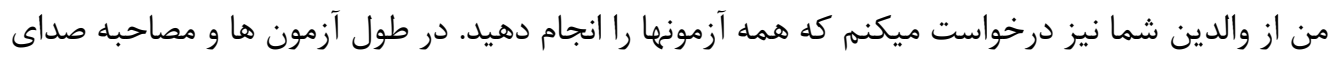
شما و والدينتان ضبط خواهد شد كه اين امر در صورت رضايت شما انجام مى شود. اما در صورت نياز به استراحت ضبط صدا متوقف خواهد شد. شما مى توانيد تا دو سال بدون ارايه دليلى از اينكه ازاطلاعات

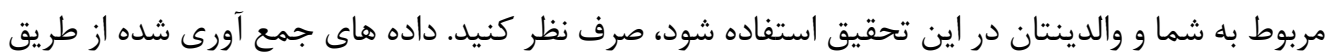
اين يروزه براى مقايسه استفاده و دانش زبان فارسى دو زبانه ها ويك زبانه ها استفاده خواهد شد. همه داده ها در اين مطالعه با نام غير واقعى ثبت مى شود، و بدون ذكر نام شما و والدينتان ارائه خواهد شد. در طى اين يروزه همه داده ها به صورت ايمن ذخيره مى شود. تنها من و اساتيد راهنما دسترسى به داده

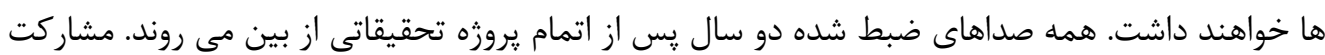


شما در اين يروزه كاملا داوطلبانه است. شما مى توانيد تا مى ؟ ا • ب بدون ارايه دليلى از اينكه ازاطلاعات

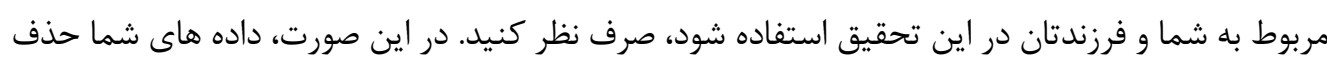

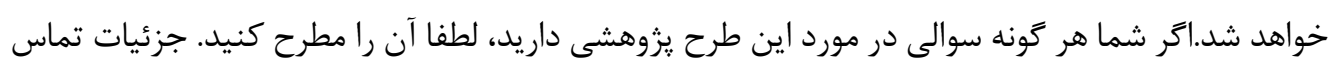

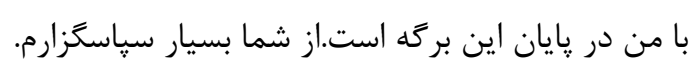

فرانك بورز

Frank.Boers@vuw.ac.nz

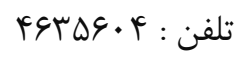

دفتر: ون زدليتز $9 \cdot 9$

خديجه غريبى

Khadij.Gharibi@vuw.ac.nz

تلفن :

دفتر: ون زدليتز 


\section{Appendix E}

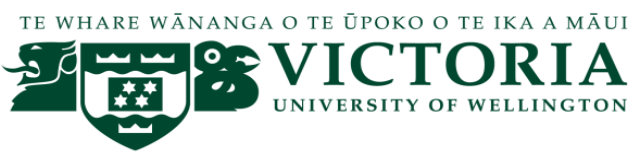

\section{Consent Form}

Title: L1 Vocabulary Knowledge in Young Iranian Bilinguals in New Zealand

Researcher: Khadij Gharibi

To: Parents

I have read the information sheet and I have been given an explanation of this research project. I have also had an opportunity to ask questions and have them answered.

I understand that I may withdraw my child or any information traceable to my child or me at any time until May 1st, 2014, without giving a reason.

- I agree that ............................, who is my child, will participate in this research.

- I agree to participate in this research and do the tasks.

- I agree that my child and I will answer the questions during the data collection period.

- I agree to have my voice and my child's voice audio recorded while answering the questions during the interview and the tasks.

- I agree that the data collected through this project will be used for comparing the use and knowledge of Persian by bilinguals and monolinguals.

Signed:

Name:

Date:

Please tick here if you wish to receive a copy of a written summary of the study at the end of the project, and give below an e-mail address to which this summary can be sent.

Email address: 


\section{Appendix F}

TE WHARE WĀNANGA O TE ŨPOKO O TE IKA A MĀUI

S9

رضايت نامه

عنوان تحقيق: دانش وازَّانى زبان اول در دوزبانه هاى نوجوان ايرانى در نيوزيلند

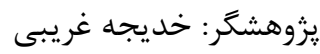

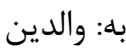

من اطلاعات اين تحقيق را مطالعه كرده ام و محقق اين طرح يزوهشى را براى من توضيح داده است و او

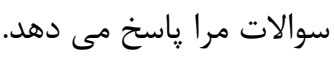

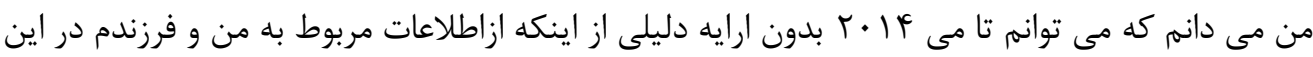
تحقيق استفاده شود، صرف نظر كنم.

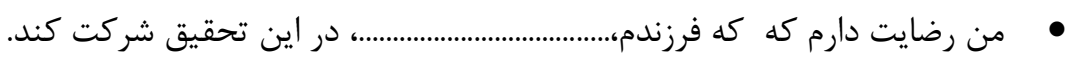
• • من رضايت دارم كه در اين تحقيق شركت كنم. • من رضايت دارم كه به سوالات يرسشنامه ياسخ دهيه.

من موافقت مى كنم كه صداى فرزند من و من در حال باسخ دادن به سوالات در طول مصاحبه و آزمونها ضبط شود. داده هاى جمع آورى شده از طريق اين يروزه براى مقايسه استفاده و دانش زبان فارسى در بين دو زبانه ها ويك زبانه ها استفاده خواهد شد.

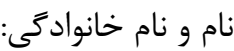

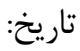

در صورتى كه تمايل به دريافت خلاصه اى از نتايج تحقيق مى باشيد آدرس ايميل خود را ذكر كنيد.

Email address: 


\section{Appendix G}

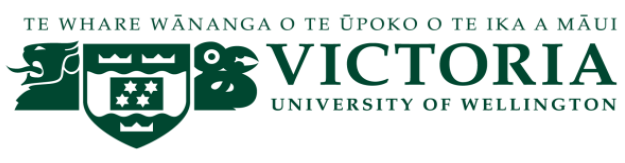

\section{Consent Form}

Title: L1 Vocabulary Knowledge in Young Iranian Bilinguals in New Zealand

Researcher: Khadij Gharibi

To: Participants (over 16)

I have read the information sheet for this research project and I have been given an explanation of this research project. I have also had an opportunity to ask questions and have them answered.

I understand that I may withdraw any information traceable to me at any time until May 1st, 2014, without giving a reason.

- I agree to participate in this research and do the tasks.

- I agree to answer the questions during the data collection period.

- I agree to have my voice audio recorded while answering the questions during interview and tasks.

- I agree that the data collected through this project will be used for comparing the use and knowledge of Persian by bilinguals and monolinguals.

Signed:

Name:

Date:

Please tick here if you wish to receive a copy of a written summary of the study at the end of the project, and give below an e-mail address to which this summary can be sent.

Email address: 


\section{Appendix H}

TE WHARE WĀNANGA O TE ŪPOKO O TE IKA A MĀUI

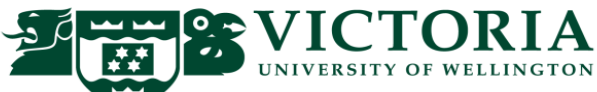

رضايت نامه

عنوان تحقيق: دانش وازَّانى زبان اول در دوزبانه هاى نوجوان ايرانى در نيوزيلند

$$
\text { بهز شرهشكر: خديجه غريبى كندان (بيش از عاسال) }
$$

من اطلاعات اين تحقيق را مطالعه كرده ام و محقق اين طرح يزوهشى را براى من توضيح داده است و او سوالات مرا ياسخ مى دهد.

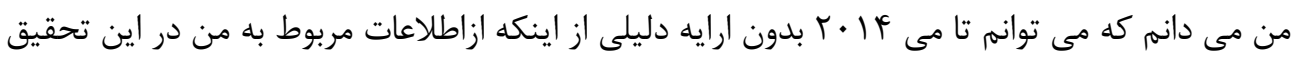

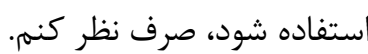

$$
\text { • من من رضايت دارم كه در اين تحقيق شركت كنهم. }
$$

• من رضايت دارم كه به سوالات يرسشنامه پِاسخ دهم.

• من موافقت مى كنم كه صداى من در حال ياسخ دادن به سوالات در طول مصاحبه و آزمونها

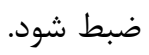

داده هاى جمع آورى شده از طريق اين يروزه براى مقايسه استفاده و دانش زبان فارسى در بين دو زبانه ها ويك زبانه ها استفاده خواهد شد.

در صورتى كه تمايل به دريافت خلاصه اى از نتايج تحقيق مى باشيد آدرس ايميل خود را ذكر كنيد.

Email address: 


\section{Appendix J}

\section{"Family background and Language use questionnaire"}

Name:

Your child's name:

Date:

This questionnaire consists of five sections to get an impression of the family background and language use of Iranian migrants and their children in New Zealand. Some of your background information will be used to match your children to monolinguals in Iran.

\section{Section 1: Family background}

1) Parent's age: mother father

2) How many children do you have?

3) How old are they?

4) How old is your child who is regarded as a subject in this study?

5) Where was she/he born? Country city.

6) How old was she/he when you moved to New Zealand?

7) What is the highest level of education you have completed?

Mother

Father

8) When did you move to New Zealand?

9) Why did you move to New Zealand?

1) Studies

2) immigration

2) 3) Work 4) other

10) Apart from New Zealand, have you ever lived in a country other than Iran? - No

- Yes in: country for years

11) What is your current profession?

Mother

Father

12) Have you and your child ever been back to Iran since leaving for New Zealand?

- Never 
- Seldom

- Sometimes

- Regularly, every other year

- Regularly, once a year

13) When have you and your child been to Iran for the last time?

14) If you have indicated that you have been back to Iran, could you please indicate what the reason or reasons for such a visit were (you may tick more than one box here)?

- Because of urgent family matters (such as a wedding or a funeral)

- To visit without a particular reason

- For another reason

15) Do your parents (the subject's grandparents) come and visit you in New Zealand? How often?

- Yes (.....Never .....Seldom .....Sometimes ...... Regularly)

- No

- They live in New Zealand.

\section{Section 2: Language background}

16) What language(s) did you speak while you lived in Iran?

- Persian............

- Persian \& other (Azerbayjani, Kurdish, Lurish, Gilaki, Mazandarani, ...) .............

17) What language(s) did your child speak while you lived in Iran?

- Persian............

- Persian \& other (Azerbayjani, Kurdish, Lurish, Gilaki, Mazandarani, ...) ..............

18) What language(s) did you acquire before coming to New Zealand?

- Persian .........

- Persian \& other

19) What language(s) did your child acquire before coming to New Zealand?

- Persian

- Persian \& other

20) Did your child attend any English classes before coming to New Zealand? (this has to be in an educational environment, like a school or some similar institution):

- No 
- yes, less than 3 months

- yes, less than 6 months

- yes, less than 1 year

- yes, more than 1 year

21) Is your child learning any other languages at present? Yes ......

(.............) No ..........

22) Has your child ever attended Persian classes while living in New Zealand?

- yes, in (year): for the period of:

..........months hours a week

- no

23) In general, how would you rate your English language proficiency before you moved to New Zealand?

........None $\quad . .$. very little $\quad \ldots$. little $\quad \ldots$ Enough $\quad \ldots$ good
..... very good

24) In general, how would you rate your English language proficiency at present?

........None $\quad . .$. very little $\quad . .$. little $\quad .$. Enough $\quad$.... good ..... very good

25) In general, how would you rate your child's English language proficiency before you moved to New Zealand?

........None $\quad . .$. very little $\quad \ldots$. little $\quad \ldots$... Enough $\quad \ldots$ good
..... very good

26) In general, how would you rate your child's English language proficiency now?

........None ..... very little $\quad$.... little $\quad .$. Enough $\quad \ldots$ good

27) In general, how would you rate your child's Persian language proficiency before you moved to New Zealand?

........None $\quad . .$. very little $\quad \ldots$. little $\quad \ldots$... Enough $\quad \ldots$ good

28) In general, how would you rate your child's Persian language proficiency at present?

.......None $\quad . .$. very little $\quad \ldots$. little $\quad \ldots$ Enough $\quad \ldots$ good
..... very good

\section{Section 3: Family language use}

29) How often do you speak Persian? 
..very rarely

.......rarely

occasionally

frequently . always

30) How often do you speak Persian with your child/ children?

very rarely

........rarely occasionally ...frequently always

31) What language or languages do you mostly use when talking to your spouse?

- only English

- both Persian and English, but mostly English

- both Persian and English, without preference

- both Persian and English, but mostly Persian

- only Persian

- other

32) What language or languages does your spouse mostly use when talking to you?

- only English

- both Persian and English, but mostly English

- both Persian and English, without preference

- both Persian and English, but mostly Persian

- only Persian

- other

33) What language or languages do you mostly use when talking to your children?

- only English

- both Persian and English, but mostly English

- both Persian and English, without preference

- both Persian and English, but mostly Persian

- only Persian

- other

34) In general, do you have more Persian- or English-speaking friends in New Zealand?

- only English-speaking friends

- both, but more English-speaking friends

- $\quad$ as many Persian- as English-speaking friends

- both, but more Persian-speaking friends

- only Persian-speaking friends

35) How did you (and your child) meet most of these people?

- at home 
- through a Persian club or organization

- through mutual friends

- through work or the children's school

- through another way, namely:

36) Are you in frequent contact with relatives and friends in Iran?

......very rarely . always ..rarely occasionally ..frequently

37) How do you keep in touch with those relatives and friends in Iran?

Skype- telephone - Facebook - e-mail - another way, namely:

38) What language or languages do you mostly use to keep in touch with relatives and friends in Iran?

- only English

- both Persian and English, but mostly English

- both Persian and English, without preference

- both Persian and English, but mostly Persian

- only Persian

- other

39) Do you ever intend to move back to Iran?

- Yes - Not clear - No

40) Do you feel more comfortable speaking Persian or English?

- English - Persian - no preference

\section{Section 4: Children's language use and Language choice}

41) How often does your child speak Persian?

......very rarely .rarely occasionally frequently .......... always

42) Does your child know how to read and write in Persian?

- Yes - no

43) Does your child can read and write in Penglish (writing Persian words using the Latin alphabets)?

- Yes - no

44) If she/he can read and write in Persian, how often does your child read books in Persian?

......very rarely $\quad$........rarely $\quad \ldots . .$. occasionally $\quad \ldots . .$. ...frequently


What kind of books does she/he read?

45) If she/he can read and write in Persian, how often does your child write anything in Persian?

......very rarely

........rarely

occasionally frequently

.......... always

46) If she/he can read and write in Penglish, how often does your child read and write?

......very rarely

........rarely

occasionally

ffrequently

.......... always

47) If she/he can read and write in Persian, how would you rate her/his literacy in Persian?

very little

little

enough

good

very good

48) Does your child listen to Persian songs?

............ alway rarely $\quad$........rarely $\quad . . . .$. occasionally $\quad$........frequently

49) Does your child watch Persian animations or films?

very rarely rarely occasionally frequently always

50) If you have indicated that your child never listens to Persian songs, that she/he doesn't watch Persian animations or films, could you indicate why you think that is?

51) What language or languages do your children mostly use when talking to you?

- only English

- both Persian and English, but mostly English

- both Persian and English, without preference

- both Persian and English, but mostly Persian

- only Persian

- other

52) Does your child feel more comfortable speaking Persian or English?

- English

- Persian

- no preference

53) Could you please indicate in which language your child speaks to these people and in the domains provided? You may simply tick the box. 


\begin{tabular}{|c|c|c|c|c|c|c|}
\hline & $\begin{array}{l}\text { Always } \\
\text { in } \\
\text { Persian }\end{array}$ & $\begin{array}{l}\text { In } \\
\text { Persian } \\
\text { more } \\
\text { often } \\
\text { than } \\
\text { English }\end{array}$ & $\begin{array}{l}\text { In } \\
\text { Persian } \\
\text { and } \\
\text { English } \\
\text { almost } \\
\text { equally }\end{array}$ & \begin{tabular}{|l|} 
In \\
English \\
more \\
often \\
than in \\
Persian \\
\end{tabular} & $\begin{array}{l}\text { Always } \\
\text { in } \\
\text { English }\end{array}$ & \begin{tabular}{|l|} 
Not \\
applicable
\end{tabular} \\
\hline $\begin{array}{l}\text { To } \\
\text { Father }\end{array}$ & & & & & & \\
\hline $\begin{array}{l}\text { To } \\
\text { Mother }\end{array}$ & & & & & & \\
\hline $\begin{array}{l}\text { To } \\
\text { Siblings }\end{array}$ & & & & & & \\
\hline $\begin{array}{l}\text { To } \\
\text { Friends } \\
\text { at School }\end{array}$ & & & & & & \\
\hline $\begin{array}{l}\text { To } \\
\text { Iranian } \\
\text { Peers }\end{array}$ & & & & & & \\
\hline $\begin{array}{l}\text { To } \\
\text { Iranian } \\
\text { Adults }\end{array}$ & & & & & & \\
\hline To Pets & & & & & & \\
\hline $\begin{array}{l}\text { At } \\
\text { School }\end{array}$ & & & & & & \\
\hline In shops & & & & & & \\
\hline $\begin{array}{l}\text { Sending } \\
\text { Texts }\end{array}$ & & & & & & \\
\hline $\begin{array}{l}\text { Emails \& } \\
\text { Facebook }\end{array}$ & & & & & & \\
\hline Skype & & & & & & \\
\hline
\end{tabular}

\section{Section 5: Parents' attitude}

54) Do you consider it important to maintain your child's Persian?

- unimportant

- relatively unimportant

- not very important 
- important

- very important

55) Do you encourage your children to speak Persian?

- no, never

-yes, occasionally

-yes, often

56) Do you encourage your children to read and write in Persian?

- no, never

- yes, occasionally

- yes, often

57) Did /do you ever correct your children's Persian?

......never .......very rarely $\quad$.........sometimes $\quad$.........regularly

58) If your children do not speak or understand Persian, do you regret that?

......not at all .......not much ..... no opinion ......abit ......very

much ........no answer

59) Do you think your child's Persian language proficiency has changed since you moved to New Zealand?

- yes, I think it has become worse

- no

- yes, I think it has become better

60) Do you see your child as bilingual? In other words, do you think she/he is as proficient in Persian as in English?

- she/he is more proficient in English

- both

- she/he is more proficient in Persian

* Is there anything you would like to add? This can be anything from language-related comments to remarks about the questionnaire or research itself.

"Thank you so much for your cooperation" 


\section{Appendix K}

" يرسشنامه پِيشينه خانوادكى و استفاده از زبان"

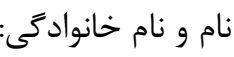
نام فرزند شما: . تاريخ :

من اميدوارم كه با استفاده از اين يرسشنامه، تصويرى از يُيشينه خانواده و استفاده از زبان فارسى

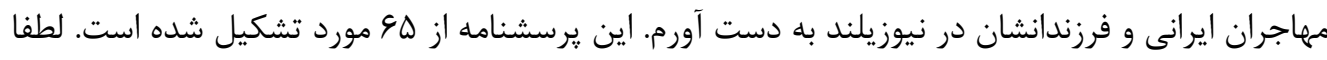

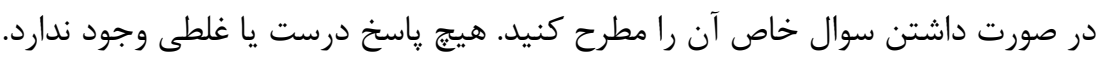

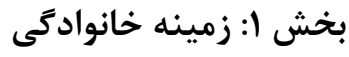

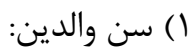

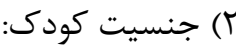

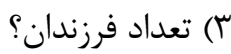

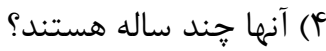

$$
\begin{aligned}
& \text { ه) فرزند شما كه در اين تحقيق شركت مى كند جند ساله است؟ } \\
& \text { 9) او كجا متولد شده است؟ كشور ........... شهر .......... مليت : ايرانى ..... كيوى ............................ }
\end{aligned}
$$

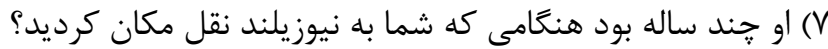

$$
\begin{aligned}
& \text { () آخرين سطح آموزش شما جيست؟ }
\end{aligned}
$$

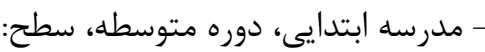

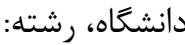

$$
\begin{aligned}
& \text { 9) جه زمانى شما به نيوزيلند آمديد؟ } \\
& \text { • (1) جرا مهاجرت كرديد و جرا به نيوزيلند به طور خاص؟ } \\
& \text { م ادامه تحصيل ........ } \\
& \text { م مهاجرت } \\
& \text { O كار } \\
& \text { O غيره . } \\
& \text { |) (1آيا شما به جز نيوزيلند تا به حال در كشورى غير از ايران زندكى كرده ايد؟ } \\
& \text { ه } 0
\end{aligned}
$$




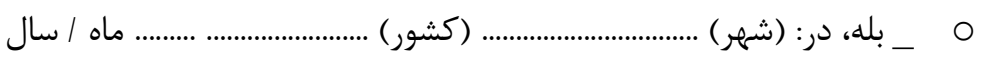

$$
\begin{aligned}
& \text { 1 (I ) شغل فعلى شما جيست؟ } \\
& \text { rا (آر شما קندين شغل داشته ايد، لطفا آنها را به ترتيب زمانى ذكر كنيد؟ }
\end{aligned}
$$

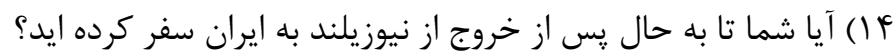

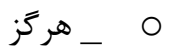

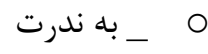

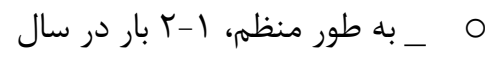

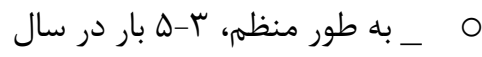

$$
\begin{aligned}
& \text { O _ _به طور منظه، بيش از له بار در سال }
\end{aligned}
$$

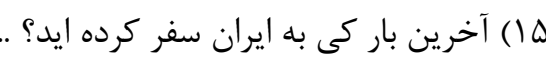

ع|) اكر شما به ايران سفر كرده ايد، دليل يا دلايل اين سفر را ذكر كنيد (شما مى توانيد بيش از يك مورد را عنوان كنيد)؟

O _ _ به دليل مسائل فورى خانواده (مانند عروسى و يا مراسم تشييع جنازه)

$$
\text { O }
$$

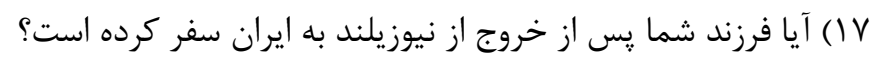

$$
\text { هر - O }
$$$$
\text { O _ مبه ندرت }
$$

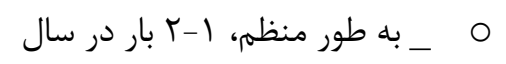

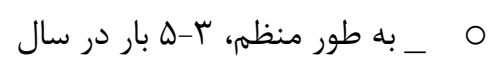

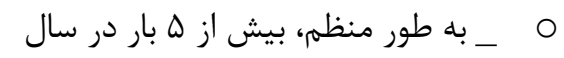

1) اتر بله، دليل يا دلايل اين سفر را ذكر كنيد (شما مى توانيد بيش از يك مورد را عنوان كنيد)؟

$$
\begin{array}{r}
0 \\
0
\end{array}
$$

9 (1) زمانى كه شما در ايران زندگى مى كرديد، به كدام گويش از زبان فارسى شما صحبت مى كرديد؟ 
• (广) در حالى كه شما در ايران زندگى مى كرديد، به كدام گويش از زبان فارسى با كودى خود صحبت مى كرديد؟ . . (1) (T) جه زبان (ها) شما قبل از آمدن به نيوزيلند به دست آوردن؟ (.... فارسى .... فارسى و ديخر .... ديخر

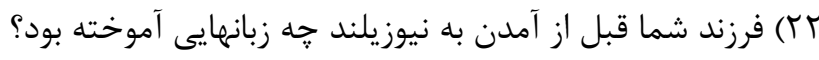

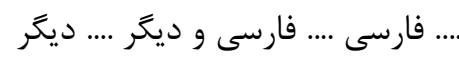

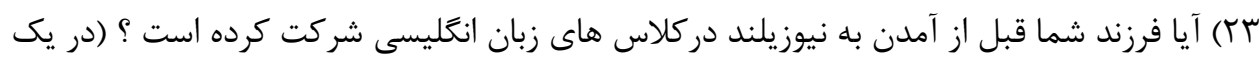
محيط آموزشى، مانند مدرسه يا موسسه هاى زبان انغليسى): O هيج O م بله، كمتر از 1 ماه O م بله، كمتر از ب ماه ماه O مبله، كمتر از ع باه

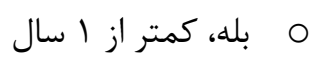

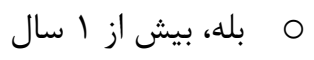

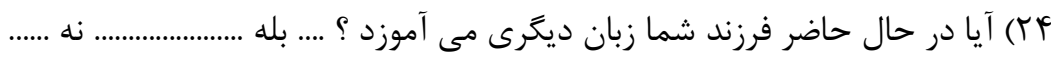

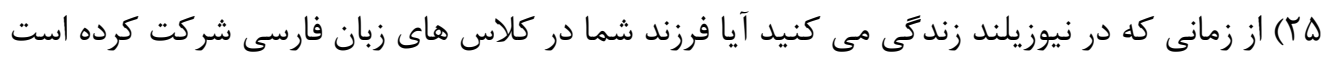

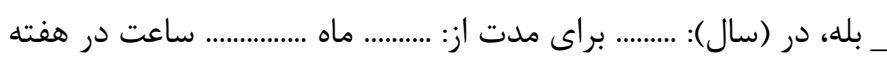

$$
\begin{aligned}
& \text { ـ - }
\end{aligned}
$$

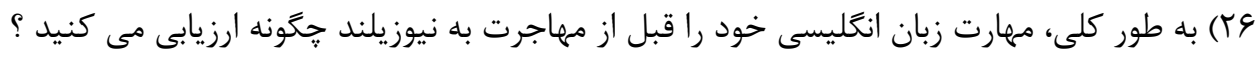

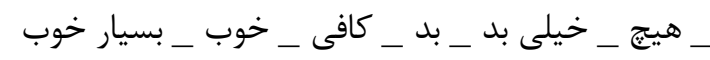

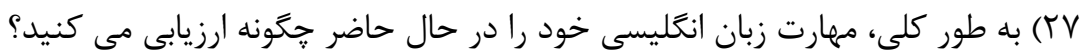

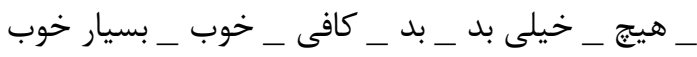

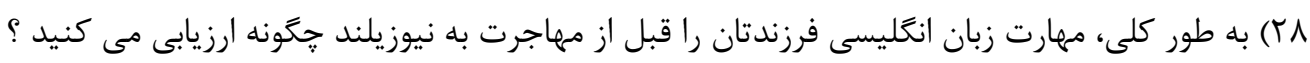

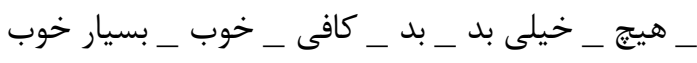

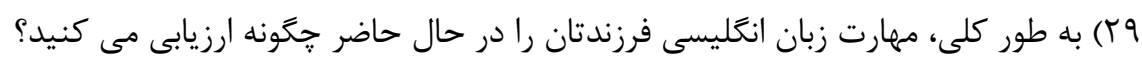

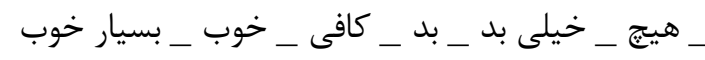

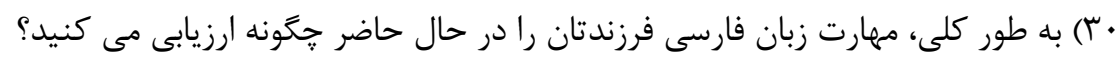

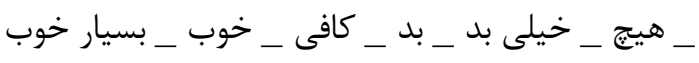




\section{بخش r: استفاده از زبان خانواده}

$$
\begin{aligned}
& \text { (با) هر جند وقت شما فارسى صحبت مى كنند؟ }
\end{aligned}
$$

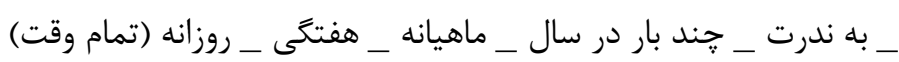

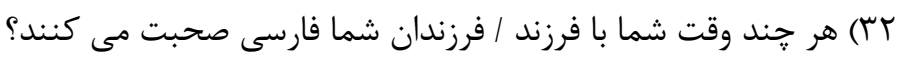

$$
\begin{aligned}
& \text { _ به ندرت _ جند بار در سال _ ماهيانه _ هفتتى _ روزانه (تمام وقت) } \\
& \text { rץ) اغلب به جه زبان يا زبانهايى با همسر خود صحبت مى كنيد؟ }
\end{aligned}
$$

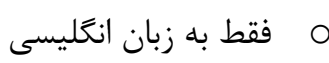

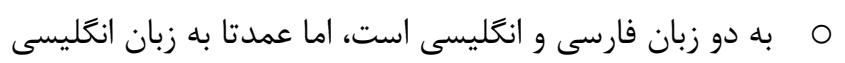

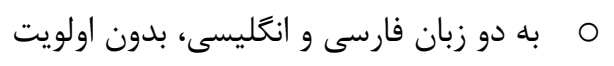

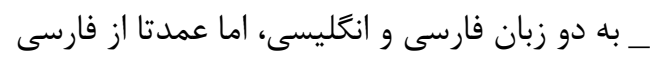

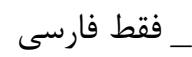

$$
\begin{aligned}
& \text { _ ديخر و يا بدون ياسخ } \\
& \text { هم (MF } \\
& \text { م فقط به زبان انخليسى } \\
& \text { ○ به دو زبان فارسى و انخليسى است، اما عمدتا به زبان انغليسى }
\end{aligned}
$$

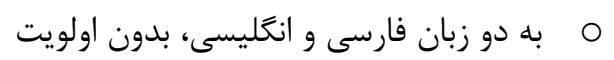

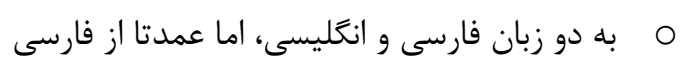

$$
\begin{aligned}
& \text { O مقط فارسى } \\
& \text { O ميكر و يا بدون ياسخ فارسى }
\end{aligned}
$$

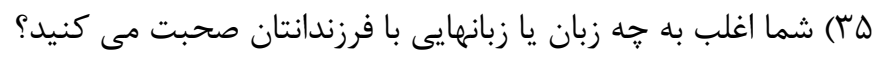

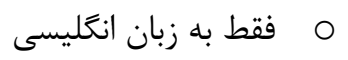

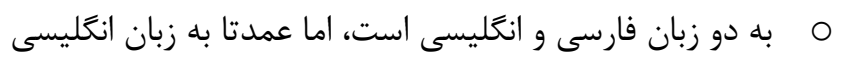

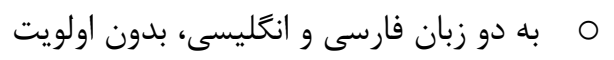

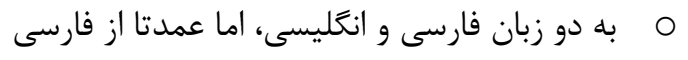

$$
\begin{aligned}
& \text { O مقط فارسى }
\end{aligned}
$$

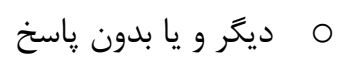

$$
\begin{aligned}
& \text { o هر دو، اما بيشتر دوستان انغليسى زبان }
\end{aligned}
$$




$$
\begin{aligned}
& \text { O مبه تعداد تقريبا مساوى } \\
& \text { O هر دو، اما بيشتر فارسى زبان } \\
& \text { م فقط دوستان فارسى زبان }
\end{aligned}
$$

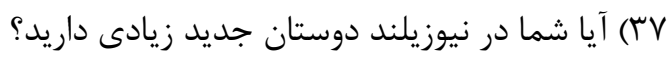

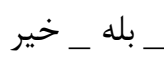

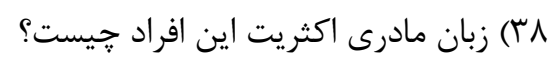

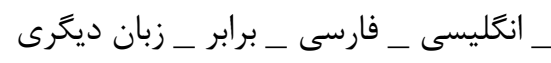

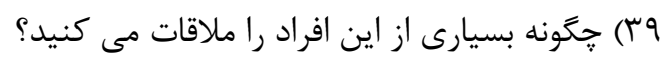$$
\text { م در خانه شما }
$$

$$
\text { O انجمن ايرانيان }
$$

$$
\text { O م از طريق دوستان متقابل }
$$

$$
\text { O از طريق كار يا مدرسه كودكان }
$$

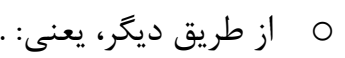

(F.

_ خيلى به ندرت _ به ندرت _ كاهى _ اغلب _ تمام زمان

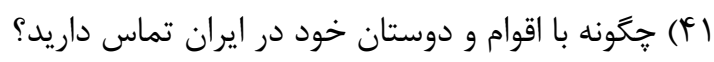

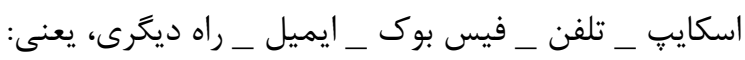

(FT) به جه زبان يا زبانهايى اغلب با اقوام و دوستان خود در ايران صحبت مى كنيد؟

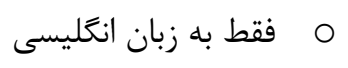

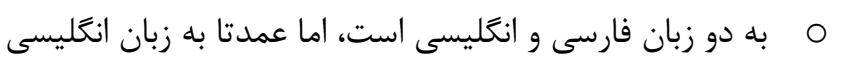

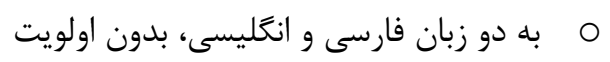

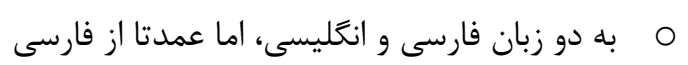

$$
\text { O مقط فارسى }
$$

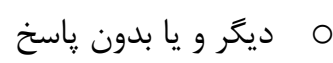

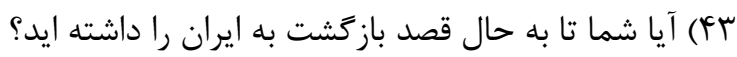

$$
\text { ○ } 0
$$

(F) آيا شما احساس راحتى بيشترى مى كنيد وقتى به زبان فارسى يا انحليسى صحبت مى كنى كنيد؟ 


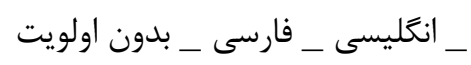

أه آيا مى توانيد باسخ خود راتوضيح دهيد: هرا شما احساس راحتى بيشترى مى كنيد وقتى به زبان

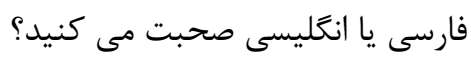

بخش f: استفاده از زبان براى كودكان و انتخاب زبان

$$
\begin{aligned}
& \text { ฯ\$ף) هر حند وقت يكبار فرزند شما فارسى صحبت مى كند؟ }
\end{aligned}
$$

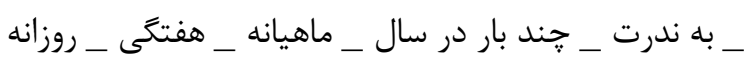

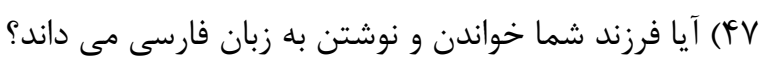

$$
\begin{aligned}
& 0
\end{aligned}
$$$$
\text { م او / او فقط مى تواند بخواند }
$$

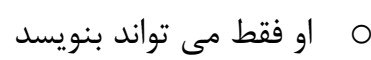$$
0
$$

1F^) اتر او خواندن و نوشتن به زبان فارسى مى داند ، حقدر به زبان فارسى كتاب مى خواند ؟

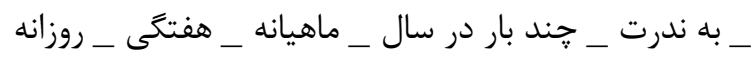

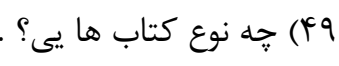

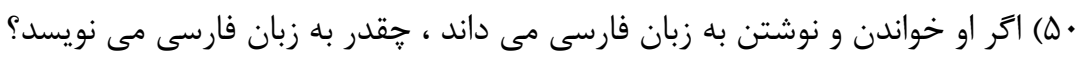

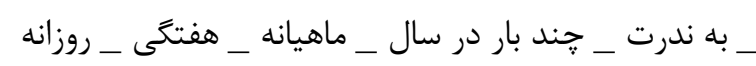

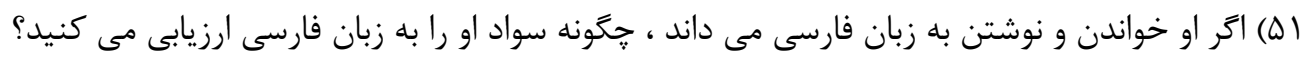

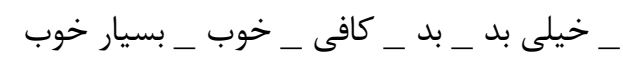

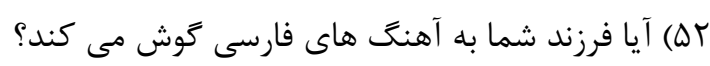

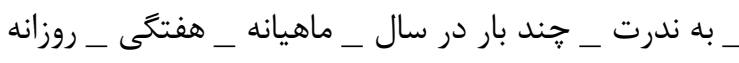

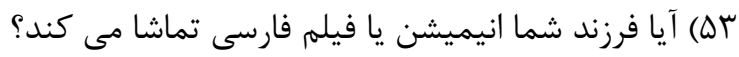

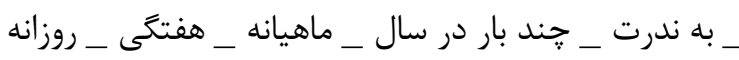

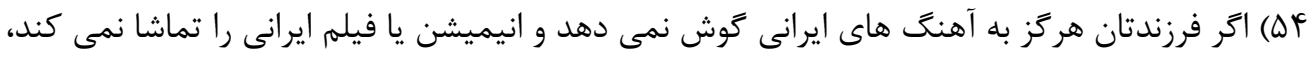

فه فرزندان شما بيشتر به جه زبان يا زبانهايى با شما صحبت مى كنند؟

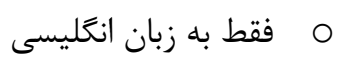


O به دو زبان فارسى و انغليسى است، اما عمدتا به زبان انخليسى

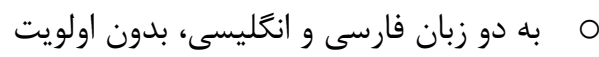

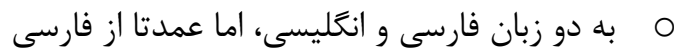

$$
\text { O مقط فارسى }
$$

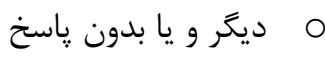

(ه؟) آيا فرزند شما احساس راحتى بيشترى در صحبت به زبان فارسى يا انخليسى دارد؟ باسح

$$
\text { _ انخليسى _ فارسى _ _بدون اولويت }
$$

(DV آيا مى توانيد پاسخ خود را توضيح دهيد: جرا فرزند شما احساس راحتى بيشترى در صحبت به زبان

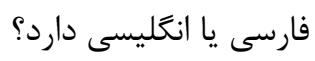

\begin{tabular}{|c|c|c|c|c|c|c|}
\hline هيجكدام & هميشه به & فيش انغليسى & به فارسى و & به فارسى & هميشه به & \\
\hline & & & & & & با پيدر \\
\hline & & & & & & با مادر \\
\hline & & & & & & با خواهر و برادرها \\
\hline & & & & & & دا دوستان \\
\hline & & & & & & همسالهاى \\
\hline & & & & & & با دوستان \\
\hline & & & & & & خا حيوانات \\
\hline & & & & & & در مدرسه \\
\hline
\end{tabular}

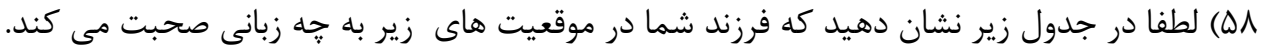




\begin{tabular}{|l|l|l|l|l|l|l|}
\hline & & & & & & \\
\hline & & & & & & \\
\hline & & & & & & \\
\hline & & & & & & \\
\hline & & & & & & \\
\hline
\end{tabular}

بخش ه: ادراك و نتخرش يدر و مادر

(D9 ) حفظ زبان فارسى فرزند شما برايتان جقدر اهميت دارد ؟

$$
\text { O }
$$

•) برايتان جقدر اهميت دارد كه فرزندانتان بتوانند به فارسى صحبت كنند و بفهمند ؟

$$
\text { O }
$$

(ع) آيا شما فرزندان خود را به فارسى صحبت كردن تشويق مى كنيد؟

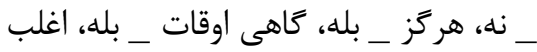

بع) آيا شما فرزندان خود را به خواندن و نوشتن به زبان فارسى تشويق مى كنيد؟ بهـ

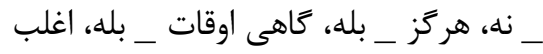

بو) آيا شما تا به حال فارسى فرزندان خود را تصحيح كرده ايد؟

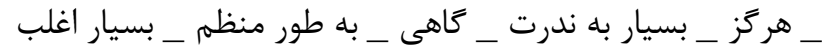

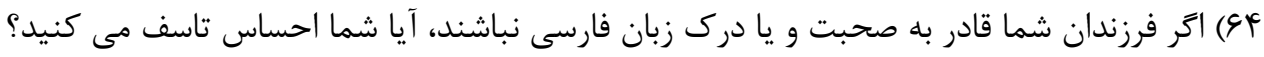
_ زيادى در همه _ نيست _ بدون نظر _ كمى _ بسيار _ بدون زباسخ 
هـ آيا شما فكر مى كنيد از زمانى كه شما به نيوزيلند مهاجرت كرده ايد مهارت زبان فارسى فرزند شما تغيير كرده است؟

$$
\text { O }
$$

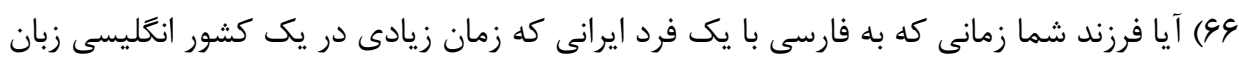

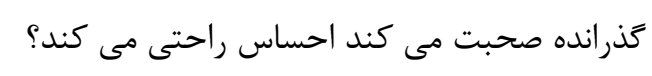

م بله،

$$
\text { O ماهى اوقات }
$$

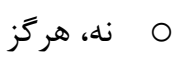

( \&V آيا به نظر شما فرزند شما دو زبانه است؟ به عبارت ديكر، آيا شما فكر مى كنيد كه او به زبان فارسى

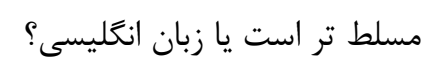

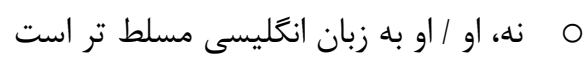

م بله

$$
\begin{aligned}
& \text { O ن مه، او / او به زبان فارسى مسلط است } \\
& \text { O من نمى دانم، جرا كه: }
\end{aligned}
$$

凡) اگر تمايل داريد مى توانيد هر نكته اى در مورد ياسخهاى خود در يرسشنامه اضافه كنيد .

\section{با تشكر}

